\title{
Caregivers' experiences with aggressive behaviour of nursing home residents
}

Citation for published version (APA):

Zeller, A. (2013). Caregivers' experiences with aggressive behaviour of nursing home residents. [Doctoral Thesis, Maastricht University]. Maastricht University. https://doi.org/10.26481/dis.20130612az

Document status and date:

Published: 01/01/2013

DOI:

10.26481/dis.20130612az

Document Version:

Publisher's PDF, also known as Version of record

\section{Please check the document version of this publication:}

- A submitted manuscript is the version of the article upon submission and before peer-review. There can be important differences between the submitted version and the official published version of record.

People interested in the research are advised to contact the author for the final version of the publication, or visit the DOI to the publisher's website.

- The final author version and the galley proof are versions of the publication after peer review.

- The final published version features the final layout of the paper including the volume, issue and page numbers.

Link to publication

\footnotetext{
General rights rights.

- You may freely distribute the URL identifying the publication in the public portal. please follow below link for the End User Agreement:

www.umlib.nl/taverne-license

Take down policy

If you believe that this document breaches copyright please contact us at:

repository@maastrichtuniversity.nl

providing details and we will investigate your claim.
}

Copyright and moral rights for the publications made accessible in the public portal are retained by the authors and/or other copyright owners and it is a condition of accessing publications that users recognise and abide by the legal requirements associated with these

- Users may download and print one copy of any publication from the public portal for the purpose of private study or research.

- You may not further distribute the material or use it for any profit-making activity or commercial gain

If the publication is distributed under the terms of Article $25 \mathrm{fa}$ of the Dutch Copyright Act, indicated by the "Taverne" license above, 
Caregivers' experiences with aggressive behaviour of nursing home residents 
Caregivers' experiences with aggressive behaviour of nursing home residents Adelheid Zeller

ISBN

Cover photo: Nicole Achermann (2013), with permission

Printing: Schmid-Fehr AG, CH-9403 Goldach 


\title{
CAREGIVERS' EXPERIENCES WITH AGGRESSIVE BEHAVIOUR OF NURSING HOME RESIDENTS
}

\author{
DISSERTATION \\ To obtain the degree of Doctor at the Maastricht University, \\ on the authority of the Rector Magnificus, Prof. dr. L.L.G. Soete \\ in accordance with the decision of the Board of Deans, \\ to be defended in public on Wednesday June $12^{\text {th }}, 2013$ at 10.00 hours \\ by
}

Adelheid Zeller 
SUPERVISORS

Prof. dr. G.J. Kok

Prof. dr. T. Dassen, Charité, Universitätsmedizin, Berlin, Germany

CO-SUPERVISOR

Dr. R. J.G. Halfens

\section{ASSESSMENT COMMITTEE}

Prof. dr. J.M.G.A. Schols (chairman)

Prof. dr. J.P.H. Hamers

Prof. dr. H. Nijman, Radboud University Nijmegen

Prof. dr. D. Richter, Bern University of Applied Sciences, Switzerland

Prof. dr. R. Ruiter 


\section{Content}

Chapter 1

General Introduction

Chapter 2

Aggressive behavior of nursing home residents: a systematic

literature review

Chapter 3

Nursing home caregivers' explanations for and coping

strategies with resident' aggression: a qualitative study

Chapter 4

Nurses experiences with aggressive behaviour of nursing home

residents: a cross-sectional study in Swiss nursing homes

Chapter 5

Dealing with aggressive behaviour in nursing homes: caregivers'

use of recommended measures

Chapter 6

Factors associated with resident aggression toward

caregivers in nursing homes

Chapter 7

General discussion

Chapter 8

Summary

Samenvatting

Zusammenfassung

Acknowledgements

Curriculum vitae 

Chapter 1

General Introduction 


\subsection{Introduction}

Aggressive behaviour of residents in nursing homes is an ongoing and important issue for caregivers who work in direct contact with residents. The risk of caregivers experiencing aggression from nursing home residents is high, with prevalence rates averaging $60-80 \%$ (Gerberich et al. 2006, Franz et al. 2010). Moreover, the European Nurses Early Exit Study (NEXTStudy) demonstrated that nursing staff in geriatric wards experience the third highest frequency of aggression of all clinical settings; only nurses in psychiatric and emergency wards were more often confronted with aggression (Camerino et al. 2008). Sometimes aggressive behaviour results in physical injuries. A study in US nursing homes revealed that $34 \%$ of nursing assistants had received physical injuries from assaults by residents (Tak et al. 2010).

Reasons for resident aggression are multifaceted and related to resident factors, characteristics and competencies of the caregiver, and environmental aspects (Gates et al. 2003). Regarding resident factors, the relation between dementia and aggressive behaviour is one of the most widely discussed aspects, as people suffering from dementia are particularly vulnerable to aggression. Several studies confirm an association between residents' cognitive impairment and the occurrence of aggressive behaviour (Talerico et al. 2002, Voyer et al. 2005, Pulsford \& Duxbury 2006, Testad et al. 2007). At an advanced stage of dementia, people typically become unaware of time and place, have difficulty recognising relatives and friends, have an increasing need for assisted self-care, and experience behaviour changes that may escalate and include aggression (World Health Organisation (WHO) 2012). Oh et al. (2004) compared aggressive with non-aggressive residents and found that aggressive residents had significantly more cognitive impairment, and had stayed longer in the nursing home than non-aggressive residents.

Nevertheless, residents without a diagnosis of dementia also show aggressive behaviour (Gates et al. 1999, Schmidt et al. 2012) and therefore further associated factors should be discussed, such as caregiver characteristics and competencies in dealing with aggressive behaviour. Studies show a correlation between caregivers' burnout, age, staff ratios as well as occupational strain and experienced resident aggression (Gates et al. 2003, Isaksson et al. 2008). In addition, caregivers' competencies in dealing with resident aggression may influence the interaction between resident and caregiver. Caregivers with more clinical experience and a higher level of professional training more often use need-based approaches to minimize aggression, whereas caregivers with less experience tend to use more chemical or physical restraint (Nakahira et al. 2009).

Furthermore, environmental factors should be taken into consideration, as we know that people suffering from dementia are sensitive to changes in their environment (Hall \& O'Connor 2004). It is known for example that mandatory overtime and the lack of time for 
appropriate support of residents in activities of daily living result in a significantly higher proportion of physical assaults (Tak et al. 2010). Also stimulants like a public location, olfactory stimulation, or media use as part of the physical environment can trigger aggressive behaviour by residents (Yeom \& Watson 2009). Due to their way of giving care and performing other activities in nursing homes, caregivers shape or create the residents' environment. The mode of routine daily care activities significantly affects aggressive behaviour and the quality of life of people living in nursing homes (Dettmore et al. 2009).

It is well known that caring for residents with aggressive behaviour is a demanding task and associated with high burden and stress for caregivers in nursing homes (Gates et al. 2003, Morgan et al. 2005). Aggressiveness is one of major factors causing distress for caregivers and is related to a high rate of burnout and a lower quality of general health (Schmidt et al. 2012). Possible emotions of caregivers experiencing resident aggression are anxiety, shame, guilt, anger or resignation (Gates et al. 2003, Needham et al. 2005b, Lundström et al. 2007). In some cases caregivers become aggressive towards residents and neglect residents' wishes and/or needs (Aström et al. 2004). Graneheim et al. (2005) describe the interaction with people suffering from dementia and behavioural disturbances like aggression as a balancing act between contradictory positions; namely, meeting the person in my versus her/his world, feeling powerless versus capable, and feeling rejected versus accepted. For some caregivers aggressive behaviour seems to be a 'natural' consequence and they consider these events as unavoidable, irresolvable and as an inevitable constituent of daily work (Gates et al. 1999, Sandvide et al. 2004).

Despite the well-known increase in people suffering from dementia and the expected increase in behavioural symptoms like aggression, aggression in Swiss nursing homes has been sparsely investigated. Most available studies focus on mental health care (Needham et al. 2005a, Abderhalden et al. 2007) and hospitals (Hahn et al. 2012). Therefore the main goal of this dissertation is to explore caregivers' experiences with resident aggression in nursing homes. This thesis investigates the experiences of caregivers with resident aggression as well as caregivers' strategies and measures for dealing with aggression. Finally, factors associated with the occurrence of resident aggression will be examined.

In the following section the theoretical background of this thesis will be described. Starting with the background of resident aggression and followed by describing models explaining the occurrence of resident aggression and strategies caregivers used to handle it. Next, the implications for research and practice are described followed by the research questions which guided this thesis. This chapter ends with a short overview of the contents of the dissertation. 


\subsection{Theoretical Framework}

\section{Aggression: definition and models}

Defining aggressive behaviour by residents in nursing homes is controversial as there is an overlap between several terms like violence, agitation, resistive behaviour or overt verbal and physical aggression, disturbed or disruptive behaviour as well as behavioural problems, or behavioural symptoms (Gruber-Baldini et al. 2004, Hall \& O'Connor 2004).

A description of violence is given by the WHO (2002), which defines it as any incident where staff are abused, threatened or assaulted in circumstances related to their work, involving an explicit or implicit challenge to their safety, well-being or health(World Health Organisation (WHO) 2002). Violence is also defined as excessive negative aggression and as behaviours by individuals that intentionally threaten, attempt, or inflict physical harm on others (Liu 2004). In this context, aggression and violence can be differentiated. Aggression is clearly included in the definition of violence, but some forms of aggression do not threaten or inflict harm on others; instead, they aim to protect and preserve the individual (Liu 2004). This is may be the reason why the term 'violence' seldom appears in dementia care literature (Pulsford \& Duxbury 2006).

A further and major point for discussion regarding resident aggression is the question of how targeted and intended this aggressive behaviour can be if they possibly suffer from dementia. In the case of people who are cognitively impaired it is often difficult to identify the person's intention. For this reason Patel and Hope (1992) use the term 'aggressive behaviour' and defined it as an overt act, involving the delivery of noxious stimuli to (but not necessarily aimed at) another organism, object or self, which is clearly not accidental.

This study focused on aggressive behaviour from nursing home residents and we used the definition of Patel and Hope (1992) and the operationalization of aggressive behaviour of McKenna (2004), which delineates verbal aggression as the use of abusive or offensive language (including sexually abusive language), derogatory remarks, or profane or obscene comments; threats as warnings of intent to injure another person with or without an object or weapon; harassment (including sexual); and physical intimidation and physical assault, including slapping, pinching, pushing, shoving, spitting, or kicking, with or without the use of weapons. Awareness that caregivers have different views on resident aggression and their perception of aggression is subjective led to inclusion of the definition by Steinert (1995): aggressive behaviour occurs if a person feels threatened, attacked or injured. 


\section{Models of aggression}

Aggression and related behaviours have been studied in a wide range of disciplines including anthropology, biology, economy, political science, communication research, history, and sociology. The most aggression-relevant theories developed in the last decades are psychoanalytic theory, drive theory and social learning theories (Bjørkly 2006, p. 27-44). Due to several limitations of these historically dominant theories further development led to more complex models which take several factors into consideration and emphasise that aggression is a complex interplay of different factors.

The general aggression model (GAM) represents one of these theories which give a comprehensive overview of the origin of human aggression (Anderson \& Bushman 2002). As this thesis focuses on resident aggression in nursing homes, the theoretical framework was supplemented by the need-driven dementia-compromised behaviour model (NDB-Model), which provides a rich framework for studying resident aggression particularly in the nursing home setting (Algase et al. 1996). As the interaction between caregivers and residents is an important factor regarding resident aggression the model of interactive behaviour of caregivers, developed by Höwler (2008), is included in this thesis. Although these three theoretical approaches show some overlapping factors, they mainly complement each other and form the basis of its theoretical background.

\section{The general aggression model}

The general aggression model (GAM) integrates existing theories of aggression. It distinguishes three main foci: person and situation inputs, cognitive, affective, and arousal routes through which these input variables have their impact, and outcomes of the underlying appraisal and decision processes (see Figure 1.1).

Inputs

Biological, environmental, psychological, and social factors influence aggressive behaviour. These factors can be categorised as features of the situation or as features of the person in the situation. Person factors include all the characteristics a person brings to the situation, e.g. demographic characteristics, personality traits, attitudes, beliefs and values as well as knowledge structures. Together, person factors comprise an individual's preparedness to commit aggression. Situational factors include any important features of the situation, such as presence of a provocation or an aggressive cue. Aggressive cues are objects that prime aggression-related concepts in memory. Provocations include insults, slights or other forms of verbal or physical aggression which interfere with one's attempts to attain an important goal. Also non-social aversive conditions, such as pain and discomfort (e.g., hot temperature, loud noises, and unpleasant odours), increase the likelihood of aggression. 
Routes

The above-mentioned input variables influence final outcome behaviour through the present internal state that they create. The internal states of most interest are cognition, affect, and arousal. Cognition factors are hostile thoughts precipitated for example due to media violence which can increase the relative accessibility of aggressive concepts in memory. Affective factors are mood and emotion and expressive motor responses. Input variables, e.g. pain, can directly influence the emotion of a person and increase state hostility or anger. Expressive motor responses described by Anderson \& Buschman (2002, p 39) as automatic reactions that occur in conjunction with specific emotions, largely in the face.

Arousal can influence aggression in three ways: First, arousal from an irrelevant source can energize or strengthen the dominant action tendency, including aggressive tendencies. Second, arousal elicited by irrelevant sources (e.g. exercise) can be mislabelled as anger in situations involving provocation, thus producing anger-motivated aggressive behaviour. A third, and as yet untested, possibility is that unusually high and low levels of arousal may be aversive states, and may therefore stimulate aggression in the same way as do other aversive or painful stimuli (Anderson \& Bushman 2002, p. 39). As shown in Figure 1.1, the contents of these three routes are highly interconnected.

\section{Outcomes}

The outcomes include several complex information processes. As shown in Figure 1.1, contents from the inputs enter into the appraisal and decision processes through their effects on cognition, affect and arousal. Immediate appraisal is a more automatic process, whereas reappraisal refers to more controlled processes. Immediate appraisal is an automatic, relatively effortless, spontaneous process and depends on the circumstances of the present internal state, which is based on personal characteristics and features of the situation. The present internal state determines, to a great extent, which type of automatic inference is generated. The reappraisal process "... involves searching for alternative views of the situation. It can include a search for relevant information about the cause of the event, a search for relevant memories, and a search for features of the present situation. Reappraisal may include numerous cycles as alternatives are considered and discarded. At some point the recycling process ceases and a thoughtful course of action occurs" (Anderson \& Bushman 2002, p. 41). 


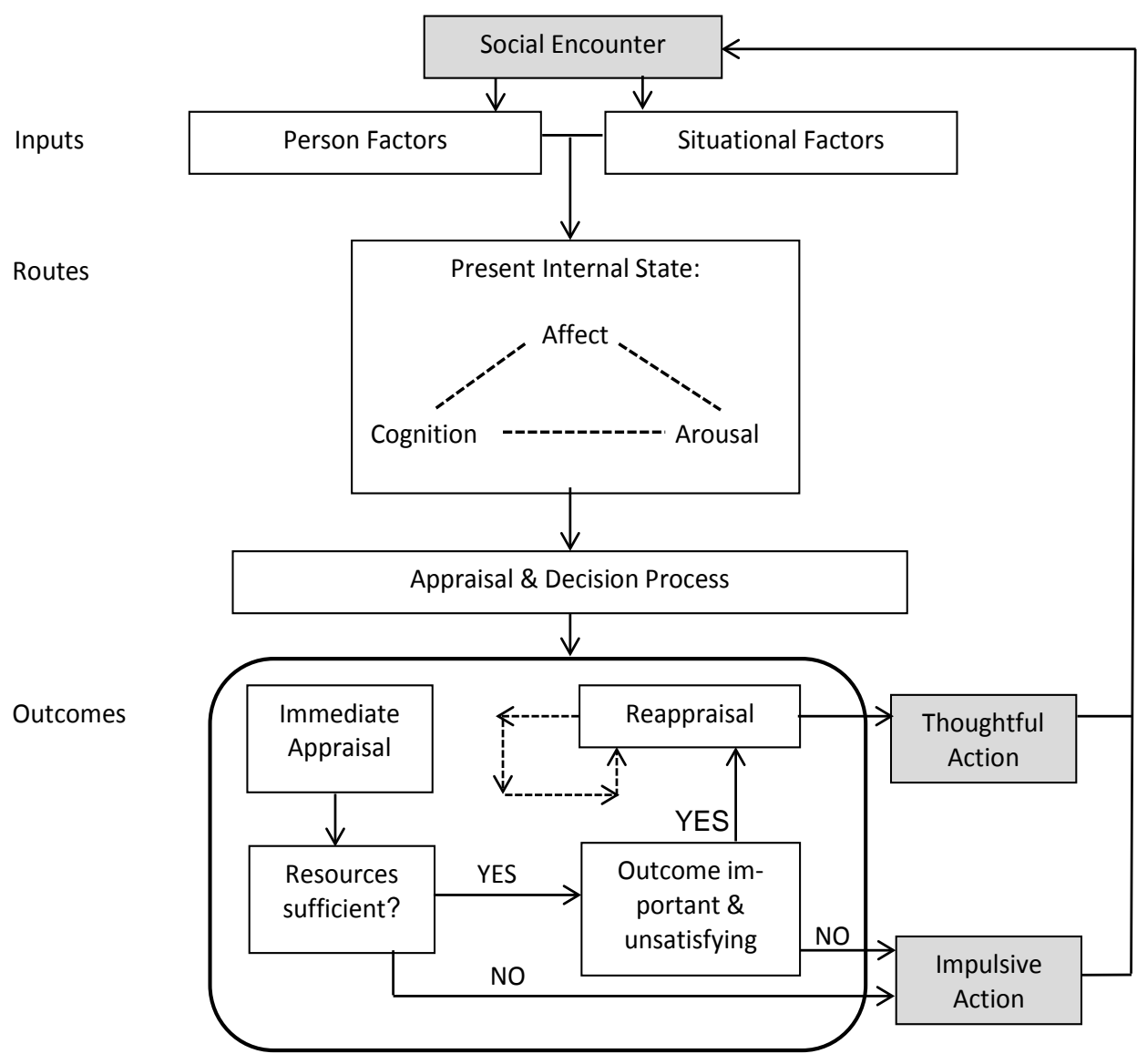

Figure 1.1: The General Aggression Model (Anderson, 2002) 
Need-driven dementia-compromised behaviour model

Algase et al. (1996) offers a view of disruptive behaviour, which includes aggression, as an expression of unmet needs or goals and provides a comprehensive conceptual framework to guide clinical practice: the need-driven dementia-compromised behaviour model (NDBModel) (Figure 1.2). Based on empirical investigations and clinical experience, they propose a framework from which to study behaviours like aggression by considering their meaning to persons who display them. While behaviours such as aggression may interfere or disrupt clinical care routines, they may actually express or embody the cognitively impaired person's goal or needs. Algase et al. (1996) believe that need-driven dementia-compromised behaviour (NDB) arises in pursuit of a goal or as an expression of a need. NDBs constitute the most integrated and meaningful response possible, given limitations imposed by a dementing condition. As an example, when cognitively impaired persons can no longer satisfy their needs or goals, they may become aggressive as a way of dealing with the resulting frustration. Thus, aggression might reflect diminished ability to deal with frustration or ambiguity. Seen in this way, these behaviours become meaningful and therefore, potentially useful in directing nursing care.

Furthermore, the NDB-Model supports caregivers in identifying persons at greatest risk of becoming aggressive and in isolating those needs with highest likelihood of precipitating these behaviours. Antecedents to need-driven, dementia-compromised behaviours within the model include both background factors and proximal factors. Background and proximal factors interact to produce behaviours. According to Algase et al. (1996), background factors are relatively stable and include neurological, cognitive, health, and psychosocial variables. Background factors are those that shape the more enduring patterns of behaviour. Proximal factors, or current situational issues and events, are more amenable to intervention and often precipitate the NDB. They include variables within the person like hunger, thirst or pain, physical environmental aspects like light and sound level, and social environmental factors like ward ambiance (Algase et al. 1996, Kolanowski 1999). Proximal factors are the more fluid or fluctuating aspects of the immediate physical and social environment and the dynamic or changing needs and states within the cognitively impaired person. 


\begin{tabular}{|c|c|}
\hline Background Factors & Proximal Factors \\
\hline $\begin{array}{l}\text { Neurological factors } \\
\text { - } \quad \text { Specific regional brain involvement } \\
\text { - } \quad \text { Neurotransmitter imbalance } \\
\text { - } \quad \text { Circadian rhythm deterioration } \\
\text { - } \quad \text { Motor ability }\end{array}$ & $\begin{array}{l}\text { Physiological need state } \\
\text { - } \quad \text { Hunger or thirst } \\
\text { - } \quad \text { Elimination } \\
\text { - } \quad \text { Pain } \\
\text { - } \quad \text { Discomfort } \\
\text { - } \quad \text { Sleep disturbance }\end{array}$ \\
\hline $\begin{array}{l}\text { Cognitive factors } \\
\text { - } \quad \text { Attention } \\
\text { - } \text { Memory } \\
\text { - } \quad \text { Visuo-spatial ability } \\
\text { - } \quad \text { Language skills } \\
\end{array}$ & $\begin{array}{l}\text { Psychological need state } \\
\text { - } \quad \text { Affect } \\
\text { - } \quad \text { Match of assistance to ability }\end{array}$ \\
\hline $\begin{array}{l}\text { Health status } \\
\text { - } \quad \text { General health } \\
\text { - } \quad \text { Functional ability } \\
\text { - } \quad \text { Affective state }\end{array}$ & $\begin{array}{ll}\text { Physical environment } \\
\text { - } \quad \text { Light level } \\
\text { - } \quad \text { Sound level } \\
\text { - } \quad \text { Head index / temperature }\end{array}$ \\
\hline $\begin{array}{l}\text { Psychosocial factors } \\
\text { - } \quad \text { Gender } \\
\text { - } \quad \text { Education, Occupation } \\
\text { - } \quad \text { Personality type } \\
\text { - History of psychosocial stress } \\
\text { - } \quad \text { Behavioural response to stress }\end{array}$ & $\begin{array}{l}\text { Social environment } \\
\text { - } \quad \text { Staff mix } \\
\text { - } \quad \text { Staff stability } \\
\text { - } \quad \text { Ward ambiance } \\
\text { - } \quad \text { Presence of others }\end{array}$ \\
\hline Aggression, wande & $\begin{array}{l}r \\
\text { lematic vocalisation }\end{array}$ \\
\hline
\end{tabular}

Figure 1.2: Need-driven dementia-compromised behaviour model (Algase et al. 1999)

The development of the NDB-Model was a turning point in the way nurses viewed behavioural symptoms, e.g. aggressive behaviour, in dementia. Previously, behaviour symptoms were often viewed as a chaotic, random result of brain pathology and were framed in terms of how the behaviours were problematic for staff. The NDB-Model shifted the focus of nurses from controlling random behavioural symptoms to viewing these behaviours as indicative of physical and psychological needs (Kovach et al. 2005). 
The model of interactive behaviour of caregivers developed by Höwler (2008) provides an explanation for different ways in which caregivers handle resident aggression or challenging behaviour. Whether to reduce, eliminate or allow situational challenging behaviour from people suffering from dementia depends on caregivers' personality, psycho-social skills, e.g. empathy, interactive skills, self-reflection as well as their motivation to respond to residents' needs. Caregivers' attitude towards residents with aggressive behaviour is shown in their approach to dealing with it. The model shows the interplay of emotions and strategies of caregivers (see Figure 1.3)

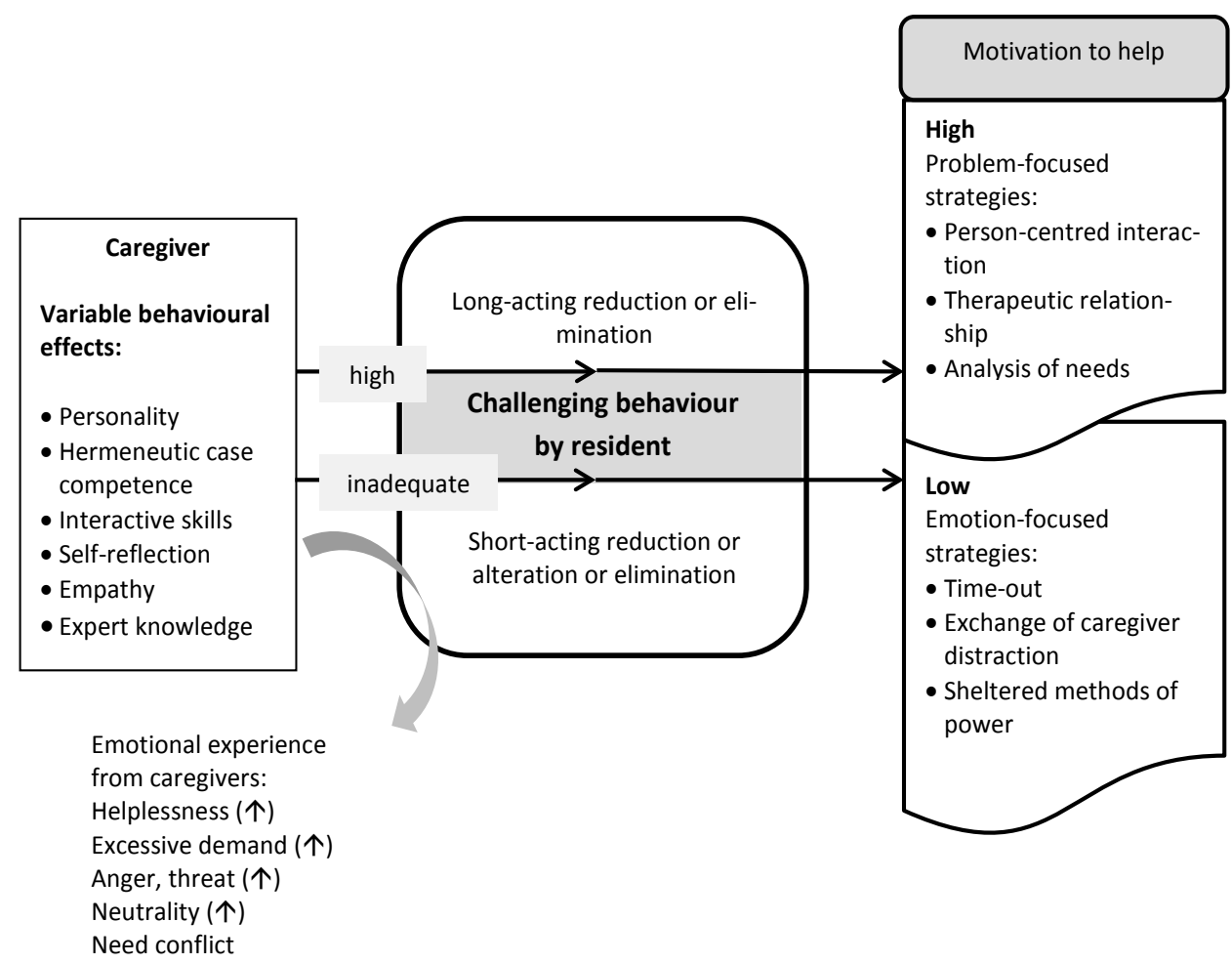

Figure 1.3: Model of interactive behaviour of caregivers (Höwler 2008)

A relationship can be established between caregivers' emotional stress and their commitment to help. Caregivers who have difficulties in understanding residents' behaviour and have no hermeneutical case competence together with feelings of failure about their own coping, experience contact with the challenging resident as stress, helplessness, anger and threat, or feel dissatisfied with the situation. The higher the emotional stress of caregivers in dealing with experienced aggression, the lower is their motivation to support aggressive 
residents in a problem-centred manner. They use more emotion-focused strategies, such as a time-out or a change of person as the short-term "solution" to the problem. The experience with the aggressive behaviour limits caregivers. They assess the resident negatively and avoid contact with them.

Caregivers with mental stability and psycho-social skills, like empathy and self-reflection in connection with a person-centred attitude, are able to apply problem-focused strategies with residents who show aggressive behaviour. Their motivation to help is high (Höwler 2008).

\section{Summary}

In summary the models described above provide important information about the complex situation in which resident aggression occurred und contribute a structured and systematic approach for issues in this field. Whereas the GAM provides a comprehensive description of the origin of human aggression, the NDB-Model focuses on the specific situation of elderly people who may suffer from dementia. Nevertheless, some overlapping factors can be identified in these two models. Both models include personal characteristics of the people involved as well as situational factors in which the interaction takes place.

Since many people living in nursing homes suffer from dementia, the NDB-Model provides a comprehensive framework for investigating resident aggression in this setting, as it gives a broad overview of the factors associated with resident aggression. It includes, besides resident characteristics, physical and social environmental factors which should be taken into consideration regarding the occurrence of resident aggression. Finally, the model of interactive behaviour of caregivers focuses on strategies caregivers can use for dealing with resident aggression. The model provides an insight into underlying factors which are relevant for caregivers' management of aggressive behaviour.

\subsection{Implications for research and practice}

As discussed in the introduction and derived from the theoretical background, the following implications regarding aggressive behaviour of residents in nursing homes and caregivers coping with these challenging situations can be noted for research and practice:

- There is a lack of information regarding caregivers' experience with resident aggression in Swiss nursing homes, as well as detailed factors associated with the problem in this setting. This lack of information refers to the prevalence of experienced resident aggression, the features of the situations in which aggression occurs and caregivers' handling of these situations. 
- Despite the fact that many caregivers in Swiss nursing homes have been trained in validation and basic stimulation, which are recommended measures in dealing with resident aggression, there is less information available on how often caregivers use these approaches in dealing with the aggressive behaviour of residents and whether the use of these measures depends on caregivers' characteristics. Furthermore, according to the theoretical models, resident aggression is related to multifaceted factors, but there is no knowledge available as to which factors caregivers take into consideration when they assess the reasons for resident aggression.

- A systematic capture of data with a validated questionnaire about resident aggression and related factors should provide insight into the situation of affected caregivers and residents and could help to develop concepts for training in aggression management with the aim of improving practice in nursing homes and supporting caregivers as well as residents in these challenging situations. 


\subsection{Aim and research questions}

In accordance with the implications, basic knowledge about resident aggression experienced by caregivers in Swiss nursing homes is required. With this knowledge it should be possible to reveal the general situation of caregivers in nursing homes and to improve their understanding of resident aggression. Furthermore, the knowledge gained could support the development of specific and effective approaches in dealing with resident aggression. Therefore the aim of this dissertation is to explore caregivers' experience regarding the extent of resident aggression as well as strategies and measures used by caregivers for dealing with it. Furthermore, factors associated with the occurrence of resident aggression were examined. The research, conducted in the German-speaking part of Switzerland, was led by the following research questions:

1. What types of resident aggression and its situational occurrence as well as caregivers' strategies in dealing with it are described in the international research?

2. How do caregivers explain the occurrence of aggressive behaviour among residents?

3. In what situations does aggressive behaviour in nursing home residents occur, according to the caregivers?

4. What strategies do caregivers involved in direct care use to deal with aggressive behaviour of nursing home residents?

5. How often and what types of aggression have caregivers experienced in their past working week?

6. What are the consequences of aggressive behaviour for the caregivers and residents involved?

7. Are there different groups of caregivers in terms of the use of recommended approaches for dealing with resident aggression and is there a relation with their characteristics?

8. What are risk factors for caregivers to experience aggressive behaviour in Swiss nursing homes? 


\subsection{Ethical considerations}

This study was approved by the ethics commission of the various cantons of the participating nursing homes. Nursing homes willing to participate received written information regarding the study aims, methods, questionnaire, and volunteering to participate. Also, all participants received in every part of the study written information regarding the study aims and methods. Informed consent was obtained with commitment to participate in an interview or with completion of the questionnaire and its return to the research team. Confidentiality and anonymity was ensured.

\subsection{Contents of the thesis}

The dissertation starts in the next chapter (chapter 2) with a systematic literature review. The review gives an overview of what is known regarding prevalence and types of resident aggression that caregivers experience in nursing homes, as well as information about situations in which resident aggression occur (research question 1).

Chapter 3 describes a qualitative investigation of the caregivers' perspective regarding the conditions and situations of resident aggression and practical strategies they use in dealing with aggression (research question 2, 3 and 4).

In the following chapter (chapter 4) caregivers' experiences regarding the prevalence of resident aggression were explored with a cross-sectional survey. Moreover, caregivers' coping in these situations as well as caregivers' burden with regard to resident aggression and the consequences on the caregiver-resident-relationship were investigated (research question 2, 3, 4, 5 and 6).

The purpose of the study in chapter 5 was to identify different groups of caregivers regarding their use of measures for dealing with resident aggression recommended by guidelines and the association with caregivers' characteristics (research question 7).

Chapter 6 explores caregivers' risk factors of experiencing resident aggression in Swiss nursing homes utilising multiple regression analysis (research question 8). 


\subsection{References}

Abderhalden C, Needham I, Dassen T, Halfens R, Fischer JE \& Haug H (2007) Frequency and severity of aggressive incidents in acute psychiatric wards in Switzerland. Clinical practice and epidemiology in mental health : CP \& EMH 3, 30.

Algase DL, Beck C, Kolanowski A, Whall A, Berent S, Richards K \& Beattie E (1996) Needdriven dementia-compromised behavior: An alternative view of disruptive behavior. American Journal of Alzheimer's Disease and Other Dementias 11, 10-19.

Anderson CA \& Bushman BJ (2002) Human aggression. Annual Review of Psychology 53, 2751.

Aström S, Karlsson S, Sandvide A, Bucht G, Eisemann M, Norberg A \& Saveman B (2004) Staff's experience of and the management of violent incidents in elderly care. Scandinavian Journal of Caring Sciences 18, 410-416.

Bjørkly S (2006) Psychological Theories of Aggression: Principles and Application to Practice. In Violence in Mental Health Settings (Richter D \& Whittington R eds.), pp. 27-46.

Camerino D, Estryn-Behar M, Conway P, van Der Heijden BIJM \& Hasselhorn H (2008) Workrelated factors and violence among nursing staff in the European NEXT study: a longitudinal cohort study. International Journal of Nursing Studies 45, 35-50.

Dettmore D, Kolanowski A \& Boustani M (2009) Aggression in persons with dementia: use of nursing theory to guide clinical practice. Geriatric Nursing 30, 8-17.

Franz S, Zeh A, Schablon A, Kuhnert S \& Nienhaus A (2010) Aggression and violence against health care workers in Germany - a cross sectional retrospective survey. BMC Health Services Research 10, 51.

Gates D, Fitzwater E \& Succop P (2003) Relationships of stressors, strain, and anger to caregiver assaults. Issues in Mental Health Nursing 24, 775-793.

Gates DM, Fitzwater E \& Meyer U (1999) Violence against caregivers in nursing homes. Expected, tolerated, and accepted. Journal of Gerontological Nursing 25, 12-22.

Gerberich SG, Church TR, McGovern PM, Hansen HE, Nachreiner NM, Geisser MS, Ryan AD, Mongin. S. J. \& Watt GD (2006) An epidemiological study of the magnitude and consequences of work related violence: the Minnesota Nurses' Study. Occupational and Environmental Medicine 61, 495-503.

Graneheim U, Isaksson U, Ljung I \& Jansson L (2005) Balancing between contradictions: the meaning of interaction with people suffering from dementia and "behavioral disturbances". International Journal of Aging \& Human Development 60, 145-157. 
Gruber-Baldini AL, Boustani M, Sloane PD \& Zimmerman S (2004) Behavioral symptoms in residential care/assisted living facilities: prevalence, risk factors, and medication management. Journal of the American Geriatrics Society 52.

Hahn S, Hantikainen V, Needham I, Kok G, Dassen T \& Halfens RJ (2012) Patient and visitor violence in the general hospital, occurrence, staff interventions and consequences: a cross-sectional survey. Journal of Advanced Nursing 68, 2685-2699.

Hall KA \& O'Connor DW (2004) Correlates of aggressive behavior in dementia. International Psychogeriatrics 16, 141-158.

Höwler E (2008) Herausforderndes Verhalten bei Menschen mit Demenz: Erleben und Strategien Pflegender (Challenging behaviour in people with dementia: caregivers experiences and strategies). Kohlhammer, Stuttgart.

Isaksson U, Graneheim UH, Richter J, Eisemann M \& Aström S (2008) Exposure to violence in relation to personality traits, coping abilities, and burnout among caregivers in nursing homes: a case-control study. Scandinavian Journal of Caring Sciences 22, 551-559.

Kolanowski AM (1999) An overview of the need-driven dementia-compromised behavior model. Journal of Gerontological Nursing 25, 7-9.

Kovach CR, Noonan PE, Schlidt AM \& Wells T (2005) A model of consequences of needdriven, dementia-compromised behavior. Journal of Nursing Scholarship 37, 134-140.

Liu J (2004) Concept analysis: aggression. Issues in Mental Health Nursing 25, 693-714.

Lundström M, Saveman B, Eisemann M \& Astrom S (2007) Prevalence of violence and its relation to caregivers' demographics and emotional reactions: an explorative study of caregivers working in group homes for persons with learning disabilities. Scandinavian Journal of Caring Sciences 21, 84-90.

McKenna K (2004) Study of work-related violence. Committee on Workplace Violence, North Eastern Health Board, Ireland.

Morgan DG, Stewart NJ, D'Arcy C, Forbes D \& Lawson J (2005) Work stress and physical assault of nursing aides in rural nursing homes with and without dementia special care units. Journal of Psychiatric and Mental Health Nursing 12, 347-358.

Nakahira M, Moyle W, Creedy D \& Hitomi H (2009) Attitudes toward dementia-related aggression among staff in Japanese aged care settings. Journal of Clinical Nursing 18, 807816.

Needham I, Abderhalden C, Halfens RJG, Dassen T, Haug HJ \& Fischer JE (2005a) The effect of a training course in aggression management on mental health nurses' perceptions of ag- 
gression: a cluster randomised controlled trial. International Journal of Nursing Studies $\mathbf{4 2}$, 649-655.

Needham I, Abderhalden C, Halfens RJG, Fischer JE \& Dassen T (2005b) Non-somatic effects of patient aggression on nurses: a systematic review. Journal of Advanced Nursing 49, 283-296.

Oh H, Eom M \& Kwon Y (2004) A study on aggressive behavior among nursing home residents with cognitive impairment. Taehan Kanho Hakhoe Chi 34, 1451-1459.

Patel V \& Hope RA (1992) A rating scale for aggressive behaviour in the elderly - the RAGE. Psychological Medicine 22, 211-221.

Pulsford D \& Duxbury J (2006) Aggressive behaviour by people with dementia in residential care settings: a review. Journal of Psychiatric and Mental Health Nursing 13, 611-618.

Sandvide A, Aström S, Norberg A \& Saveman BI (2004) Violence in institutional care for elderly people from the perspective of involved care providers. Scandinavian Journal of Caring Sciences 18, 351-357.

Schmidt SG, Dichter MN, Palm R \& Hasselhorn HM (2012) Distress experienced by nurses in response to the challenging behaviour of residents - evidence from German nursing homes. Journal of Clinical Nursing 21, 3134-3142.

Steinert T (1995) Aggression bei psychisch Kranken. Ferdinand Enke Verlag, Stuttgart.

Tak S, Sweeney M, Alterman T, Baron S \& Calvert G (2010) Workplace assaults on nursing assistants in US nursing homes: a multilevel analysis. American Journal of Public Health 100, 1938-1945.

Talerico K, Evans L \& Strumpf N (2002) Mental health correlates of aggression in nursing home residents with dementia. The Gerontologist 42, 169-177.

Testad I, Aasland AM \& Aarsland D (2007) Prevalence and correlates of disruptive behavior in patients in Norwegian nursing homes. International Journal of Geriatric Psychiatry 22, 916-921.

Voyer P, Verreault R, Azizah G, Desrosiers J, Champoux N \& Bedard A (2005) Prevalence of physical and verbal aggressive behaviours and associated factors among older adults in long-term care facilities. BMC Geriatrics 5, 13.

World Health Organisation (WHO) (2002) Framework guidelines for addressing workplace violence in the health sector. Available at:http://www.who.int/violence_injury_ prevention/violence/interpersonal/en/WVguidelinesEN.pdf (accessed 11 November 2012). 
World Health Organisation (WHO) (2012) 10 Facts on Dementia. Available at: http://www.who.int/features/factfiles/dementia/en/ (accessed 11 November 2012).

Yeom H \& Watson NM (2009) Patterns of antecedents of catastrophic reactions in nursing home residents with dementia in the United States. Asian Nursing Research 3, 99-110. 


\section{Chapter 2}

\section{Aggressive behavior of nursing home residents:}

a systematic literature review

Zeller A, Hahn S, Needham I, Kok G, Dassen T \& Halfens R (2009) Aggressive behavior of nursing home residents toward caregivers: a systematic literature review. Geriatric Nursing 30, 174-187. 


\subsection{Abstract}

\section{Background}

Aggression challenges and burdens caregivers face when working in nursing homes.

\section{Design and research questions}

The research questions in this review were (1) what types of residents' aggressive behavior do caregivers experience in nursing homes and how often? (2) In what situations does aggressive behavior occur? (3) What strategies do caregivers employ to manage aggressive behavior?

\section{Results}

Twenty one publications in English and/or German from 1996 to 2006 were identified by search strategies conducted in Medline, CINAHL, PsycINFO, and supplemented by screening citations, references, and unpublished manuscripts. Results show that all types of aggressive behavior occur in nursing homes with verbal and physical aggressive behavior combined. Personal care of the residents was the most frequent context in which aggressive behavior occurs. Strategies for preventing and dealing with aggressive behavior used by caregivers ranged from behavioral strategies aiming to prevent aggression, to medical treatment, or following written institutional guidelines for reducing aggressive behavior.

\section{Conclusion}

Some care providers demonstrated predominantly positive and others predominantly negative strategies. Furthermore, there was a lack of information about "triggering" factors and interactive events during personal care in the referenced publications. 


\subsection{Background}

Aggressive behavior of residents continues to challenge and burden caregivers working in nursing homes (Evers et al. 2002, Talerico et al. 2002). Working in a nursing home or long term care facility is associated with a high risk to experience aggression (Gerberich et al. 2006). Studies show aggressive behavior is more likely to occur among older people with cognitive impairment than among those with no cognitive impairment (Shah 1999, Talerico et al. 2002, Pulsford \& Duxbury 2006), although cognitively intact residents also threaten or assault the care givers (Gates et al. 1999). Irrespective of whether demented residents can be held responsible for their aggressive behavior, many gerontological nurses find that physical or verbal attacks by an elderly person they are giving nursing care to is one of the most difficult, emotionally distressing, and potentially dangerous aspects of their work (Hagen \& Sayers 1995), often resulting in feelings of powerlessness, sadness, anger, and insufficiency (Aström et al. 2002).

Some studies investigate the prevalence of aggression and associated factors in nursing homes, but it is probable that aggressive behavior of residents in nursing homes often goes underreported both in prevalence measures and in the nursing documentation. Possible causes for underreporting are a lack of competence to cope with aggressive behavior, feelings of failure or the assumption that aggressive behavior is a common feature in the care of the elderly, especially of the psychologically disturbed (Cohen-Mansfield 1996, Shah et al. 2000, Evers et al. 2002, Pulsford \& Duxbury 2006). Psychological disturbances and other illnesses in the elderly may lead to aggressive behavior irrespective of situational factors. However, as such illness processes can only be indirectly influenced by nursing interventions this review will focus on situations in which aggressive resident behavior occurs and on which nurses can potentially influence (Brodaty et al. 2001, Wancata et al. 2003).

The aim of this literature review is to summarize research based facts about aggression in nursing homes. The main questions were therefore: (1) what types of residents' aggressive behavior do caregivers experience in nursing homes and how often? (2) In which situations does aggressive behavior of nursing home residents occur? (3) What strategies do caregivers employ to deal with aggressive behavior?

For the purpose of this literature review the following definition was used: Aggressive behavior refers to a non-accidental overt act involving the delivery of noxious stimuli to (but not necessarily aimed at) an object or towards the self or others (Patel \& Hope 1992). Aggressive behavior may be verbal or physically harming or threatening other persons (Chou et al. 1996). Because the term nursing home is not clearly defined in the literature a broad range of geriatric long-term care settings such as retirement homes, skilled nursing facilities or psycho geriatric wards were considered. 


\subsection{Methods}

The search for relevant articles involved computer searches of Medline (PubMed), Cumulative Index of Nursing and allied Health Literature (CINAHL) and PsychINFO using - where appropriate - MeSH terms (Table 2.1). Additionally citations and references in journal articles, references suggested by experts in the field, and fugitive literature were screened.

Table 2.1: Search strategy and results

\begin{tabular}{lccc}
\hline Source & Hits & Initial Selection $^{1}$ & Final Selection $^{2}$ \\
\hline Medline & 109 & 54 & 13 \\
CINAHL & 64 & 11 & 4 \\
PsychINFO & 39 & 3 & 0 \\
Reference from colleagues & 2 & 2 & 2 \\
Unpublished Master thesis & 2 & 2 & 2 \\
Total publications & 216 & 72 & 21 \\
\hline Keywords Used: & (aggression OR violence OR patient assault OR disruptive behavior) AND (nurs- \\
& ing homes) \\
Limits: & Enter Date: 1996 to 2006, only items with abstracts, only those in English and \\
\multicolumn{4}{l}{ Based on reading abstracts after elimination double hits } \\
${ }^{2}$ Based on critical appraisal of the publications
\end{tabular}

The search was limited to articles with abstracts in German or English and published from 1996 to December 2006. After an initial screening of 72 publications by the first author the following publications were excluded: (1) those regarding Veterans Health Administrations, which are comparable to acute care settings because the residents tend to have psychiatric diagnoses; (2) those in which the research results could not clearly be assigned to aggressive behavior from residents toward caregivers (e. g. research about elder abuse and neglect); (3) those that investigated associations between the illness process (e. g. of dementia) and the occurrence of aggressive behavior without further description of the situation or context in which aggressive behavior occurs; (4) and those that are not research based. The remaining 21 articles were rated by the first and the second authors using criteria for the judgment of quantitative and qualitative research reports (Polit \& Tatano Beck 2003).

Each criterion - 12 criteria for quantitative and 10 criteria for qualitative publications was rated as not fulfilled ( 0 points) or fulfilled ( 1 point). A cut off of 7 points for quantitative and 6 points for qualitative studies was defined. Seven to 8 points for quantitative and 6 to 7 for qualitative studies were taken to indicate that the study has adequate, 9-10 points (for qualitative studies 8-9 points) a good, and 11-12 points (10 points for qualitative studies) a very good research quality (Table 2.2 ).

The inter-rater reliability was calculated by AC1 statistic (Gwet 2002). This statistical measure of inter-rater reliability avoids the problem of instability accruing from differences 
in marginal probabilities between raters as can occur, for example which the Kappa statistic (Gwet 2002).

Table 2.2: Criteria for critical appraisal of research quality

Criteria
Research aim
1. Are purpose statements or research questions clearly formulated?
Design
2. Does the research question correspond to the design actually used?
3. Are concepts or key variables under study clearly defined?
4. Does the design have major flaws? (change points: Yes=0, No=1)
Sample
5. Are the characteristics of the population adequate?
6. Is the sample size adequate?
7. Was the response rate sufficient? (Not applicable to qualitative publica-
tions)
Instrument
8. Was the instrument adequately pretested? (not applicable to qualitative
publications)
9. Are information about validity and reliability (or trustworthiness) de-
scribed?
Data analysis
10. Was an appropriate statistics / analytic method used?
Interpretation of the findings
11. Are interpretations consistent with the results?
12. Are the stated implications appropriate given the results?

\subsection{Results}

\section{Methodology and study design}

Thirteen publications based on a quantitative and 8 on qualitative design (Table 2.3) were analyzed. The most frequently used quantitative method was a retrospective cross-sectional investigation or survey, with only 2 publications using a prospective approach. One publication was an observational study and 7 of 13 publications provided information about the validity, reliability, or both of the instruments used. Of the 8 qualitative publications, $2 \mathrm{em}-$ ployed a phenomenological-hermeneutic approach, 1 used the grounded theory methodology, and 1 was an ethnographic investigation. Four qualitative publications gave only minor information regarding the methodology, and 4 publications contained concrete information about trustworthiness of the methodology. Despite certain shortcomings and limitations, all 21 publications achieved at least 7 points for quantitative and 6 points for qualitative studies regarding research quality. Interrater reliability using the AC1 measure over all items was 0.93 , with ratings at the item-level ranging from 0.55 to 1.0 . We can therefore consider the interrater reliability as measured by the AC 1 measure as satisfactory to very good. 


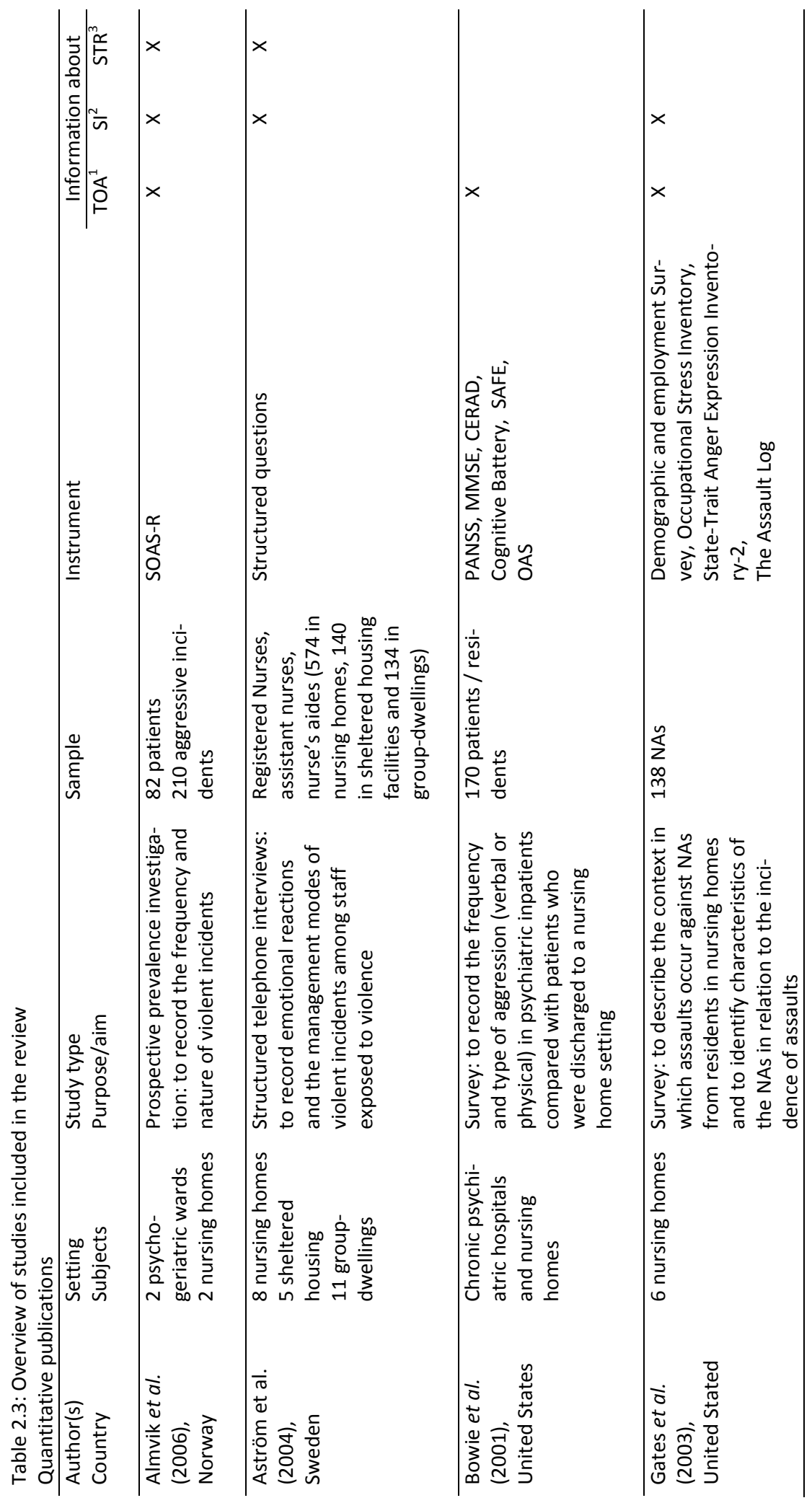




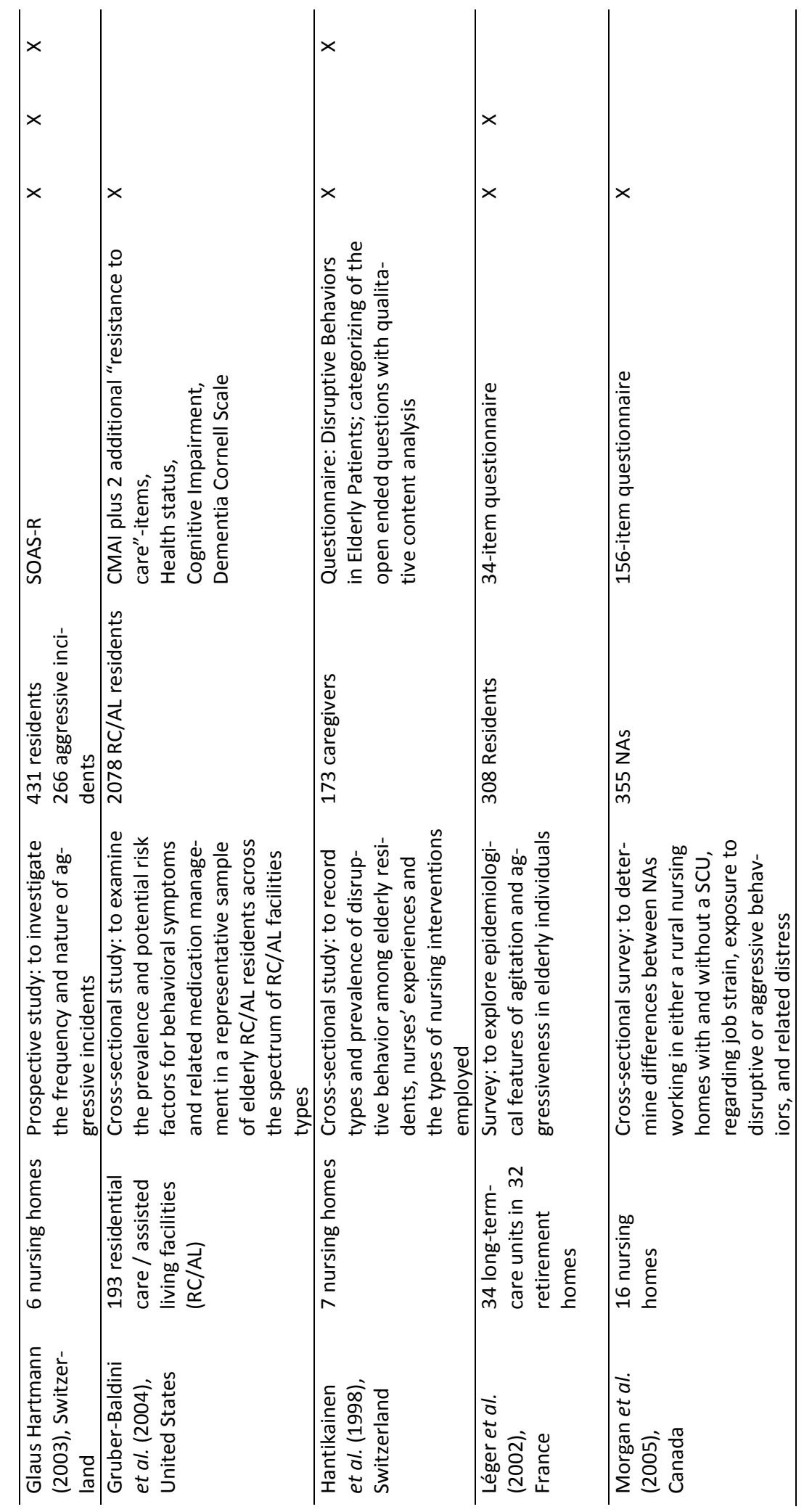




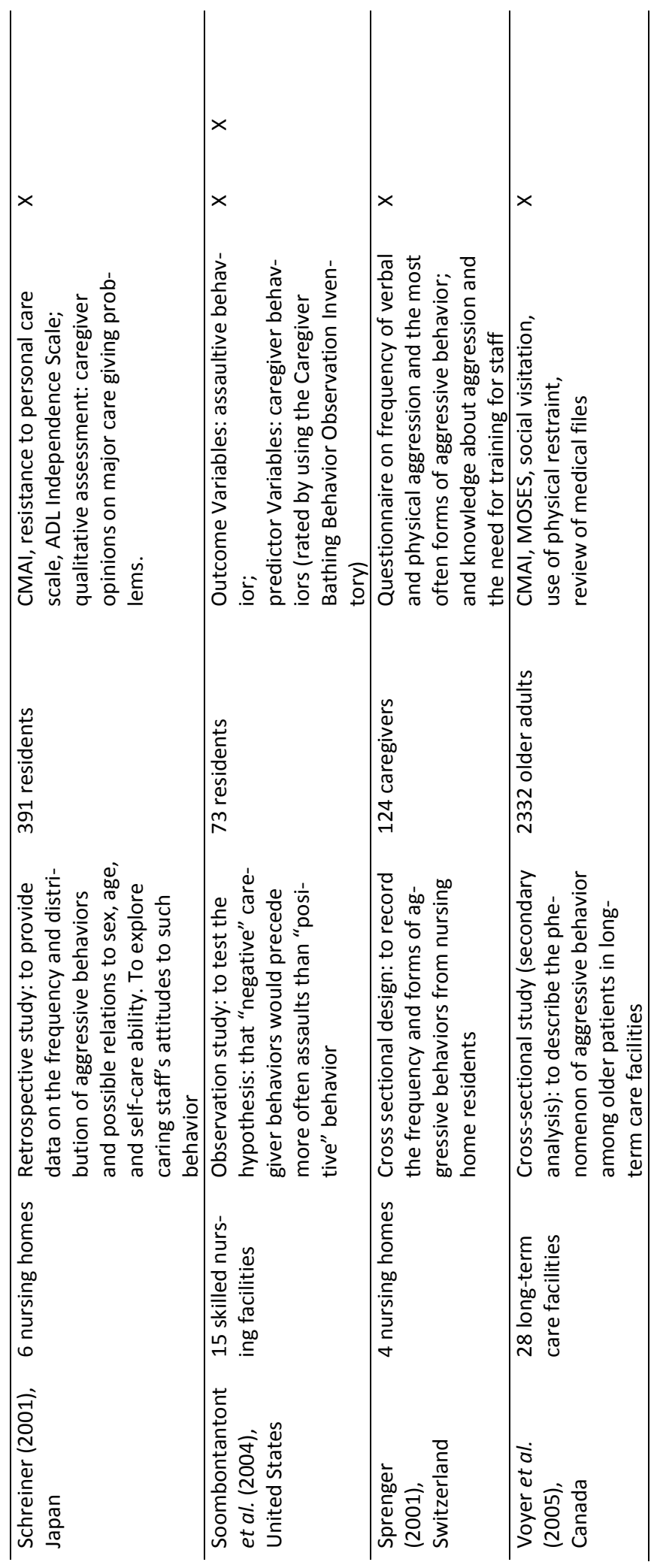




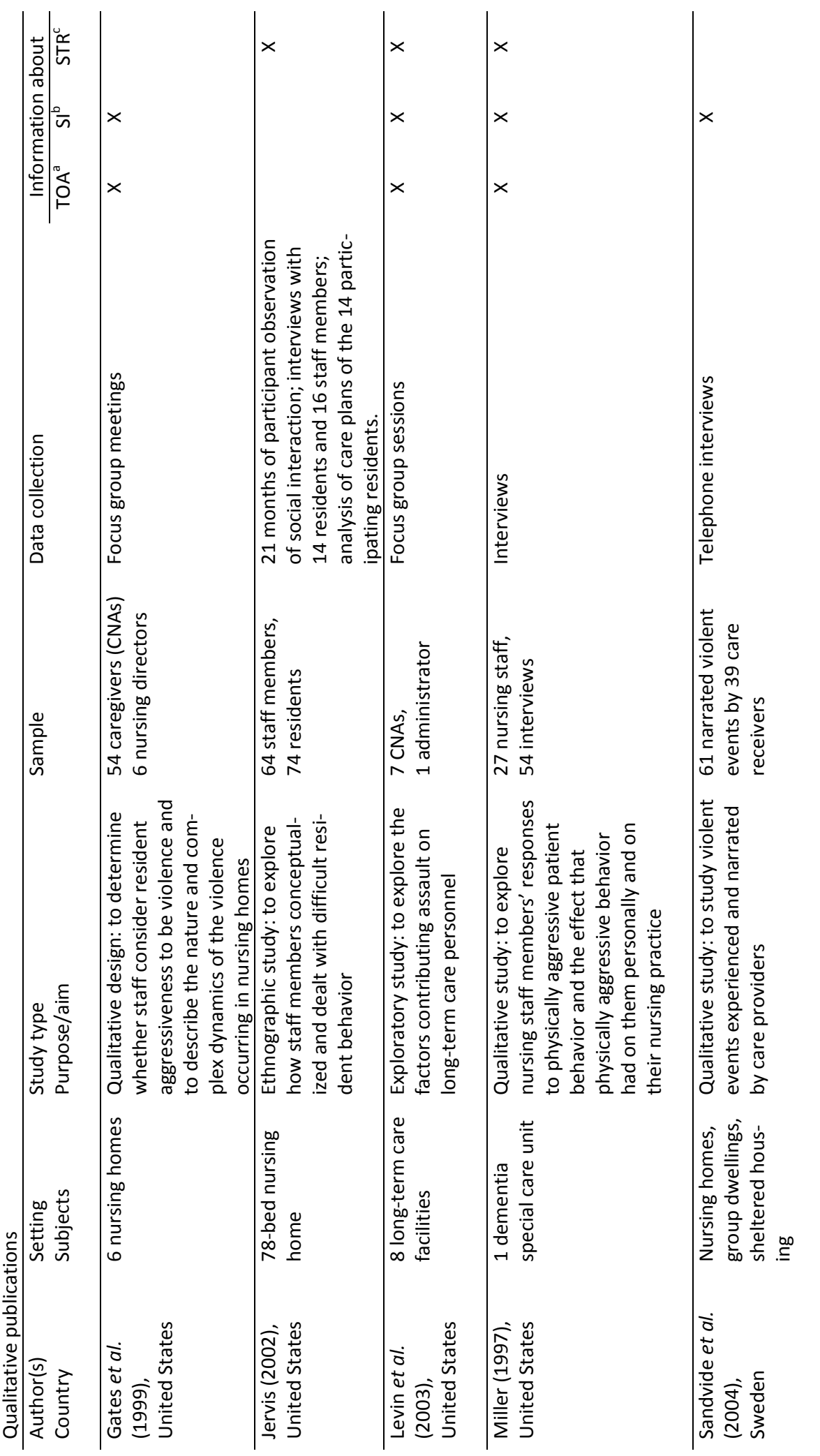




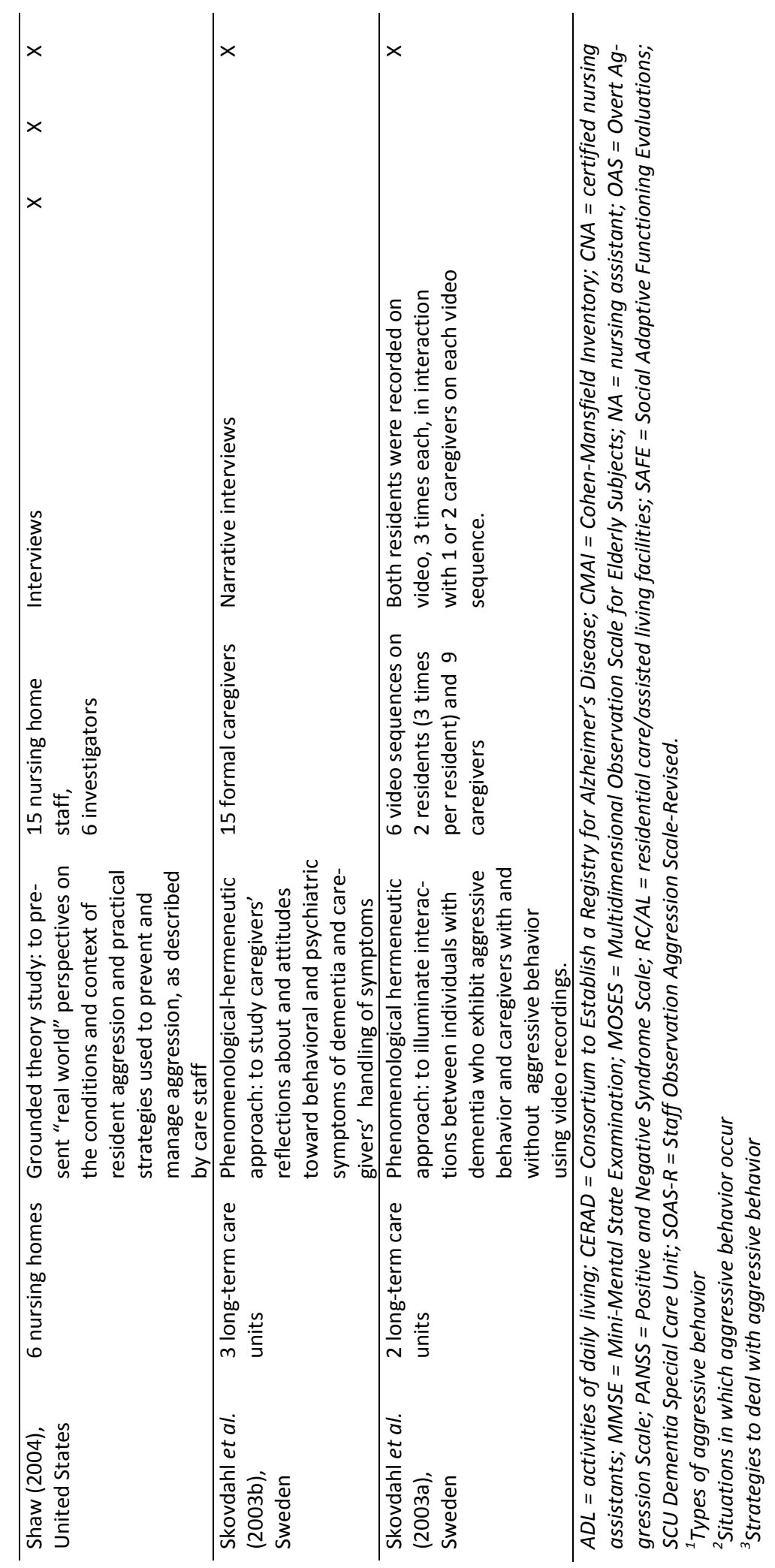




\section{Description of aggressive behavior}

The terms "aggression" or "aggressive behavior" were used in 12 of the 21 reviewed publications. The other publications used terms such as "disruptive" or "assaulting behavior", "violence" or "violent incidents", "behavioral symptoms", "problem behaviors", or "agitation". Twelve publications contain an explicit definition of terms such as aggressive behavior or assaulting behavior, and in five other studies, the term was not described but operationalized in the instrument. Four qualitative studies provided no definition of aggressive behavior because the definition was developed during the interviews by the study participants. The descriptions of aggressive behavior and all other terms used fall into two main categories: 1 ) verbal aggression, such as yelling, humiliation, or threatening, and 2) physical aggression, such as, kicking, punching, hitting, and scratching.

\section{Prevalence and types of aggressive behavior}

The prevalence of aggressive behavior was prospectively or retrospectively measured in 13 quantitative publications using various instruments. The articles report large variance in the prevalence rates of aggression ranging from 1.2 incidents per day or 1 - 4 incidents per year. These differences probably accrue from the use of different instruments and study designs. It is therefore impossible to name the exact prevalence rates of aggression (Table 2.4).

Different types of aggressive behavior are reported in 12 quantitative and 4 qualitative studies. The instruments used to investigate types of aggressive behavior in nursing homes also vary considerably. Two researchers used the Staff Observation Aggression Scale Revised (SOAS-R) and described the occurrence and prevalence of verbal aggression and physical attacks (Glaus Hartmann 2003, Almvik et al. 2006). Three further studies used the CohenMansfield Agitation Inventory (CMAI) and also described verbal and physical aggression (Schreiner 2001, Gruber-Baldini et al. 2004, Voyer et al. 2005). The other quantitative studies used various instruments with varying information on their development.

The types of verbal aggression encompass shouting angrily, mild insults, threats of violence (Bowie et al. 2001, Schreiner 2001, Glaus Hartmann 2003, Gruber-Baldini et al. 2004, Voyer et al. 2005, Almvik et al. 2006), verbal aggressiveness and agitation (Léger et al. 2002) as well as swearing, insulting, threatening, or verbal sexual harassment (Sprenger). The types of physical aggression were swings and misses, grabbing at clothes, causing bruises and welts (Bowie et al. 2001), striking, kicking, pulling hair, spitting, and throwing things (Sprenger 2001, Bowie et al. 2001, Glaus Hartmann 2003, Gates et al. 2003, Somboontanont et al. 2004, Almvik et al. 2006). Some studies describe only physical aggression, physical assaults, or physical agitation (Hantikainen et al. 1998, Morgan et al. 2005). 
The qualitative study results characterized verbal aggression, such as threats, cursing, racial slurs, screaming and yelling (Gates et al. 1999, Levin et al. 2003, Shaw 2004) and physical aggression, such as hitting with hand or objects, scratching, pulling hair, twisting wrists, and spitting (Miller 1997, Gates et al. 1999, Levin et al. 2003, Shaw 2004). In addition to verbal and physical aggression, 1 study described physical resistance to care, which included spitting out medication or refusing to eat or drink and physically threatening gestures such as a clenched fist directed toward the caregivers (Miller 1997).

Table 2.4: Prevalence and types of aggressive behavior

\begin{tabular}{|c|c|c|}
\hline Author(s) & Sample & Prevalence and types of aggressive behavior \\
\hline $\begin{array}{l}\text { Almvik et al. } \\
\text { (2006) }\end{array}$ & $\begin{array}{l}82 \text { patients } \\
210 \text { inci- } \\
\text { dents }\end{array}$ & $\begin{array}{l}\text { Prevalence: } 82 \text { patients generated } 210 \text { incidents in three months } \\
\text { Types: verbal aggression }(58 \%) \text {, chair }(13.7 \%) \text {, glassware }(6.1 \%) \text {, spit- } \\
\text { ting }(15.6 \%) \text {, hand }(55.2 \%) \text {, foot }(11.8 \%) \text {, teeth }(4.2 \%) \text {, knife }(0.5 \%)\end{array}$ \\
\hline $\begin{array}{l}\text { Aström et al. } \\
(2004)\end{array}$ & $\begin{array}{l}848 \text { nurs- } \\
\text { ing staff }\end{array}$ & $\begin{array}{l}\text { Prevalence: } 11.4 \% \text { of nurses had been exposed to aggressive behavior } \\
\text { during } 1 \text { year (range: } 1-4 \text { incidents) }\end{array}$ \\
\hline $\begin{array}{l}\text { Bowie et al. } \\
\text { (2001) }\end{array}$ & $\begin{array}{l}170 \text { pa- } \\
\text { tients/ } \\
\text { residents }\end{array}$ & $\begin{array}{l}\text { Prevalence/type: aggressive behavior in the previous } 7 \text { days included } \\
\text { Verbal aggression: angry shouting }(26.5 \%) \text {, mild insults }(13.3 \%) \text {, mod- } \\
\text { erate threats of violence }(10.6 \%) \text {, clear threats of violence }(3.5 \%) ; \\
\text { physical aggression: swings and misses/grabs at clothes }(6.2 \%) \text {, } \\
\text { strikes/pulls/kicks (3-6\%), causes bruises/welts (3.5\%) }\end{array}$ \\
\hline $\begin{array}{l}\text { Gates et al. } \\
(2003)\end{array}$ & $\begin{array}{l}138 \text { nurs- } \\
\text { ing assis- } \\
\text { tants }\end{array}$ & $\begin{array}{l}\text { Prevalence: assaults during } 80 \text { hours of work: } 94 \text { nursing assistants } \\
\text { reported } 624 \text { assaults; mean number of assaults for all nursing assis- } \\
\text { tants: 4.52; Types: hitting or punching ( } 51 \%) \text {, grabbing, pinching, or } \\
\text { pulling hair }(40 \%) \text {, kicking }(27 \%) \text {, scratching or biting }(23 \%) \text {, spitting } \\
(11 \%) \text {, throwing or hitting with object }(9 \%)\end{array}$ \\
\hline $\begin{array}{l}\text { Glaus Hart- } \\
\text { mann (2003) }\end{array}$ & $\begin{array}{l}431 \text { resi- } \\
\text { dents } \\
266 \text { inci- } \\
\text { dents }\end{array}$ & $\begin{array}{l}\text { Prevalence: } 431 \text { patients generated } 266 \text { incidents in } 8 \text { weeks; } 1.2 \\
\text { incidents per day or } 4 \text { to } 5 \text { times per week; Types: physical attacks } \\
\text { (hitting, pulling hair, scratching), } 3 \text { to } 4 \text { times per week: verbal attacks } \\
\text { (threats, insults) }\end{array}$ \\
\hline $\begin{array}{l}\text { Gruber-Baldini } \\
\text { (2004) }\end{array}$ & $\begin{array}{l}2078 \\
\text { residents }\end{array}$ & $\begin{array}{l}\text { Prevalence/types: study period was } 1 \text { year; any aggression (13\%); } \\
\text { cursing, verbal aggression ( } 12 \%) \text {; hitting, kicking, pushing, biting, } \\
\text { scratching, aggressive spitting (6\%); grabbing people, throwing things, } \\
\text { tearing things, or destroying property (5\%); other aggressive behavior } \\
\text { or self-abuse (3\%) }\end{array}$ \\
\hline $\begin{array}{l}\text { Hantikainen et } \\
\text { al. (1998) }\end{array}$ & $\begin{array}{l}173 \text { nurs- } \\
\text { ing staff }\end{array}$ & $\begin{array}{l}\text { Prevalence/types on } 1 \text { measurement point: physical aggression ( } 24 \% \text { : } \\
\text { daily, } 28.7 \% \text { : weekly, } 47.3 \% \text { : seldom), verbal aggression ( } 20.2 \% \text { : daily, } \\
28.6 \%: \text { weekly, } 51.2 \% \text { : seldom), sexual aggression ( } 3.7 \% \text { : daily, } 4.3 \% \text { : } \\
\text { weekly, } 92 \% \text { : seldom) }\end{array}$ \\
\hline $\begin{array}{l}\text { Léger et al. } \\
\text { (2002) }\end{array}$ & $\begin{array}{c}308 \text { resi- } \\
\text { dents }\end{array}$ & $\begin{array}{l}\text { Prevalence/types on } 1 \text { measurement point: verbal aggressiveness } \\
\text { (76\%), verbal agitation (68\%), physical agitation (60\%), strolling (52\%), } \\
\text { physical aggressiveness (48\%). }\end{array}$ \\
\hline $\begin{array}{l}\text { Morgan et al. } \\
\text { (2005) }\end{array}$ & $\begin{array}{l}355 \text { nurs- } \\
\text { ing aides }\end{array}$ & $\begin{array}{l}\text { Prevalence: } 73.4 \% \text { of nursing aides in had been physically assaulted in } \\
\text { the past } 12 \text { months }\end{array}$ \\
\hline
\end{tabular}




\begin{tabular}{|c|c|c|}
\hline $\begin{array}{l}\text { Schreiner et } \\
\text { al. (2001) }\end{array}$ & $\begin{array}{c}391 \text { resi- } \\
\text { dents }\end{array}$ & $\begin{array}{l}\text { Prevalence/typies: study period was } 2 \text { weeks; any aggressive behavior } \\
(42.2 \%-58.2 \%) \text {, physically aggressive behavior ( } 24.4 \%-32.9 \%) \text {, verbally } \\
\left.\text { aggressive behavior ( } 37.0-48.1 \%{ }^{-}\right)\end{array}$ \\
\hline $\begin{array}{l}\text { Soombontan- } \\
\text { tont et al. } \\
(2004)\end{array}$ & $\begin{array}{l}73 \text { resi- } \\
\text { dents }\end{array}$ & $\begin{array}{l}\text { Prevalence/types: } 27 \text { video tapes of } 18 \text { residents contained physical } \\
\text { assaults against care givers; } 105 \text { episodes of resident assaults during } \\
\text { showering or bathing were identified (hitting, hitting attempt, kicking, } \\
\text { kicking attempt, biting, biting attempt, throwing things, spitting) }\end{array}$ \\
\hline $\begin{array}{l}\text { Sprenger } \\
\text { (2001) }\end{array}$ & $\begin{array}{l}124 \text { care } \\
\text { givers }\end{array}$ & $\begin{array}{l}\text { Prevalence/types on } 1 \text { measurement point: frequency of verbal ag- } \\
\text { gression: } 69 \% \text { consistently and } 31 \% \text { very rarely; frequency of physical } \\
\text { aggression: } 50 \% \text { consistently, } 38 \% \text { very rarely and } 11 \% \text { never }\end{array}$ \\
\hline $\begin{array}{l}\text { Voyer et al. } \\
\text { (2005) }\end{array}$ & $\begin{array}{l}2332 \text { older } \\
\text { adults }\end{array}$ & $\begin{array}{l}\text { Prevalence/types: cross-sectional study (secondary analysis) } \\
21.2 \% \text { physical aggressive behavior (hitting, pushing, kicking), } 21.5 \% \\
\text { verbal aggressive behavior (insults are the most common), } 11.2 \% \\
\text { displayed both behaviors }\end{array}$ \\
\hline
\end{tabular}

\section{Situations in which aggressive behavior occur}

The publications reviewed describe the situations in which aggressive behavior occurs at various levels. Some researchers focused on the interaction between caregiver and residents during direct care. Entering a person's personal space which is impossible to avoid during personal care, seems to be the most important factor for triggering aggressive behavior. Bath and shower situations, oral hygiene, dressing, toileting, feeding or helping the resident transfer from chair to bed or vice versa were identified as the precipitating events in most of the cases (Miller 1997, Gates et al. 1999, Glaus Hartmann 2003, Gates et al. 2003, Aström et al. 2004, Sandvide et al. 2004, Shaw 2004, Almvik et al. 2006).

An additional factor that favors the occurrence of aggressive behavior is psychosocial stress of the resident, including death of a spouse, a family member moving away, the residents being asked to do something they do not wish to do, and the denial of residents' wishes (Léger et al. 2002, Glaus Hartmann 2003).

Another approach for identifying causes promoting aggressive behavior are organizational or policy aspects that affect the staff's attitudes and the interaction between caregiver and resident. Personal factors, such as lack of respect for residents or disregarding residents' preferences; workplace factors, such as being short staffed or rushed; lack of communication about specific resident needs between shifts; and lack of work ethic and responsibility (e.g. caregivers attending to residents only after they have actively demanded attention) are factors contributing to assaults on long-term care personnel (Levin et al. 2003).

Care providers seem to accept violence as a natural consequence of their work because the events are seen as an unavoidable and constituent part of their job and impossible to solve (Sandvide et al. 2004). The demanding nursing home environment provides the context for aggression toward staff, with residents, their families, and administration placing multiple and simultaneous demands on care staff, creating an atmosphere in which residents' care is often rushed and limited to the task at hand. Some aggression toward staff 
was the result of personalities and prejudices. According to staff members, not explaining care before providing it, looking at residents the wrong way, or denying attention to the residents sometimes provoked aggression. When residents interpreted care as dangerous or threatening, they became fearful and overwhelmed, and sometimes resisted care to protect themselves (Shaw 2004, Somboontanont et al. 2004).

\section{Caregivers' strategies for dealing with aggressive behavior}

In summarizing the results on caregivers' strategies for dealing with aggressive behavior from the 4 quantitative and 6 qualitative studies reviewed, 5 categories can be identified: 1 ) strategies aiming to prevent or detect aggressive behavior in an early stage, 2) calming and deescalating strategies when signs of aggressive behavior appear, 3) repressive or sanctioning interventions, 4) medical treatment, and 5) policy based strategies.

Strategies aiming to prevent or detect aggressive behavior in an early stage included, for example, checking residents' mood at the door, waiting until the patient invites you to act, watching for warning signs, preserving patients' dignity, practicing vigilance, and intuiting (Miller 1997, Levin et al. 2003, Shaw 2004). Furthermore, supporting the residents' exercising of their rights and competence to make decisions was reported to prevent aggressive behavior (Skovdahl et al. 2003b).

Calming and deescalating strategies when first signs of aggressive behavior appear included interventions such as talking to patients, considering their wants and needs, being friendly, being nice and joking with them, and working calmly and systematically (Hantikainen et al. 1998, Jervis 2002, Glaus Hartmann 2003, Skovdahl et al. 2003a, Almvik et al. 2006).

The strategies falling into the category repressive or sanctioning interventions are seclusion and isolation, holding with force, ignoring care recipients' needs for help, giving reprimands, and ignoring protests to perform the care (Hantikainen et al. 1998, Glaus Hartmann 2003, Skovdahl et al. 2003a, Aström et al. 2004, Almvik et al. 2006).

Administering medication as a further way to reduce aggressive behavior is mentioned in 4 publications (Hantikainen et al. 1998, Jervis 2002, Glaus Hartmann 2003, Almvik et al. 2006).

Policy-based strategies such as staff job descriptions and resident care plans with descriptions of generic procedures to deal with aggressive occurrences, such as behavior monitoring, validation therapy, or behavioral contracts, were reported in only 1 publication (Jervis 2002). 


\subsection{Discussion}

This literature review reveals that caregivers in nursing homes were confronted with a broad spectrum of aggressive behaviors ranging from verbal aggression (e.g. threats and insults) to physical aggression (e.g. kicking, biting, or causes bruises). The use of differing terms for the same behavior (e. g. disruptive or assaulting behavior or challenging behavior) as measured by the quantitative instruments renders comparisons difficult (Halek \& Bartholomeyczik 2006). It is also difficult to compare the prevalence rates due to the different measurement methods, although the figures underline the importance of the topic for caregivers and their superiors. Nevertheless, it is obvious how arduous and, in some cases, even dangerous working in a nursing home can be.

The examination of the literature also reveals diverse situations in which nursing home residents' aggressive behavior towards caregivers occurs. The most frequently cited situations involve personal care activities such as washing, bathing, dressing or feeding. These findings suggest that the invasion of residents' personal space or the violation of personal territory may account for their aggressive behavior (Kihlgren et al. 1994). Given that the invasion of personal space is an integral part of a daily routine, particularly in personal care for the elderly (Rapp \& Gutzmann 2000), such caregiving activities should be critically reviewed relating to the performance and interaction between caregiver and recipient. Only a few studies investigated the role of interaction during caregivers' care activities with regard to the occurrence of residents' aggressive behavior.

Factors giving rise to psychosocial stress of the residents, such as death of a spouse or the denial of residents' wishes, also encourage the occurrence of aggressive behavior. Excessive demand of the concerned resident was seen as the cause for aggression in this case (Léger et al. 2002).

Organizational and policy aspects which may influence caregivers' attitudes towards the residents are further points taken into consideration regarding aggressive behavior.

Disregarding residents' preferences, lack of respect, or loss of the right to make decisions seem to be additional aspects that provoke aggressive behavior. This proposition is corroborated by other authors who maintain that the interpersonal style adopted by a caregiver may trigger agggressive incidents (Kitwood 1997, Keene et al. 1999). Additionally, the demanding nursing home environment provide a context for aggression toward staff due to short staffing, rushed task fulfillment, or caregivers' attitude that aggression is a part of one's working in a nursing home (Sandvide et al. 2004).

The third question in this review referred to strategies which caregivers use to deal with aggressive behavior. The study results demonstrate that many strategies for handling aggression aim to create and establish positive interaction between caregiver and resident, 
such as talking to residents, being friendly and empathizing with them, and keeping residents calm. However, other strategies, such as forceful holding, seclusion, fixation, and ignoring protests or recipients' requests for help (Aström et al. 2004), seem to be perceived more negatively by residents. All in all, there is a lack of evidence regarding the effectiveness of various approaches and strategies to handle aggressive behavior, and it is currently impossible to give clear recommendations as to which approaches should be adopted as best practice (Halek \& Bartholomeyczik 2006, Pulsford \& Duxbury 2006).

\section{Limitations of the study}

The heterogeneity of the studies and the differing definitions of aggressive behavior render comparisons difficult, and therefore the comparative analysis must be treated with caution. Each study reveals only a limited part of the complex picture, and questions related to situations and strategies are open to a broad spectrum of diverse interpretations. Finally, despite an extensive research strategy, publication bias cannot be excluded.

\subsection{Conclusions and recommendations for further research}

The results of this literature review demonstrate the difficulty to establish exact prevalence rates of residents' aggressive behavior toward caregivers and the complex interplay between several factors contributing to such behavior. Although reasons for the occurrence of aggressive behavior are numerous, it would seem that such behavior depends on the complex interplay between resident and the environment, including interpersonal style of interaction and organizational factors. In addition to the lack of evidence on the effectiveness of various approaches and strategies to handle aggressive behaviour, there is also a lack of data on the preferred measures that caregivers use in practice to deal with aggressive behavior. To support caregivers in their challenging tasks and to develop preventive strategies, more studies should investigate organizational, personnel related, and other interacting factors that contribute to aggressive behavior. 


\subsection{References}

Almvik R, Rasmussen K \& Woods P (2006) Challenging behaviour in the elderly - monitoring violent incidents. International Journal of Geriatric Psychiatry 21, 368-374.

Aström S, Bucht G, Eisemann M, Norberg A \& Saveman B (2002) Incidence of violence towards staff caring for the elderly. Scandinavian Journal of Caring Sciences 16, 66-72.

Aström S, Karlsson S, Sandvide A, Bucht G, Eisemann M, Norberg A \& Saveman B (2004) Staff's experience of and the management of violent incidents in elderly care. Scandinavian Journal of Caring Sciences 18, 410-416.

Bowie CR, Moriarty PJ, Harvey PD, Parrella M, White L \& Davis KL (2001) Aggression in elderly schizophrenia patients: a comparison of nursing home and state hospital residents. The Journal of Neuropsychiatry and Clinical Neurosciences 13, 357-366.

Brodaty H, Draper B, Saab D, Low L, Richards V, Paton H \& Lie D (2001) Psychosis, depression and behavioural disturbances in Sydney nursing home residents: prevalence and predictors. International Journal of Geriatric Psychiatry 16, 504-512.

Chou KR, Kaas MJ \& Richie MF (1996) Assaultive behaviour in geriatric patients. Journal of Gerontological Nursing 22, 30-38.

Cohen-Mansfield J (1996) Behavioral and mood evaluations: assesssment of agitation. International Psychogeriatrics 8, 233-245.

Evers W, Tomic W \& Brouwers A (2002) Aggressive behaviour and burnout among staff of homes for the elderly. International Journal of Mental Health Nursing 11, 2-9.

Gates D, Fitzwater E \& Succop P (2003) Relationships of stressors, strain, and anger to caregiver assaults. Issues in Mental Health Nursing 24, 775-793.

Gates DM, Fitzwater E \& Meyer U (1999) Violence against caregivers in nursing homes: expected, tolerated, and accepted. Journal of Gerontological Nursing 25, 12-22.

Gerberich SG, Church TR, McGovern PM, Hansen HE, Nachreiner NM, Geisser MS, Ryan AD, Mongin. S. J. \& Watt GD (2006) An epidemiological study of the magnitude and consequences of work related violence: the Minnesota Nurses' Study. Occupational and Environmental Medicine 61, 495-503.

Glaus Hartmann M (2003) Aggressionsereignisse von PflegeheimbewohnerInnen [Aggressive incidents by nursing home residents]. Masterthesis. Universität Maastricht / Weiterbildungszentrum für Gesundheitsberufe Aarau. 
Gruber-Baldini AL, Boustani M, Sloane PD \& Zimmerman S (2004) Behavioral symptoms in residential care/assisted living facilities: prevalence, risk factors, and medication management. Journal of the American Geriatrics Society 52.

Gwet K (2002) Inter-Rater Reliability: dependency on trait prevalence and marginal homogenity. Available at: "http://www.stataxis.com/files/articles/inter_rater_reliability_dependency.pdf"

Hagen BF \& Sayers D (1995) When caring leaves bruises: the effects of staff education on resident aggression. Journal of Gerontological Nursing 21, 7-16.

Halek M \& Bartholomeyczik S (2006) Verstehen und Handeln - Forschungsergebnisse zur Pflege von Menschen mit Demenz und herausforderndem Verhalten. Schlütersche Verlagsgesellschaft, Hannover.

Hantikainen V, Isola A \& Helenius H (1998) Störendes Verhalten älterer HeimbewohnerInnen und die Anwendung von Pflegemethoden [Disruptive behavior of elderly residents and the use of nursing methods]. Pflege 11, 78-88.

Jervis LL (2002) Contending with "problem behaviors" in the nursing home. Archives of Psychiatric Nursing 16, 32-38.

Keene J, Hope T, Fairburn CG, Jacoby R, Gedling K \& Ware CJ (1999) Natural history of aggressive behaviour in dementia. International Journal of Geriatric Psychiatry 14, 541548.

Kihlgren M, Hallgren A, Norberg A \& Karlsson I (1994) Integrity promoting care of demented patients. Patterns of interaction during morning care. International Journal of Aging and Human Development 39, 303-319.

Kitwood T (1997) Dementia reconsidered. The person comes first. Open University Press, Buckingham.

Léger JM, Moulias R, Robert P, Vellas B, Chapuy PH, Monfort JC, Khoshnood B, Bouee S, Rebah N \& Gerard D (2002) Agitation and aggressiveness among the elderly population living in nursing or retirement homes in France. International Psychogeriatrics 14, 405416.

Levin PF, Hewitt JB, Misner ST \& Reynolds S (2003) Assault of long-term care personnel. Journal of Gerontological Nursing 29, 28-35.

Miller MF (1997) Physical aggressive resident behavior during hygienic care. Journal of Gerontological Nursing 23, 24-39. 
Morgan DG, Stewart NJ, D'Arcy C, Forbes D \& Lawson J (2005) Work stress and physical assault of nursing aides in rural nursing homes with and without dementia special care units. Journal of Psychiatric and Mental Health Nursing 12, 347-358.

Patel V \& Hope RA (1992) A rating scale for aggressive behaviour in the elderly - the RAGE. Psychological Medicine 22, 211-221.

Polit DF \& Tatano Beck C (2003) Nursing research: principles and methods, 7th edn. Lippincott Williams \& Wilkins, Philadelphia.

Pulsford D \& Duxbury J (2006) Aggressive behaviour by people with dementia in residential care settings: a review. Journal of Psychiatric and Mental Health Nursing 13, 611-618.

Rapp MA \& Gutzmann H (2000) Invations of personal space in demented and nondemented elderly persons. International Psychogeriatrics 12, 345-352.

Sandvide A, Aström S, Norberg A \& Saveman BI (2004) Violence in institutional care for elderly people from the perspective of involved care providers. Scandinavian Journal of Caring Sciences 18, 351-357.

Schreiner AS (2001) Aggressive behaviors among demented nursing home residents in Japan. International Journal of Geriatric Psychiatry 16, 209-215.

Shah A (1999) Aggressive behaviour in the elderly. International Journal of Psychiatry in Clinical Practice, 85-103.

Shah A, Chiu E, Ames E, Harrigan S \& McKenzie D (2000) Characteristics of aggressive subjects in Australian (Melbourne) nursing homes. International Psychogeriatrics 12, 145161.

Shaw MMC (2004) Aggression toward staff by nursing home residents: findings from a grounded theory study. Journal of Gerontological Nursing 30, 43-54.

Skovdahl K, Kihlgren AL \& Kihlgren M (2003a) Dementia and aggressiveness: video recorded morning care from different care units. Journal of Clinical Nursing 12, 888-898.

Skovdahl K, Kihlgren AL \& Kihlgren M (2003b) Different attitudes when handling aggressive behaviour in dementia - narratives from two caregiver groups. Aging \& Mental Health 7, 277-286.

Somboontanont W, Sloane PD, Floyd FJ, Holditch-Davis D, Hogue CC \& Mitchell CM (2004) Assaultive behavior in alzheimer's disease: identifying immediate antecedents during bathing. Journal of Gerontological Nursing 30, 22-29. 
Sprenger R (2001) Aggressives Verhalten von Patienten gegenüber Pflegenden, Fortbildungsbedarf im Zusammenhang mit Aggression [Aggressive behaviour from patients towards care givers, demand for advanced training in connection with aggression]. Masterthesis. Universität Maastricht/Weiterbildungszentrum für Gesundheitsberufe Aarau.

Talerico K, Evans L \& Strumpf N (2002) Mental health correlates of aggression in nursing home residents with dementia. The Gerontologist 42, 169-177.

Voyer P, Verreault R, Azizah G, Desrosiers J, Champoux N \& Bedard A (2005) Prevalence of physical and verbal aggressive behaviours and associated factors among older adults in long-term care facilities. BMC Geriatrics 5, 13.

Wancata J, Benda N, Meise U \& Windhaber J (2003) Non-cognitive symptoms of dementia in nursing homes: frequency, course and consequences. Social Psychiatry and Psychiatric Epidemiology 38, 637-643. 


\section{Chapter 3}

\section{Nursing home caregivers' explanations for and coping}

strategies with resident' aggression: a qualitative study

Zeller A, Dassen T, Kok G, Needham I \& Halfens RJG (2011) Nursing home caregivers' explanations for and coping strategies with residents' aggression: a qualitative study. Journal of Clinical Nursing 20, 2469-2478. 


\subsection{Abstract}

\section{Aims and objectives}

This study explored caregivers' perspectives regarding the conditions and situations of resident aggression and practical strategies caregivers use to deal with aggression.

\section{Background}

Working in a nursing home is associated with a high risk to experience aggression from residents or patients. Despite existing recommendations for dealing with aggression there is a lack of information about caregivers' ways of dealing with it in practice.

\section{Design}

A qualitative study with focus group method was conducted.

\section{Method}

Five focus group interviews, with a total of 30 participants, from nursing homes in Switzerland were undertaken employing a semi-structured interview guideline. For analysing the data, qualitative content analysis was employed.

\section{Results}

Analysis of the data produced three themes with additional sub-themes. One main theme concerns the explanations of the caregivers in regard to the occurrence of aggressive behaviour. This theme is subdivided into two areas, the contributory resident related factors and the caregiver related factors. The measures for handling aggressive behaviour are illustrated in the second theme 'dealing with residents'. The third theme refers to the strategies of the caregivers when confronted with aggressive behaviour - 'self-protection' and 'coping with the situation'.

\section{Conclusion}

Caregivers use a broad spectrum of interventions for reducing aggression, some of which are recommended by guidelines but often ignore the link between aggressive behaviour and physiological issues like pain or elimination. The caregivers only very rarely linked their practical knowledge about aggressive behaviour with theoretical knowledge.

\section{Relevance to clinical practice}

The results give insight into the caregivers' perspectives on factors leading to aggression and their coping strategies. Caregivers are informed about relevant reasons for aggressive behaviour and its management, but do not apply a systematic approach. Furthermore, the anxiety of caregivers involved in aggression incidents is an under examined area. 


\subsection{Introduction}

Working in a nursing home or long term care facility is associated with a high risk to experience aggression from persons for which caregivers provide care (Gerberich et al. 2006, Franz et al. 2010). Although data on the prevalence of aggressive behaviour often varies considerably - due to different measurement methods and populations - it underlines the importance of the topic for caregivers and their superiors. In several studies various types of aggression and their prevalence have been identified. Caregivers are confronted with a broad spectrum of types of aggressive behaviour ranging from verbal aggression like threats and insults to physical aggression like kicking, biting, throwing objects or scratching (Zeller et al. 2009).

\section{Background}

Beside the term 'aggressive behaviour' the label 'challenging behaviour' is used in long term care facilities. Challenging behaviour is defined as 'culturally abnormal behaviour of such intensity, frequency or duration that the physical safety of the person or others is placed in serious jeopardy, or behaviour which is likely to seriously limit or deny access to the use of ordinary community facilities' (Emerson 2001). Within this term, further distinctions are made between behavioural excesses, such as disruptive vocalisation, or aggression and behavioural deficits, such as lack of social interaction or lack of self-care (Allen-Burge et al. 1999, Douglas et al. 2004).

The focus of the present study is solely on 'aggressive behaviour' which is defined as an overt act, involving the delivery of noxious stimuli to (but not necessarily aimed at) another organism, object or self, which is clearly not accidental (Patel \& Hope 1992, p. 212). Aggressive behaviour may be verbal or physical harm or threats to other persons. Physical aggression includes e.g. hitting, kicking, scratching, pushing, biting, punching, grabbing, throwing objects, pinching, cutting and stabbing. Verbal aggression is typically considered as insulting, obscene or profane language or sexual advances (Chou et al. 1996).

Studies show that cognitive impairment and especially dementia, is strongly associated with the occurrence of aggressive behaviour (Chou et al. 1996, Shah 1999, Talerico et al. 2002, Voyer et al. 2005, Pulsford \& Duxbury 2006). Beside the cognitive impairment as a reinforcing factor for aggressive behaviour, several additional factors like environmental and organisational factors as well as caregiver characteristics are discussed in the literature (Hall \& O'Connor 2004, Morgan et al. 2005, Isaksson et al. 2008, Zeller et al. 2009).

A broad view on explanations for aggressive behaviour in geriatric care is given in the Need-Driven-Dementia-Compromised Behaviour Model (NDB). In this model dementiacompromised behaviours reflect the interaction of relatively stable individual characteristics (background factors) and more changeable environmental triggers (proximal factors) that 
precipitate behaviour. Background factors place residents at risk for behavioural symptoms of dementia and include dementia-compromised functions, health status, demographic variables and premorbid characteristics. Proximal factors precipitating dementia behaviours include physiological need states, psychosocial need states, physical and social environments.

The NBD Model presents a perspective that conceptualises dementia behaviours as potentially understandable needs and requires caregivers to look beyond the aggressive behaviour (Kolanowski 1999). For fostering the awareness for these factors among caregivers, several guidelines and recommendations have been developed to support the caregivers in their work with residents showing aggressive behaviour [International Labour Office (ILO) et al. 2002, Bundesministerium für Gesundheit 2006, International Council of Nurses (ICN) 2007].

The existing guidelines state that non-pharmacological interventions should have precedence over medication in cases of aggressive behaviour. They recommend interventions like systematic assessment of the aggressive behaviour, validation therapy, reminiscence therapy, activity therapy or other multisensory approaches. Prerequisites for the implementation of such guidelines are organisational requirements, caregivers' communicative competencies, knowledge about the disease process and related factors concerning aggressive behaviour and assessment skills.

Previous studies have investigated and demonstrated stress and burden on caregivers are associated with managing residents' aggression (Rodney 2000, Gates et al. 2003, Morgan et al. 2005). Acceptance of aggressive behaviour seems to be a 'natural' consequence for caregivers because the events are seen as unavoidable, irresolvable and as an inevitable constituent of daily work (Gates et al. 1999, Sandvide et al. 2004).

However, there is even less information available how caregivers deal with aggressive behaviour and if they take the various factors around the complex phenomena of aggressive behaviour into account in their practice. This was confirmed by a search in current databases such as PubMed and Cumulative Index of Nursing and Allied Health Literature (CINAHL) where no publication was found with the specific focus on caregivers' assumptions related to aggressive behaviour. However, in spite of the vast body of knowledge regarding residents' aggression it remains unclear to what extent caregivers utilise such know how in the course of their daily practice.

Therefore, the main focus in this qualitative investigation is to explore the caregivers' perspective regarding the conditions and situations of resident aggression on the one hand and practical strategies caregivers use to deal with aggression on the other hand. Against this background the following research questions were formulated: 
1 How do caregivers explain the occurrence of aggressive behaviour of residents?

2 In which situations does aggressive behaviour of nursing home residents occur according to the caregivers?

3 What strategies do caregivers involved in direct care use to deal with aggressive behaviour of nursing home residents?

\subsection{Method}

\section{Design}

The focus group method was chosen for this qualitative study for a variety of reasons. The focus group method is a useful data collection method when the aim is to clarify, explore or confirm ideas with a wide range of participants on a predefined set of issues. Focus groups endeavour to obtain the views and experiences of a selected group by using the discussion format to incite associative thinking processes amongst the participants and therefore to uncover the maximal amount of variance on a topic which may lead to an increased understanding of the subject matter. Focus groups, therefore, have the potential to provide a rich source of data (Gerrish \& Lacey 2006). As smaller groups make it easier to provide an environment where all participants can actively participate in the discussion no more than eight caregivers took part in each group (Smithson 2008).

\section{Sample selection}

Due to the aim of this investigation, it was necessary to recruit caregivers who are involved in direct care of nursing home residents. Head nurses from four nursing homes were asked for permission to recruit caregivers for participation. One focus group consisted of nursing students in their last year of training with main focus on long term care. The school directorate granted permission to recruit their students as participants for the study.

All four nursing homes were willing to take part in the study and motivated their caregivers to participate in the planned focus group interviews. Both, the head of the nursing school and the heads of the four nursing homes informed their students or their caregivers about the planned study. Interested caregivers were invited to participate whereby the superiors did not influence entry to the focus groups. Caregivers who were willing to participate in the study reported their interest to the researcher directly.

Consequently, it was possible to conduct a focus group interview in four nursing homes and one interview with a group of nursing students. All focus groups consisted of five to eight participants from different wards. In total 30 caregivers participated. 


\section{Participants}

All study participants were involved in direct care of the nursing home residents. Regarding educational levels, 18 persons were registered nurses, 5 nursing assistants and 7 nursing students. The mean age of the 30 persons was 35.5 (SD 13.7, range: 19-64 years). Only two persons were male. The professional experience of the participants has an average of 11.5 years with a range from 1-40 years. The participants' professional experience in the care of older people was on average 6.2 years (SD 6.2, range: 1-24 years). All students participating in this study have at a minimum one year professional experience because of their internships during their education.

\section{Ethical considerations}

Since the focus group format involves multiple participants the researcher cannot guarantee confidentiality to the individual participants. Therefore a list of 'dos and don'ts' were discussed at the onset of each focus group. The main points included asking the participants to respect each other's confidence and not repeat the content of the focus group elsewhere. Participation was voluntary and the participants were informed in writing and orally at the beginning of the focus group session. It was guaranteed that the data would be processed such as to avoid inferences on individual participants. Prior to the study the local ethical committee was consulted and informed about the study. The ethical committee gave permission for the study to be conducted.

\section{Data collection}

Data was collected by the first author in five focus group interviews lasting between 60 and 90 minutes. The interviews were conducted in the respective nursing homes where the participants work. Following the instruction on the handling of information in the group all participants received the guiding questions in written form at the start of the interview session. The opening question invited the participants to report an example of their experience with aggressive behaviour of nursing home residents. During the course of the interviews we employed the following semi structured interview guide to ensure the coverage of all topics:

1 Could you tell me something about your experience with aggressive behaviour of the residents? (opening question)

2 In which situations do the residents become aggressive?

3 In your opinion why do residents become aggressive?

4 How do you react to residents' aggressive behaviour? How do you handle it?

5 In your opinion which nursing interventions or strategies are meaningful in dealing with aggressive behaviour? 


\section{Data analysis}

After verbatim transcription of the interviews, the data were analysed by the first author employing qualitative content analysis (Mayring 2003). In the analysis significant statements were identified in order to generate meaningful units and to develop a descriptive 'essence'. The analysis was conducted using the following steps (Mayring 2003):

Step 1: Determination of the units of analysis (words, phrases or sections).

Step 2: Determination of an appropriate level of abstraction and generalisation of the paraphrases into comprehensible propositions.

Step 3: Paraphrasing the analytic units concisely using techniques of generalisation, construction, integration, selection, omission and bundling.

Step 4: Grouping paraphrases with identical content to provide a synoptic view of the material.

Step 5: Wording comprehensive propositions.

Step 6: Compilation of the statements in a suitable new system of categories.

Steps 1 to 4 were conducted on the data of each interview and steps 5 and 6 included analysis of all interviews concurrently at a synoptic level. For analysis steps 1 through 3 the MAX.QDA software, Version 2, was used. Remaining steps of analysis were conducted manually.

Three strategies were employed during the process of analysis to establish the credibility or trustworthiness of the findings (Lincoln \& Guba 1985):

- Member checks were conducted to determine the accuracy of the qualitative findings by presenting the findings to three participants who were invited to give their opinion on the accuracy of the findings.

- Peer debriefing was employed to enhance the accuracy of the account. Three participants were involved as peer debriefers and were confronted with the results of the analysis and prompted to give critical feedback. The reviewers attested that the analysis was representative of their experiences.

- Finally, two external auditors supervised and reviewed the data analysis throughout the entire project. 


\subsection{Results}

Content analysis of the data produced three main themes with variations in the sub-themes (Table 3.1). One main theme concerns the explanations of the caregivers in regard to the occurrence of aggressive behaviour. This main theme is subdivided into two areas, which on the one hand reveal the contributory factors from the point of view of the residents and on the other hand the factors that are perceived by the caregivers. The measures for subduing aggressive behaviour are illustrated in the second main theme 'dealing with residents'. The third main theme - 'self protection and coping with the situation' - refers to caregivers' strategies when confronted with aggressive behaviour. The main themes and the subthemes are explained below and substantiated with quotations from the interviews.

\section{Constructing explanations for aggressive behaviour}

Regarding the question of possible causes for aggressive behaviour of residents in nursing homes, the caregivers reported several factors that in their opinion could be responsible. The following two areas emerged with regard to caregivers' explanations: (a) factors relating to the residents and (b) factors relating to the caregivers.

Table 3.1: Main themes and sub-themes of the qualitative content analysis

\begin{tabular}{|c|c|c|}
\hline \multicolumn{2}{|c|}{ Main themes } & \multirow[t]{2}{*}{ Sub-themes } \\
\hline (1) & $\begin{array}{l}\text { Constructing explanations for aggressive } \\
\text { behaviour }\end{array}$ & \\
\hline (a) & Resident related factors & $\begin{array}{l}\text { - } \quad \text { residents realising their loss of faculties } \\
\text { - } \text { residents failing to understand and being } \\
\text { - } \quad \text { residents suffering from intrusion of their } \\
\text { - } \quad \text { residents' manner of expressing themselves }\end{array}$ \\
\hline (b) & Caregiver related factors & $\begin{array}{l}\text { - } \quad \text { working under pressure } \\
\text { - lacking thoughtfulness } \\
\text { - fearing residents }\end{array}$ \\
\hline$(2)$ & Dealing with residents & $\begin{array}{l}\text { - } \text { getting to know residents' habits and needs } \\
\text { - } \quad \text { continuing the quest for new solutions } \\
\text { - } \quad \text { confronting their behaviour } \\
\text { - } \quad \text { practising coercion }\end{array}$ \\
\hline (3) & Self-protection and coping with the situation & $\begin{array}{l}\text { - to be attentive } \\
\text { - to be calm in the situation } \\
\text { - to reconstitute themselves after the } \\
\text { experience }\end{array}$ \\
\hline
\end{tabular}




\section{Factors relating to the residents}

Caregivers observed aggressive behaviour primarily in residents suffering from dementia with associated destructive failures of cognitive impairment such as memory, thinking and comprehension, also in terms of changes in patterns of relationships and interactions. In situations when residents are supported by the caregivers to carry out their needs, or where the caregivers even completely take over their activities, residents often realise the loss of their abilities. In such moments residents recognise they need help with activities they previously accomplished without problem. They are able to act with self-determination in increasingly fewer areas and realise the 'loss of their faculties'. One caregiver described this phenomenon in the following manner:

I noticed that the resident could previously carry out these activities by himself without any problem. Once it struck him that something was wrong with him. Then the dependency in this situation can trigger aggression.

Mutual misunderstanding is a difficult and challenging aspect for caregivers when attending residents. In general, the diminishing cognitive faculties of the residents are the reason they no longer understand everyday care activities, such as personal hygiene or residents' 'failure to understand and become overwhelmed'.

All of the caregivers interviewed describe invasion into personal space - which is unavoidable, given the necessity to administer personal care to the residents - as a particularly difficult moment in the caring process. When residents 'suffer from intrusions into their personal space' aggressive behaviour occurs frequently:

She started to struggle when the nightdress had to come off, when it comes to the undershirt there is a moment of nakedness that can hardly be avoided. It is also difficult during washing of her intimate area. If you only want to change the diaper, the moment where she has nothing on between the legs and is naked again is quite critical with her.

A deterioration of verbal communication faculties often accompanies and is linked to decreasing cognitive faculties. Residents' lose the ability to communicate their needs. Therefore, caregivers often perceive residents' aggressive behaviour as their last remaining possibility and 'manner to express themselves', to communicate or to attract attention to themselves.

\section{Factors relating to the caregivers}

Whereas the loss of cognitive faculties increases in people suffering from dementia, their emotional competences remain stable for a relatively long time. The so called antennae for interpersonal relationships is often well conserved - even with an advanced disorder - and consequently the residents often register stress, haste and changes in the voice of the caregiver. 
Caregivers feel that caring for residents whilst under time pressure is particularly difficult regarding aggressive behaviour. 'Working under pressure' prevents caregivers from adapting to the abilities and the rhythm of the residents. One caregiver reported:

When I'm under pressure and want to press on, I note that rushing is of absolutely no use with a demented resident. I simply have to take more time otherwise it becomes worse. And then it's impossible to go on.

Caregivers also consider that 'lacking of thoughtfulness' - which may be stress or haste induced or may accrue from private worries - may also trigger residents' aggressive behaviour. They assume that they lack emotional presence and attention and fail to show the necessary empathy for the residents in such situations. Caregivers also suspect that their own 'fear of the resident' and their uncertainty may trigger aggressive behaviour. Caregivers suppose that in such moments they are unable to transmit necessary feelings of security to the residents:

I was afraid of him. I entered into the room feeling insecure and I think that he also sensed that as he threatened me and struck out. I was very afraid of him. I hardly said a word to him and constantly watched out that he didn't hit me when I was washing him and constantly watched his arm. And he sensed that.

\section{Dealing with residents}

Caregivers use various means to pacify aggressive residents, to keep the situation under control and to avoid any harm. As 'knowing the residents' habits and needs' are of central importance to the caregiver they gather information on the biographical background of new residents and involve the relatives in information collection. They would typically ask for examples about daily rhythms and habits, particularly relating to needs such as eating, sleeping, personal hygiene or excretion. Caregivers also investigate areas where support is needed, where residents are independent and how the caregivers can respect the wishes of the residents:

It is important to know each resident's preferences, e.g. eating, drinking or music etc. Knowing this, one can do some good pre-emptive work. They respond well to that.

However, despite caregivers' efforts to reveal which type of care is well accepted by the resident and in which situations aggression occurs; they discover again and again that there is no easy and fast solution. Therefore the 'quest for new solutions' for aggressive resident behaviour is a continuous process. What the resident accepts well now or today may trigger an opposite reaction a couple of hours or a day later.

When aggressive behaviour occurs in the care situation, the caregivers try first and foremost to 'pacify and distract' the situation both verbally and non-verbally. The approaches they use are for example a calming chat, prompting the residents to reflect on their behavioural pattern, or attempts to distract residents from their demeanour. The essential aim 
of all of these strategies is to interrupt the aggressive behaviour and to impede further escalation.

In some situations the caregivers 'confront the residents with their behaviour' to encourage understanding and to help reduce aggressive behaviour:

When I feel that the resident is up to it, then I confront him with the situation. I look together with him at what happened and try to make him understand what actually took place. It really depends on the situation of the resident, but if possible then I confront him and don't just put up with his behaviour.

In some cases the caregivers see no other alternative than to administer care against the will of the residents or even to 'practice coercion'. This occurs particularly when the skin of incontinent residents is endangered. In the case of physical aggression against the caregiver or with attacks on other residents, the caregivers are obliged to intervene:

She was lying from head to foot in a wet bed. I also think that I get to a certain point or that I am crossing it, but then I really have to do it. Then you really have to care for them against their wishes and put care above everything else.

\section{Self-protection and coping with the situation}

The caregivers' strategies refer to their own safety, to possible states of mind where aggressive behaviour occurs and to sanctions following aggressive events. With regard to the caregivers' personal safety they are aware that something can happen at any time and are therefore attentive when dealing with residents and possible aggressive reactions. The caregivers are observant and 'attentive' in order to recognise the possible danger in time and to establish a spatial distance if necessary.

When aggressive behaviour toward caregivers involves swearing, threats or attempts of physical attack the caregivers try to 'remain calm in the situation' and mentally distance themselves from the situation. In some cases caregivers try to change the emotional tension when they believe that the situation allows it. This strategy includes reactions such as humour or occasionally laughter over the situation. One caregiver reported:

So in such situations I simply take a deep breath and don't react immediately. I try to breathe deeply, to wait a little and accept the situation. I don't take it personally.

Following aggressive incidents the caregivers search for ways to process the experience, to become stronger and to organise themselves again. They 'reconstitute themselves after the experience'. The team plays an important role here and caregivers look first of all for dialogue and support from their co-workers:

It helps me a lot when I can talk it over afterwards. When I can tell others what happened to me. I think that also teaches me how to get over it. Then I suddenly realise that it not only happens to me. 


\subsection{Discussion}

This qualitative study illuminates nursing home caregivers' explanations for residents' aggression and their strategies to deal with it. The caregivers have numerous ideas about the reasons for aggressive behaviour and its possible triggers. They share their assumptions in two areas: resident related factors and caregiver related factors. As resident factors, caregivers mentioned phenomena which are associated with the decreasing cognitive abilities of the nursing home residents like memory, thinking and comprehension. As many of the residents suffer from dementia, their loss of faculties in daily living activities and their failure to understand what is happening are deemed important factors for residents' aggression in the opinion of caregivers. Egan et al. (2009) stated in their study, that aggressive behaviour of someone who was known to have been independent prior to the onset of dementia could be understood as reaction to intense frustration at requiring help for simple tasks. Furthermore, residents' suffer from intrusion into their personal space and react with aggression which caregivers' assume as the last (or the only) remaining possibility that residents' have to express themselves.

The present finding that intimate care seems to be a main factor precipitating aggressive behaviour, is in keeping with the results of other studies (Keene et al. 1999, Glaus Hartmann 2006, Zeller et al. 2009). The participants are willing to critically reflect their own behaviour which may contribute to the genesis of aggressive incidents whilst caring for older people. They point out that time pressure, the lack of emotional presence and attention and fear of the resident can provoke aggressive behaviour. These factors affect the interaction between caregiver and resident by hampering the caregivers' intentions to encounter persons with cognitive impairment in his or her uniqueness. As a consequence the resident probably feels neglected and reacts with aggression.

The assumption of the participants that workplace factors like short-staffing and timepressure is associated with residents' aggression is consistent with results of other studies (Levin et al. 2003, Isaksson et al. 2008). Isaksson et al. (2008) for example found in wards with a significantly lower caregiver-to-resident ratio a high prevalence of aggression.

A novel sub theme which emerged is the participants' 'fear of the resident' as a triggering factor for aggressive behaviour. In the literature residents anxiety has been described as an encouraging factor for aggression but the caregivers' anxiety of their residents or patients with aggressive behaviour is rarely described (Zeller et al. 2009). Breer et al. (2008a) mention that resident aggression may sometimes blur the boundaries between professional and private experience and may lead to caregivers taking aggression personally (Breer et al. 2008a). This may gradually induce anxiety in the caregivers who for example may experience fear before entering the room of the resident. 
The findings related to the reasons and triggers for aggressive behaviour indicate that caregivers have knowledge of a broad range of possible reasons for residents' aggression. This is in keeping with the Need-Driven Dementia-Compromised Behaviour Model (NDB), which was developed to explain the causes of aggressive behaviour in geriatric care (Kolanowski 1999).

Although the participants in the present study stated relevant aggression enhancing factors presented by the NBD Model, it was remarkable that no participant drew on theoretically based argumentation regarding possible reasons for aggressive behaviour. Remarkable as well was that no participant mentioned the link between aggressive behaviour and physiological issues like pain, elimination and hunger or thirst. In a study by Leonard et al. (2009) an association between physical aggression and constipation was identified but they did not find a statistical association with pain, fever or urinary tract infections. Despite this weak evidence, guidelines recommended the assessment and treatment of physiological issues as an attempt to reduce aggressive behaviour.

The second theme identifies interventions which caregivers use in dealing with residents' aggression. Getting to know the person, their habits and needs and the continual quest for new solutions are general interventions in nursing homes. These interventions seem especially important for residents who demonstrate aggressive behaviour. An anecdotal report suggests that caregivers who understand the importance of past events in residents' lives and who can transfer this understanding to the residents' current situation are better equipped to individualise care and reduce aggressive behaviour (Miller 1997). Entering the resident's world involves getting to know the person behind the aggression and normalising their experiences. Caregivers are encouraged to become a part of the residents' lived experience and to strive for mutual understanding and action. Resident negativity is downplayed and interactions are shaped in positive outcomes for caregivers as well as residents (Finfgeld-Connett 2009). A further study has demonstrated that the impact of knowledge of the life history of the patient can induce positive behaviour changes (Egan et al. 2007). These two sub-themes reflect an attitude of the caregivers which are reminiscent of the person-centred approach which attempts to understand the poorly communicated need being expressed by the aggressive person and finding individualised ways to meet that need (Kitwood 1997). Caregivers who strive to understand the meaning behind resident's behaviour could be more successful at curbing aggression than caregivers who act merely in a custodial role (Skovdahl et al. 2003).

Further sub-themes were pacifying, distracting, confronting residents with their behaviour and applying coercion. Whereas pacifying and distracting as well as confronting residents with their behaviour are strategies to calm residents and to gain control applying coercion is seen as a last resort for the participants to handle the difficult situation. Another 
study found, in contrast, that physical restraints were commonly used in residential care settings (Shaw 2004).

The study participants make no reference to guidelines or official recommendations related to helpful or evidence based interventions for dealing with aggressive behaviour. This result is in line with an investigation on geriatric caregivers in Germany which demonstrates that caregivers are aware of factors which encourage aggression but they did not consider these factors in their approach in dealing with aggressive behaviour (Breer et al. 2008b).

The third theme describes caregivers' strategies for self protection and coping with the situation. The sub-themes that emerged were to be attentive when dealing with residents, to try to remain calm and to reconstitute oneself after having experienced an aggressive incident. Similar results are described in a qualitative study by Isaksson et al. (2009). The caregivers spoke about having to be on their guard when preparing to help a resident who was known to be potentially or manifestly aggressive. In such situations caregivers report that they act cautiously. They were more observant, more careful and adopted a wait-andsee strategy. The caregivers also spoke about seeking support and believed that getting proper support could contribute to regaining control and having some relief (Isaksson et al. 2009). These results are also comparable with the study by Skovdahl et al. (2003) where one group of participants saw it as a vitally important for being able to handle aggressiveness and to cope with demanding behaviour from residents.

\subsection{Conclusions}

Caregivers who have to deal with aggressive behaviour are faced with a complex and challenging task. They have to consider several factors which may encourage or trigger aggressive behaviour. Both the caregiver and the resident are involved in an interactive process, because aggressive behaviour usually occurs during personal care. Despite existing models and guidelines, which recommended interventions in dealing with aggression, the results in this study show, that caregivers in practice do not refer to existing theoretical knowledge. Caregivers are well informed about relevant reasons for aggressive behaviour and its management but they do not apply a systemic approach. The anxiety of caregivers in situations involving aggression and the effect of this on their managing of aggressive behaviour is an under examined area. 


\section{Limitations of the study}

One possible limitation of this study is the fact that the three main issues addressed in the research question and employed in the interview guide produced the same three main themes after data analysis. A more open interview format could have yielded other experiences of dealing with residents' aggression. A further limitation could be that the interviews were carried out in focus groups. Due to the fact that the participants know each other it is possible that the participants may have felt inhibited to express their own opinions and to share their experiences with their co-workers. Thus, some degree of social acceptance cannot be excluded.

\section{Relevance to clinical practice}

This study shows that caregivers' who have to manage aggressive behaviour from nursing home residents' are informed about several factors which encourage aggression. However, no participant mentioned the link between aggressive behaviour and physiological issues like pain, elimination and hunger or thirst. Furthermore, the findings show that caregivers use various interventions for managing aggressive behaviour but they do not apply a systematic approach or follow official recommendations. These findings have implications for identifying areas and gaps in knowledge for managing aggressive behaviour in nursing homes. Thus the content of training programs for managing aggressive behaviour might be ameliorated in the light of these findings.

\section{Acknowledgements}

This research was unfunded. The authors gratefully acknowledge the contributions of the research participants.

\section{Contributions}

Study design: $A Z$; data collection and analysis: $A Z$ and IN; manuscript preparation: $A Z, I N, G K$, TD, RJGH.

\section{Conflict of interest}

There are no conflicts of interest in relation to this paper. 


\subsection{References}

Allen-Burge R, Stevens AB \& Burgio LD (1999) Effective behavioral interventions for decreasing dementia-related challenging behavior in nursing homes. International Journal of Geriatric Psychiatry 14, 213-228.

Bundesministerium für Gesundheit (2006) Rahmenempfehlungen zum Umgang mit herausforderndem Verhalten bei Menschen mit Demenz in der stationären Altershilfe (Guidelines regarding handling of challenging behaviour by persons with dementia in residential facilities). Available at: https://www.bundesgesundheitsministerium.de/fileadmin/dateien/ Publikatoinen/Pflege/Berichte/Bericht_Rahmenempfehlungen_zum_Umgang_mit_ herausforderndem_Verhalten_bei_Menschen_mit_Demenz_in_der_stationaeren_Altenhilfe.pdf [accessed 01 June 2010].

Breer A, Frischkorn M, Kathmann T \& Panke-Kochinke B (2008a) Gewalt gegen Pflegende Teil 1: Gewohnte Muster durchbrechen (Violence against nurses - 1: Breaking through accustomed patterns). Pflege Zeitschrift 61, 145-148.

Breer A, Frischkorn M, Kathmann T \& Panke-Kochinke B (2008b) Gewalt gegen Pflegende Teil 2: Der offene Umgang mit Ängsten (Violence against nurses - 2: Openly dealing with anxieties). Pflege Zeitschrift 61, 201-204.

Chou KR, Kaas MJ \& Richie MF (1996) Assaultive behaviour in geriatric patients. Jounal of Gerontological Nursing 22, 30-38.

Douglas S, James I \& Ballard C (2004) Non-pharmacological interventions in dementia. Advances in Psychiatric Treatment 10, 171-179.

Egan MY, Munroe S, Hubert C, Rossiter T, Gauthier A, Eisner M, Fulford N, Neilson M, Daros B \& Rodrigue C (2007) Caring for residents with dementia and aggressive behavior: impact of life history knowledge. Journal of Gerontological Nursing 33, 24-30.

Emerson E (2001) Challenging behaviour: Analysis and intervention in people with severe intellectual disabilities. Cambridge University Press, Cambridge.

Finfgeld-Connett D (2009) Management of aggression among demented or brain-injured patients. Clinical Nursing Research 18, 272-287.

Franz S, Zeh A, Schablon A, Kuhnert S \& Nienhaus A (2010) Aggression and violence against health care workers in Germany--a cross sectional retrospective survey. BMC Health Services Research 10, 51.

Gates D, Fitzwater E \& Succop P (2003) Relationships of stressors, strain and anger to caregiver assaults. Issues in Mental Health Nursing 24, 775-793. 
Gates DM, Fitzwater E \& Meyer U (1999) Violence against caregivers in nursing homes: expected, tolerated and accepted. Journal of Gerontological Nursing 25, 12-22.

Gerberich SG, Church TR, McGovern PM, Hansen HE, Nachreiner NM, Geisser MS, Ryan AD, Mongin. S. J. \& Watt GD (2006) An epidemiological study of the magnitude and consequences of work related violence: the Minnesota Nurses' Study. Occupational and Environmental Medicine 61, 495-503.

Gerrish K \& Lacey A, eds. (2006) The Research Process in Nursing, 5th edn. Oxford. Blackwell Publishing.

Glaus Hartmann M (2006) Aggressionsmuster erkennen und Auslöser reduzieren (Identifying patterns and reducing triggers of aggressive behaviour). Krankenpflege 99, 24-26.

Hall KA \& O'Connor DW (2004) Correlates of aggressive behavior in dementia. International Psychogeriatrics 16, 141-158.

International Council of Nurses (ICN) (2007) Guidelines on coping with violence in the workplace, Geneva.

International Labour Office (ILO), International Council of Nurses (ICN), World Health Organisation (WHO) \& Public Services International (PSI) (2002) Workplace violence in the health sector, Geneva.

Isaksson U, Graneheim UH \& Aström S (2009) Female caregivers' experiences of exposure to violence in nursing homes. Journal of Psychiatric and Mental Health Nursing 16, 46-53.

Isaksson U, Aström S, Sandman P \& Karlsson S (2008) Factors associated with the prevalence of violent behaviour among residents living in nursing homes. Journal of Clinical Nursing 18, 972-980.

Keene J, Hope T, Fairburn CG, Jacoby R, Gedling K \& Ware CJ (1999) Natural history of aggressive behaviour in dementia. International Journal of Geriatric Psychiatry 14, 541-548.

Kitwood T (1997) Dementia reconsidered: The person comes first. Open University Press, Buckingham.

Kolanowski AM (1999) An overview of the need-driven dementia-compromised behavior model. Journal of Gerontological Nursing 25, 7-9.

Leonard R, Tinetti ME, Allore HG \& Drickamer MA (2006) Potentially modifiable resident characteristics that are associated with physical or verbal aggression among nursing home residents with dementia. Archives of Internal Medicine 166, 1295-1300.

Levin PF, Hewitt JB, Misner ST \& Reynolds S (2003) Assault of long-term care personnel. Journal of Gerontological Nursing 29, 28-35. 
Lincoln YS \& Guba EB (1985) Naturalistic Inquiry. Sage Publications, Newbury Park London New Dehli.

Mayring P (2003) Qualitative Inhaltsanalyse: Grundlagen und Techniken (Qualitative content analysis: basics and techniques), 8th edn. Beltz, Weinheim, Basel.

Miller MF (1997) Physical aggressive resident behavior during hygienic care. Journal of Gerontological Nursing 23, 24-39.

Morgan DG, Stewart NJ, D'Arcy D, Forbes D \& Lawson J (2005) Work stress and pysical assault of nursing aides in rural nursing homes with and without dementia special care units. Journal of Psychiatric and Mental Health Nursing 12, 347-358.

Patel V \& Hope RA (1992) A rating scale for aggressive behaviour in the elderly - the RAGE. Psychological Medicine 22, 211-221.

Pulsford D \& Duxbury J (2006) Aggressive behaviour by people with dementia in residential care settings: a review. Journal of Psychiatric and Mental Health Nursing 13, 611-618.

Rodney V (2000) Nurse stress associated with aggression in people with dementia: its relationship to hardiness, cognitive appraisal and coping. Journal of Advanced Nursing 31, 172-180.

Sandvide A, Aström S, Norberg A \& Saveman BI (2004) Violence in institutional care for elderly people from the perspective of involved care providers. Scandinavian Journal of Caring Science 18, 351-357.

Shah A (1999) Aggressive behaviour in the elderly. International Journal of Psychiatry in Clinical Practice, 85-103.

Shaw MMC (2004) Aggression toward staff by nursing home residents: findings from a grounded theory study. Journal of Gerontological Nursing 30, 43-54.

Skovdahl K, Kihlgren AL \& Kihlgren M (2003) Different attitudes when handling aggressive behaviour in dementia - narratives from two caregiver groups. Aging \& Mental Health 7, 277-286.

Smithson J (2008) Focus Groups. In The SAGE Handbook of Social Research Methods (Alasuutari P, Bickmann L \& Brannen J, eds.). Sage Publications, London, pp. 357-370.

Talerico KA, Evans LK \& Strumpf NE (2002) Mental health correlates of aggression in nursing home residents with dementia. The Gerontologist 42, 169-177.

Voyer P, Verreault R, Azizah GM, Desrosiers J, Champoux N \& Bédard A (2005) Prevalence of physical and verbal aggressive behaviours and associated factors among older adults in long-term care facilities. BMC Geriatrics 5. 
Zeller A, Hahn S, Needham I, Kok G, Dassen T \& Halfens RJG (2009) Aggressive behaviour of nursing home residents toward caregivers: a systematic literature review. Geriatric Nursing 30, 174-187. 


\section{Chapter 4}

Nurses experiences with aggressive behaviour of nursing home residents: a cross-sectional study in Swiss nursing homes

Zeller A, Needham I, Dassen T, Kok G \& Halfens RJG (accepted for publication in Pflege) Nurses experiences with aggressive behaviour of nursing home resident: a cross sectional study in Swiss nursing homes. 


\subsection{Abstract}

\section{Design and objectives}

The present exploratory descriptive cross-sectional study with the participation of 814 (51.8\%) caregivers in 21 Swiss nursing homes provides insight into caregivers' experiences and handling of residents' aggressive behaviour. Moreover, caregiver burden with regard to resident aggression and the consequences on the caregiver-resident-relationship were investigated. The survey was carried out by means of a validated questionnaire.

\section{Results}

Approximately $38 \%$ of participants experienced aggressive incidents during the last seven days prior to data collection. In most cases aggressive behaviour was caused by residents' suffering from dementia and/or depression and occurred during nursing interventions involving physical contact. As a trigger for aggressive behaviour participants predominately assumed 'non-understanding and excessive demand' of residents. Reassuring conversation and keeping oneself at a distance were most often used to calm the situation. Approximately $40 \%$ of participants experienced physical attacks as especially distressing and circa $23 \%$ were frightened, particularly when aggressive behaviour occurred without warning. Approximately $4 \%$ of caregivers avoided contact with residents after an aggressive incident and $12.3 \%$ perceived a disturbed relationship.

\section{Conclusion}

It can be assumed that caregivers do not adequately perceive emotions possibly underlying aggressive behaviour in the escalation phase and therefore may not identify early signs of aggression. 


\subsection{Introduction}

Caring for residents in nursing homes is a demanding task for caregivers. It is associated with serious challenges, particularly if residents behave aggressively (Gerberich et al. 2006, Hegney et al. 2010). As a German study pointed out, $83.9 \%$ of caregivers in nursing homes were confronted with physical aggression during the last 12 months of their professional life and over 90\% experienced verbal aggression (Franz et al. 2010). In the study by Isaksson et al. (2008) almost $68 \%$ of caregivers were exposed to aggression during the past 12 months and 22\% several times per week. As the 'Nurses Early Exit Study' (NEXT-Study) reveals, caregivers in geriatric departments show the third highest prevalence for frequent exposure to aggression of residents or relatives compared to other clinical areas (Camerino et al. 2008). Snyder et al. (2007) reported about aggressive behaviour of residents toward caregivers in six geriatric institutions during a period of two weeks. These caregivers were confronted with an average of 64 aggressive incidents during this period (median 26). Most frequently they experienced blows, dragging by the hair and verbal insults (Snyder et al. 2007).

Inconsistency in the study results can be explained by different assessment methods and various instruments. Irrespective of this, it may be assumed that aggressive behaviour is a significant phenomenon for caregivers in nursing-homes (Zeller et al. 2009). They are confronted with aggressive behavior particularly during nursing interventions, involving physical contact with residents, e.g. mobilisation, personal care or continence support. As indicated in a systematic review, these interventions often cause aggression (Zeller et al., 2009), expressed by defensive behaviour (e.g. beating, biting, spitting) of residents (Somboontanont et al. 2004, Whall et al. 2008), especially if nursing interventions are carried out against their will (Skovdahl et al. 2003).

Experiencing aggressive behavior is distressing for nurses. In a study by Glaus Hartmann (2006) almost 39\% of aggression-affected caregivers felt threatened or deeply hurt. $15.8 \%$ of aggressive incidents led to painful physical consequences and visible injuries. The interaction between caregivers and residents is strained as a result of the aggressive incident. Anxiety, anger, shame, guilt and resignation are characteristic of caregivers' emotional response to aggressive behaviour(Rodney 2000, Gates et al. 2003).

The consequences for residents are also described, e.g. caregivers themselves behave aggressively toward residents or they ignore their needs or wishes (Aström et al. 2004). The results of the study by Graneheim et al. (2005) indicate the tensions caregivers are exposed to during an aggressive incident: On the one side, they intend to respect the residents in their individual world, on the other side they are also responsible for ensuring the welfare of all persons involved. At the moment of the aggressive incident they often feel powerless, but try to keep control and to master the difficult situation in a competent way. Caregivers feel 
rejected, but in the next moment residents again are dependent on their help and cherish their support (Graneheim et al. 2005). In some cases nurses interpret aggressive behaviour as an inevitable problem of their professional life, without any prospect of a solution (Sandvide et al. 2004). Emotional exhaustion, depersonalisation, emotional withdrawal and aversion toward residents are described as possible consequences of frequent exposure to aggression (Scott et al. 2011).

\section{Problem and research question}

Concerning aggressive incidents, the situation in Swiss nursing homes is hardly known and so far only one publication has been dedicated to this subject (Glaus Hartmann 2006). This prospective prevalence study provides insight into the frequency of aggressive behaviour of residents and investigates possible triggers. How many nurses experience aggressive behaviour and how they cope with this situation is not in the focus of this study. Additionally, apart from recommendations for managing aggressive and challenging behaviour (Bundesministerium für Gesundheit 2006), the behaviour of caregivers and their interventions in these highly demanding caring situations has not yet been investigated.

The current study intends to contribute to a deeper insight into the experiences of caregivers exposed to aggressive behaviour in nursing homes in the German speaking part of Switzerland. The following research questions were guiding:

- How frequently and in which way caregivers experienced aggressive behaviour of residents during the past 12 months or during the past seven working days prior to data collection?

- Which interventions and behaviour are characteristic of caregivers' response to aggressive incidents?

- Is it possible to identify specific patterns in aggressive incidents experienced by caregivers during the past seven working days with regard to residents' characteristics, situational triggers and nursing interventions?

- How distressing was the aggressive incident for caregivers and which influence did it have on the caregiver-resident-relationship?

Assessing and evaluating behaviour always depends on subjective aspects. Therefore, in the present study Steinert's (1995) definition of aggressive behavior was chosen. It takes into account the subjective aspects of evaluation: Aggressive behavior implicates, that a person feels threatened, attacked or hurt (Steinert 1995). This definition was supplemented by McKenna (2004). He developed the following categorization of aggressive behaviour and explained it by several examples: 
- Verbal insult: e.g. offensive language, cursing, personal insults, or obscene comments,

- Threatening: e.g. declaring the intention of violating a person, harassment, physical intimidation, threatening with a weapon

- Physical attack: e.g. beating, pinching, pushing, spitting, kicking, use of a weapon.

McKenna's categorization (2004) was chosen, because it serves as the basis of the instrument used in the current study and also underlies the results of the study by Hahn et al. (2012), performed in a Swiss university hospital. So the results obtained in two different settings in Switzerland could be compared.

\subsection{Method and material}

\section{Study design and research field}

To answer the research questions, a descriptive explorative cross sectional study with an accidental sampling was conducted in nursing homes in the German-speaking part of Switzerland. Institutions were recruited by means of an announcement in two national nursing journals. 23 nursing managers declared their interest in participating. After communicating the aims and the expense for performing the study 21 institutions definitely agreed and permitted to conduct the survey among their caregivers. 14 of the participating institutions were in public ownership and seven privately owned. The term "caregiver" refers to persons with different levels of nursing education, working in direct care in nursing homes.

\section{Data collection}

Data collection was performed by means of a questionnaire in paper version between November 2010 and April 2011. All participating institutions could freely choose a date for data collection. In 14 of 21 institutions all caregivers participated, in seven institutions caregivers of one to three units participated in the study. The questionnaire, an information sheet about the aims of the study and an addressed response envelope were distributed by nurse managers. Participants could return the completed questionnaire directly to the principal investigator. After expiry of the deadline all contact persons of participating institutions were informed about their response-rate, with a request to further motivate their colleagues for participating in the study.

\section{Instrument}

The German version of the "Survey of Violence Experienced by Staff (SOVES-G)" was used. This questionnaire was originally developed by McKenna (2004) to investigate workplace aggression. The content validity was evaluated by the ,European Violence in Psychiatry Re- 
search Group' and was considered of good quality. In a pilot study McKenna (2004) evaluated the reliability of the SOVES-subscales with satisfying results (Cronbachs's $\alpha$ 0.87-0.91). Within the framework of a study in a German-speaking hospital the questionnaire was translated into German and validated by Hahn et al. (2011) (German Version of the Survey of Violence Experienced by Staff revised, SOVES-G-R). The German version of the questionnaire consists of seven parts $(A-G)$ :

A Sociodemographic characteristics of participating persons

B Experience with aggression and several forms of aggression (insults, threatening behaviour and/or physical attacks) during professional life

C Experience with aggression during the past twelve months (one time, two to eight times, twelve times and more) and information about the aggressively behaving person (resident or relative)

D Experience with aggression during the past seven working days (one time or more), information about the aggressively behaving person, impairments (e.g. impaired communication or mobility) and diagnoses of the aggressively behaving person (e.g. dementia, delirium), activity carried out at the moment of the aggressive incident (e.g. nursing intervention with or without physical contact), situational trigger (e.g. violation of intimacy, pain), and response to the aggressive incident (e.g. keeping oneself at a distance, leaving the room, reassuring conversation etc.)

E Consequences of the experienced aggression for caregivers (e.g. notification of illness as a result of the aggressive incident, experienced burden in relation to the form of aggression etc.)

F Support at the working place, possibility of documenting and reporting aggressive incidents

G Aggression management training (yes or no); importance of aggression management training

The instrument had to be slightly modified for use in nursing homes. The term ,patient' was replaced by ,resident' and diagnoses were adapted to the setting. The modified version of the questionnaire was presented to seven experts of the nursing home setting with the request to evaluate it. They confirmed the modifications as correct and adequate for the setting. Afterwards a pilot study was performed in an institution not participating in the study. In this pilot study 133 nurses completed the questionnaire and considered it as easy to understand and practicable. Consequently, no further additions or changes were made. For the main study the ,Impact of Patient Aggression on Carers Scale' (Needham et al. 2005a) was integrated into the questionnaire. With this scale the participants can assess their feelings after an aggressive incident. This instrument consists of ten items, which can be assessed with a five-point Likert scale ("never' to "always'). The ten items represent three scales: ,Im- 
pairment of the caregiver-resident-relationship', ,negative emotions' and ,negative emotions with regard to external conditions' (Cronbachs's $\alpha 0.78,0.68,0.60$ )

\section{Data Analysis}

Data were analyzed descriptively by means of IBM SPSS Statistics Version 19. Free text answers were analyzed by means of summarizing qualitative content analysis in order to categorize and quantify as well as to generate themes. Besides the descriptive analysis answers concerning the most impressing aggressive incident during the past seven working days were analyzed in a cluster analysis. Residents' diagnoses and impairments as probable triggers of aggressive incidents were integrated. An agglomerative-hierarchical method of the Ward Type, performed in "R Paket cluster", was used (Maechler et al. 2011). A classification tree was generated by means of "R Paket rpart" (Therneau \& Atkinson 2011). Results of the cluster-analysis were analyzed by means of the statistical program R Version 2.13.1 (R Development Core Team 2011).

\section{Ethical Considerations}

Voluntary participation for all caregivers was pointed out in the information sheet. Participating institutions were coded in order to calculate the response-rate of each institution. All participants have returned the completed questionnaire in an addressed, already stamped return envelope to the principal investigator. No conclusions could be drawn about the participating persons. An anonymized analysis was guaranteed. The ethics committees approved the implementation of the study on the basis of the study protocol.

\subsection{Results}

\section{Institutions and caregivers}

In total, 21 nursing homes of the German-sparking part of Switzerland participated in the study. They varied in size between 25 and 705 beds. In seven nursing homes caregivers of one to three units took part, in all other nursing homes all caregivers participated. In total, 1572 questionnaires were distributed and 814 returned. This resulted in a response rate of $51.8 \%$, varying from $29.6 \%$ to $92.5 \%$ in the respective institutions. 10 of 814 questionnaires were invalid, so 804 questionnaires could be integrated into data analysis. 749 (93.2\%) women and 50 men (6.2\%) participated, $40 \%$ of them are registered nurses. Almost $25 \%$ of them have an education as enrolled nurses. More than $25 \%$ are working as nurse assistants. Table 4.1 shows further sociodemographic characteristics of the participants. 
Table 4.1: Socio-demographic characteristics of the sample

\begin{tabular}{|c|c|c|c|}
\hline \multirow[t]{2}{*}{ Demographic characteristics } & & \multicolumn{2}{|c|}{ Total $(n=804)$} \\
\hline & & $\mathrm{n}$ & (\%) \\
\hline \multirow[t]{3}{*}{ Gender } & Female & 749 & $(93.2)$ \\
\hline & Male & 50 & $(6.2)$ \\
\hline & Missings & 5 & (0.6) \\
\hline \multirow[t]{5}{*}{ Age (years) } & $<17$ & 13 & (1.6) \\
\hline & $18-29$ & 179 & $(22.3)$ \\
\hline & $30-45$ & 250 & (31.1) \\
\hline & $>45$ & 358 & $(44.5)$ \\
\hline & Missings & 4 & $(0.5)$ \\
\hline \multirow{5}{*}{$\begin{array}{l}\text { Educational level } \\
\text { including nurses in } \\
\text { training }\end{array}$} & Registered nurses & 345 & $(42.9)$ \\
\hline & Enrolled nurses* & 207 & $(25.7)$ \\
\hline & Nursing assistants & 212 & $(26.4)$ \\
\hline & Other caregivers & 35 & $(4.4)$ \\
\hline & Missing & 5 & $(0.6)$ \\
\hline \multirow{5}{*}{$\begin{array}{l}\text { Professional experience in } \\
\text { health care (years) }\end{array}$} & $<4$ & 127 & $(15.8)$ \\
\hline & $5-9$ & 150 & $(18.7)$ \\
\hline & $10-15$ & 187 & $(23.2)$ \\
\hline & $>15$ & 335 & (41.7) \\
\hline & Missing & 5 & $(0.6)$ \\
\hline \multirow{5}{*}{$\begin{array}{l}\text { Experience in current posi- } \\
\text { tion (years) }\end{array}$} & $<1$ & 98 & $(12.2)$ \\
\hline & $1-4$ & 315 & $(39.2)$ \\
\hline & $5-10$ & 213 & $(26.5)$ \\
\hline & $>10$ & 172 & $(21.4)$ \\
\hline & Missing & 6 & $(0.7)$ \\
\hline \multirow[t]{4}{*}{ Employment level (\%) } & $80-100$ & 473 & $(58.8)$ \\
\hline & $51-79$ & 180 & $(22.4)$ \\
\hline & $\leq 50$ & 147 & (18.3) \\
\hline & Missing & 4 & $(0.5)$ \\
\hline \multirow{4}{*}{$\begin{array}{l}\text { Daily amount of time spent } \\
\text { in direct contact with resi- } \\
\text { dents (\%) }\end{array}$} & $<30$ & 29 & (3.6) \\
\hline & $30-60$ & 184 & $(22.9)$ \\
\hline & $>60$ & 585 & (72.8) \\
\hline & Missing & 6 & $(0.7)$ \\
\hline \multirow{3}{*}{$\begin{array}{l}\text { Trained in management of } \\
\text { aggressive behaviour }\end{array}$} & Yes & 356 & $(44.3)$ \\
\hline & No & 445 & $(55.3)$ \\
\hline & Missing & 3 & $(0.4)$ \\
\hline
\end{tabular}

* Caregivers with a two- or three-year education not at a diploma level 


\section{Frequency, types and characteristics of aggressive behavior}

Almost all participants (96\%) have experienced aggressive behavior of residents during their professional life. Circa 80\% reported about aggressive incidents during the last 12 months. Related to the period of the last seven working days 307 participants (38.2\%) were confronted with aggressive behavior (Table 4.2). Data about the most impressing aggressive incident showed that the participants were particularly confronted with verbal insults and physical attacks (Table 4.2).

Table 4.2: Caregivers' experience with resident aggression during the past seven working days

\begin{tabular}{|c|c|c|c|c|}
\hline & & \multicolumn{3}{|c|}{ Types of aggressive behaviour $(n=307)$} \\
\hline & \multirow[t]{2}{*}{ Frequency } & Verbal assaults & Threats & $\begin{array}{l}\text { Physical as- } \\
\text { saults }\end{array}$ \\
\hline & & n $(\%)$ & $\mathrm{n} \quad(\%)$ & n $\quad(\%)$ \\
\hline Aggressive incident dur- & once & $97 \quad(31.6)$ & $36 \quad(11.7)$ & $87 \quad(28.3)$ \\
\hline $\begin{array}{l}\text { ing the past seven work- } \\
\text { ing days* }\end{array}$ & more than once & $179 \quad(58.3)$ & $44 \quad(14.3)$ & $76 \quad(24.8)$ \\
\hline $\begin{array}{l}\text { Most salient aggressive } \\
\text { incident }\end{array}$ & & $153(49.8)$ & $23(7.5)$ & 131 (42.7) \\
\hline
\end{tabular}

*Multiple answers possible

According to participating caregivers in $80.3 \%(n=295)$ of all cases aggressively behaving residents suffered from dementia and in $28.1 \%(n=295)$ were affected by depression. Most of these residents had impaired cognitive abilities $(79.3 \% ; n=300)$, impaired mobility (63.0\%; $n=300)$, impaired communication (55.3\%; $n=300$ ) or suffered from incontinence (59.0\%; $n=300$ ). In almost $60 \%$ of all cases the aggressive incident occurred during a nursing intervention involving physical contact. During other interventions, e.g. medication (ca. 6\%) or counseling (5\%), aggressive behavior occurred significantly less frequently (Table 4.3). 
Table 4.3: Characteristics of the most salient aggressive incident during the past seven working days

\begin{tabular}{|c|c|c|c|}
\hline \multirow[t]{2}{*}{ Characteristics } & & \multicolumn{2}{|c|}{ Total $(n=307)$} \\
\hline & & $\mathrm{n}$ & $(\%)$ \\
\hline \multirow{2}{*}{$\begin{array}{l}\text { Perpetrator of the aggressive } \\
\text { incident }\end{array}$} & Resident & 299 & $(97.4)$ \\
\hline & Missing & 8 & (2.6) \\
\hline \multirow[t]{3}{*}{ Gender } & Female & 162 & $(52.8)$ \\
\hline & Male & 132 & $(43.0)$ \\
\hline & Missing & 13 & $(4.2)$ \\
\hline \multirow[t]{5}{*}{ Age (years) of the residents } & $35-49$ & 3 & $(1.0)$ \\
\hline & $50-65$ & 14 & $(4.6)$ \\
\hline & $66-74$ & 46 & $(15.0)$ \\
\hline & $>75$ & 235 & (76.5) \\
\hline & Missing & 9 & $(2.9)$ \\
\hline \multirow[t]{5}{*}{ Residents' diagnoses* } & Dementia & 237 & $(80.3)$ \\
\hline & Depression & 83 & $(28.1)$ \\
\hline & Psychosis & 50 & $(16.9)$ \\
\hline & Others & 70 & $(23.6)$ \\
\hline & Missing & 12 & $(3.9)$ \\
\hline \multirow[t]{6}{*}{ Residents' impairments } & Cognitive skills & 238 & (79.3) \\
\hline & Mobility & 189 & $(63.0)$ \\
\hline & Elimination & 177 & $(59.0)$ \\
\hline & Communication & 166 & $(55.3)$ \\
\hline & Other areas (e.g. vision, listening, etc.) & 137 & $(22.3)$ \\
\hline & Missing & 7 & $(2.3)$ \\
\hline \multirow{6}{*}{$\begin{array}{l}\text { Activity during the aggressive } \\
\text { incident }\end{array}$} & Nursing activity with physical contact & 184 & $(59.9)$ \\
\hline & Nursing activity without physical contact & 43 & $(14.0)$ \\
\hline & No resident-related activity & 22 & $(7.2)$ \\
\hline & Administration of medicines & 18 & (5.9) \\
\hline & Counselling/Information & 16 & $(5.2)$ \\
\hline & Other activities & 24 & $(7.8)$ \\
\hline
\end{tabular}

*Multiple answers possible

As a trigger for the most impressive aggressive incident it was most frequently suggested that the resident does not understand the situation (68\%; $n=300)$, was overwhelmed by the situation (57\%; $n=300)$ or was ,confused' $(45 \%$; $n=300)$. Table 4.4 shows the ten most frequently reported triggers from participants` perspective. 
Table 4.4: Triggers of the most salient aggressive incident during the past seven working days*

\begin{tabular}{llrl}
\hline Rank & Trigger & Total & $(\mathrm{n}=300)$ \\
\cline { 3 - 4 } & & $\mathrm{n}$ & $(\%)$ \\
\hline 1 & Resident does not understand the situation & 204 & $(68.0)$ \\
2 & Resident is overwhelmed by the situation & 171 & $(57.0)$ \\
3 & Resident is confused & 135 & $(45.0)$ \\
4 & Resident has communication problems & 87 & $(29.0)$ \\
5 & Resident experiences anxiety & 81 & $(27.0)$ \\
6 & Insufficient time for resident & 66 & $(22.0)$ \\
7 & Time pressure & 62 & $(20.7)$ \\
8 & Resident experiences pain & 54 & $(18.0)$ \\
9 & Noise in the environment & 53 & $(17.7)$ \\
10 & Violation of privacy & 49 & $(16.3)$ \\
\hline
\end{tabular}

*Multiple answers possible

\section{Interventions and behavioral response of caregivers}

,Reassuring conversation', ,keeping oneself at a distance from the aggressive person ', ,leaving the room' and ,request to change behaviour' were the most frequently reported interventions of caregivers after the aggressive incident (Table 4.5). All other interventions were mentioned significantly less frequently. For example, only $9 \%$ of participants triggered alarm or asked for help. In a few cases drugs were given (8.3\%) or the aggressively behaving person was restrained $(6.3 \%)$.

Table 4.5: Short-term measures after aggressive behaviour of residents*

\begin{tabular}{llrl}
\hline Rank & Short-term measures & Total & $(\mathrm{n}=301)$ \\
\cline { 3 - 4 } & & $\mathrm{n}$ & $(\%)$ \\
\hline 1 & started reassuring conversation & 167 & $(55.5)$ \\
2 & distanced herself/himself from the aggressive resi- & 155 & $(51.5)$ \\
& dent & & \\
3 & left the room & 124 & $(41.2)$ \\
4 & requested the resident to change behaviour & 100 & $(33.2)$ \\
5 & tried to hide her/his feelings & 57 & $(18.9)$ \\
6 & led the person to a quiet place & 53 & $(17.6)$ \\
7 & other measure & 52 & $(17.3)$ \\
8 & called for help & 27 & $(9.0)$ \\
9 & administered drugs & 25 & $(8.3)$ \\
10 & retained the resident, using physical force & 19 & $(6.3)$ \\
\hline
\end{tabular}

*Multiple answers possible

In reply to a question concerning long-term measures after aggressive behavior, e.g. sensory deprivation or transfer of the resident to another living area or institution, almost half of the participants $(52.8 \% ; n=290)$ reported that no long-term measures were used. The second most frequently mentioned long-term measure was sensory deprivation (19.3\%; $n=290)$ followed by sedation of the aggressively behaving person (6.2\%; $n=290)$. 


\section{Patterns of aggressive incidents during the last seven working days}

In order to recognize patterns with regard to the most impressive aggressive incident during the past seven working days a cluster analysis was carried out. It resulted in three clearly separated clusters.

The binary classification tree helps to understand the significance of the three groups of aggressive incidents (Figure 4.1). A first characterizing feature to classify aggressive incidents is ,impairment of cognitive abilities'. A sequence of yes/no questions leads to a classification by means of majority decision at the end of the branch. The number at the end of the branch indicates the number of cases in the three clusters. The first figure relates to the number of cases in cluster 1 , the second figure relates to the number of cases in cluster 2 and the third figure relates to the number of cases in cluster 3.

In the left branch in figure 1 it is evident that 42 cases, i.e. the majority, belongs to cluster 1 . In this group aggressive incidents occurred in residents with intact cognitive abilities and in most cases the residents were not affected by dementia.

In two groups (cluster 2 and 3 ) predominantly residents with impaired cognitive capacities were involved. Additionally, in group 2 residents mostly had impaired communicative abilities and the aggressive incident happened during nursing interventions involving physical contact or during diagnostic or therapeutic interventions, e.g. administering medication. Impaired communicative abilities were identified as a cause of aggression. In cluster 3 residents also suffered from impaired cognitive capacities, but their communicative abilities were intact. Aggressive behavior occurred without a violation of the resident's private sphere. 


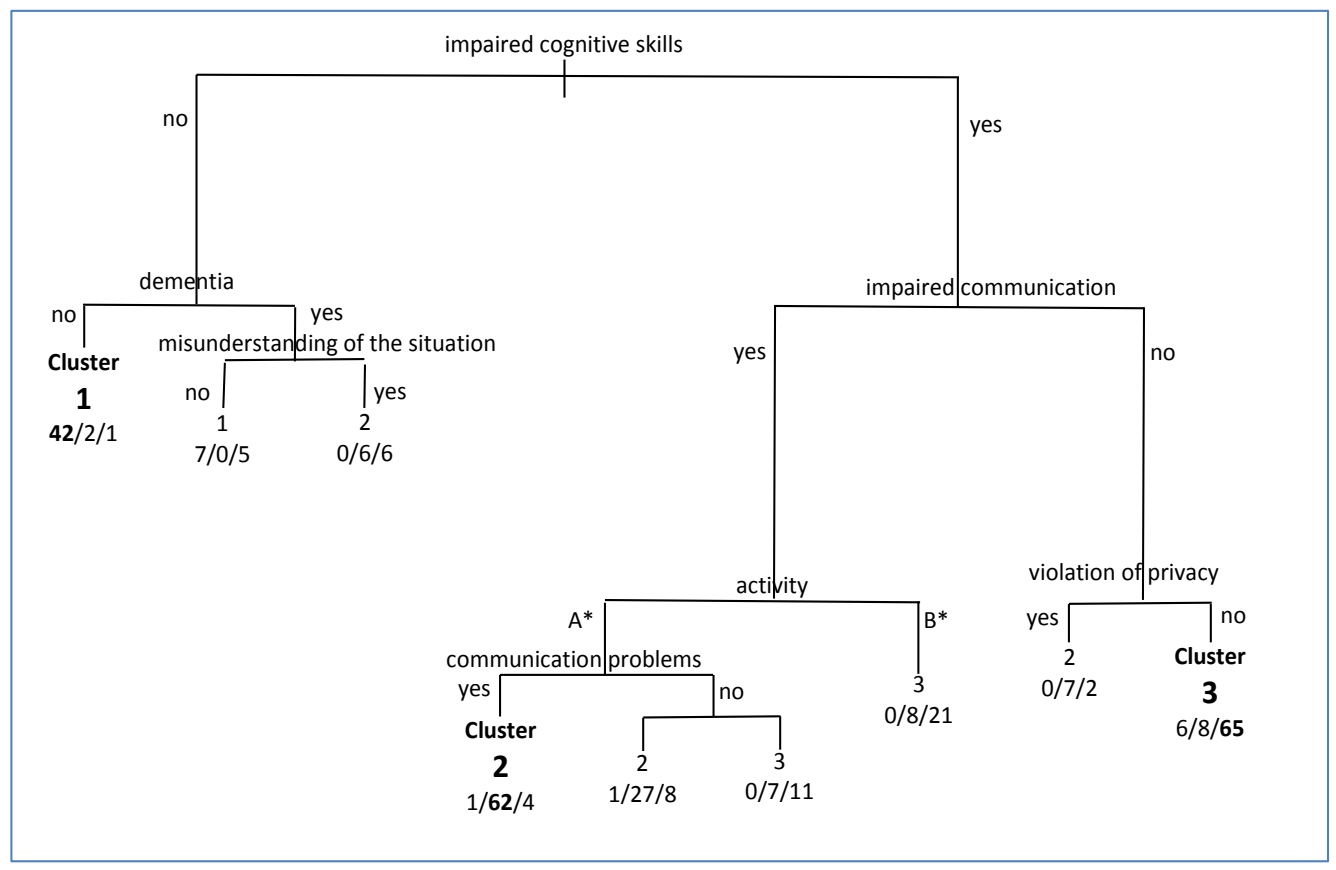

Figure 4.1: classification tree to the most salient incident of aggressive behaviour in the past seven workdays

${ }^{*} \mathrm{~A}=$ care activity with physical contact, diagnostic or therapeutic measure, drug delivery

${ }^{*} \mathrm{~B}=$ care activity without physical contact, admission, discharge, counseling/information, not resident-related activity

\section{Caregiver burden and consequences for the caregiver-resident-relationship}

Participants confronted with residents' aggression during the past 12 months were asked how burdensome the impact of this experience was for them. The analysis shows that the burden is experienced differently, depending on the form of aggression. Physical attacks are perceived as moderately to severely burdensome by almost $44 \%$. Threatening behaviour is experienced as moderately or severely burdensome by almost $38 \%$ and verbal insults by almost 30\% (Table 4.6). None of the different forms of aggression mentioned by participants is experienced as extremely burdensome. Physical attacks have a more negative effect than threatening behaviour or verbal insults. Of all participants who experienced an aggressive incident during the past 12 months 12 persons (1.8\%) reported sick at their working place. $32.6 \%$ suffered from minor physical injuries like scratching marks, hematoma and bite wounds, without need for treatment. Medical treatments due to major injuries were necessary for less than $1 \%$ of participants. 
Table 4.6: Burden of caregivers due to resident aggression during the past 12 months*

\begin{tabular}{|c|c|c|c|c|c|}
\hline \multirow[b]{2}{*}{ burden } & \multicolumn{5}{|c|}{ Types of aggressive behaviour } \\
\hline & $\begin{array}{c}\text { Verbal assaults } \\
\quad(n=598)\end{array}$ & \multicolumn{2}{|c|}{$\begin{array}{l}\text { Threats } \\
(n=209)\end{array}$} & \multicolumn{2}{|c|}{$\begin{array}{l}\text { Physical assaults } \\
\qquad(\mathrm{n}=413)\end{array}$} \\
\hline & $\begin{array}{ll}\mathrm{n} & (\%)\end{array}$ & $\mathrm{n}$ & (\%) & $\mathrm{n}$ & $(\%)$ \\
\hline very strong burden & $8 \quad(1.4)$ & 5 & (2.4) & 11 & (2.7) \\
\hline strong burden & $36 \quad(6.0)$ & 21 & $(10.0)$ & 67 & $(16.2)$ \\
\hline moderate burden & $145 \quad(24.2)$ & 58 & $(27.8)$ & 113 & $(27.4)$ \\
\hline minimal burden & $204 \quad(34.1)$ & 72 & (34.4) & 126 & $(30.5)$ \\
\hline no burden & $205 \quad(34.3)$ & 53 & $(25.4)$ & 96 & $(23.2)$ \\
\hline
\end{tabular}

*Multiple answers possible

Participants were also asked if aggressive behaviour evoked fear in them. $23.4 \%$ of the participants answered with ,yes' and described the underlying causes of their fear in free text answers.

In a summarizing content analysis eleven major statements could be generated and quantified out of 167 free text answers (Table 4.7). ,Fear of the unpredictability' of such a situation was most frequently mentioned $(n=36)$, followed by , fear to be hurt' $(n=28)$ and ,fear of own uncertainty' in this situation $(n=26)$. Further causes of fear are visible in Table 4.7.

Table 4.7: Causes of caregivers' fear when facing resident aggression

\begin{tabular}{lcc}
\hline Caregivers are afraid ... & \multicolumn{2}{c}{ Total $(\mathrm{n}=167)$} \\
\cline { 2 - 3 } & $\mathrm{n}(\%)$ \\
\hline \multirow{2}{*}{$\begin{array}{l}\text { of the unpredictability in this situation } \\
\text { of getting injured }\end{array}$} & $28(21.5)$ \\
of their uncertainty in this situation & $26 \quad(16.7)$ \\
of losing control & 15 & $(9.0)$ \\
of the resident' s physical superiority & $14 \quad(8.4)$ \\
of making a mistake & $11(6.6)$ \\
of becoming aggressive themselves & 11 & $(6.6)$ \\
of being alone in this situation & 9 & $(5.4)$ \\
of other residents being endangered & 8 & $(4.8)$ \\
of physical assaults & 7 & $(4.2)$ \\
of the resident getting injured & 2 & $(1.2)$ \\
\hline
\end{tabular}


Table 4.8 shows the results with regard to caregivers' emotional response after an aggressive incident. For reasons of clarity, different answer choices like ,never' and ,rarely' as well as ,often ' and ,always' were summarized into one category. As the estimation of the participants shows, their feelings toward residents as well as toward their workplace and their own professional capacities are rarely negatively affected. However, about $12 \%$ of participants ,often' or ,always' experience a strained relationship with residents and $4 \%$ avoid contact after an aggressive incident. About $29 \%$ of participants expressed compassion with residents and almost $6 \%$ felt insecure in contact with the residents concerned.

Table 4.8: Impact of Patient Aggression on Carers Scale

\begin{tabular}{|c|c|c|c|c|c|c|c|c|}
\hline \multirow[t]{2}{*}{ Items } & \multicolumn{2}{|c|}{ never/seldom } & \multicolumn{2}{|c|}{ sometimes } & \multicolumn{2}{|c|}{ often/always } & \multicolumn{2}{|c|}{ missing } \\
\hline & $n$ & (\%) & $n$ & (\%) & $n$ & (\%) & $n$ & (\%) \\
\hline $\begin{array}{l}\text { 1. I have a 'guilty con- } \\
\text { science' towards the } \\
\text { resident. }\end{array}$ & 450 & $(68.6)$ & 145 & $(22.1)$ & 46 & $(7.0)$ & 15 & (2.3) \\
\hline $\begin{array}{l}\text { 2. I experience a disturb- } \\
\text { ance in the relation- } \\
\text { ship with the resident. }\end{array}$ & 365 & (55.6) & 197 & $(30.0)$ & 80 & (12.3) & 14 & (2.1) \\
\hline $\begin{array}{l}\text { 3. I avoid contact with } \\
\text { this resident. }\end{array}$ & 463 & $(70.6)$ & 155 & $(23.6)$ & 26 & (4.0) & 12 & (1.8) \\
\hline $\begin{array}{l}\text { 4. I feel sorry for the } \\
\text { resident. }\end{array}$ & 208 & (31.8) & 243 & $(37.0)$ & 191 & (29.1) & 14 & (2.1) \\
\hline $\begin{array}{l}\text { 5. I feel unsecure at } \\
\text { work. }\end{array}$ & 589 & (89.8) & 37 & (5.6) & 11 & (1.7) & 19 & (2.9) \\
\hline $\begin{array}{l}\text { 6. I feel that I have to } \\
\text { deal with societies' } \\
\text { problems. }\end{array}$ & 514 & $(78.4)$ & 91 & (13.9) & 31 & (4.7) & 20 & (3.0) \\
\hline $\begin{array}{l}\text { 7. I have feelings of an- } \\
\text { ger towards the insti- } \\
\text { tution I am working in. }\end{array}$ & 578 & $(88.1)$ & 56 & (8.5) & 11 & (1.7) & 11 & (1.7) \\
\hline $\begin{array}{l}\text { 8. I feel unsecure in } \\
\text { working with the resi- } \\
\text { dent. }\end{array}$ & 462 & $(70.4)$ & 147 & $(22.4)$ & 37 & (5.7) & 10 & (1.5) \\
\hline $\begin{array}{l}\text { 9. I have feelings of be- } \\
\text { ing a failure. }\end{array}$ & 527 & $(80.3)$ & 93 & $(14.2)$ & 25 & (3.8) & 11 & (1.7) \\
\hline $\begin{array}{l}\text { 10. I feel ashamed of my } \\
\text { work. }\end{array}$ & 624 & (95.1) & 18 & (2.8) & 2 & $(0.3)$ & 12 & (1.8) \\
\hline
\end{tabular}




\subsection{Discussion}

\section{Frequency and forms of aggressive behaviour}

One aim of this study was to provide insight into the frequency and the different forms of aggressive behaviour caregivers experience in nursing homes. With regard to the period of 12 months prior to data collection, the results indicate, that experiences in Swiss nursing homes are comparable to the situation in Germany. Almost $84 \%$ of the participants in a German study experienced physical aggression and over 90\% verbal aggression (Franz et al. 2010) during a period of 12 months prior to data collection. However, results of Swedish studies reveal a significantly lower prevalence with approximately 40\% (Aström et al. 2002, Josefsson et al. 2007) and 68.4\% (Isaksson et al. 2008) of participants affected by aggression.

With regard to the past seven working days the current study shows a slightly lower prevalence in comparison with the study by Gates et al. (2004), in which 59\% of the participants were attacked at least once a week. In a further study by Gates et al. (2003) only 29\% of caregivers did not experience an aggressive incident during a period of 10 working days. In the study by Farrell et al. (2006) 68.9\% of caregivers reported experiences with aggression during the past four weeks. Comparable are also the experiences with different forms of aggression. In the study by Farrell et al. (2006) about 49\% of the participants reported about physical aggression and Boström et al. (2011) indicate a comparable relation with regard to the experience of physical (50\%) and verbal aggression (48\%).

Comparisons of study results concerning the prevalence of caregivers ' experience of aggression often reveal significant inconsistencies. They can be caused by different study designs, e.g. retro- or prospective designs, or by measurements with diverse instruments as well as by various institutional conditions (Zeller et al., 2009). However, the results emphasize the significance of this theme for caregivers in nursing homes, also in comparison with other clinical settings, e.g. acute care. A recent study in a Swiss university hospital revealed that $13.5 \%$ of caregivers were affected by aggression during the previous working week (Hahn et al. 2012). With regard to different forms of aggression the study by Hahn et al. (2012) shows recognizable differences: $19.7 \%$ of the participants reported about physical aggression and $66.9 \%$ about verbal aggression. In nursing homes verbal and physical aggression mostly occur at a similar frequency. However, in acute care verbal aggression is the dominant form of aggression (Hahn et al. 2008, Zeller et al. 2009).

\section{Interventions and behavioral response of caregivers}

The results of this study reveal that caregivers primarily intend to de-escalate the situation by means of a conversation. Restrictive measures, e.g. restraint, are used significantly less often. Frequently ,leaving the room' was mentioned as a short-term measure. In interviews 
with caregivers it was recognized that by this measure they expect a calming effect on the resident and hope to continue with nursing interventions after a certain time. Based on the assumption that aggressive behavior is a way to express or communicate needs, it might be problematic if caregivers leave the room. The needs-based behavioral model assumes that every behaviour has a cause and to identify the underlying cause of behaviour should be directive for caregivers (Algase et al. 1996, Kolanowski 1999). According to Höwler (2008) behavioural responses of caregivers can be assigned to emotion-focused strategies. They include also a distancing behavior toward residents. Emotion-focused strategies usually do not change aggressive behavior. Caregivers rely on these strategies because they fear to lose control over the situation (Höwler 2008).

\section{Patterns of aggressive incidents during the previous seven working days}

The results of the cluster-analysis shows that in two groups - according to caregivers - residents with aggressive behavior were affected by impaired cognitive abilities. This indicates a connection between aggressive incidents and dementia, as shown in previous studies (Hall \& O'Connor 2004, Voyer et al. 2005, Glaus Hartmann 2006, Testad et al. 2007).

The classification tree makes visible that aggressive incidents occurred in residents with impaired cognitive and communicative abilities during nursing interventions involving physical contact with residents' privacy being violated. As studies repeatedly have shown in such situations aggressive behavior occurs particularly often (Zeller et al. 2009). Therefore, it is astonishing that , violation of residents' privacy is mentioned by caregivers only in the tenth place. Caregivers estimate residents' ,non-understanding ',excessive demand' and ,confusion' as most important causes of aggressive behavior. This indicates that they relate aggression more often to dementia and rarely to nursing interventions. ,Not enough time for residents' and ,time pressure' are mentioned as further triggering factors of aggressive behavior. This estimation is comparable with the results of a qualitative study performed in a Swiss nursing-home (Zeller et al. 2011).

It is quite understandable that time pressure negatively influences caregiver-residentinteractions during interventions with physical contact and triggers aggressive behaviour (Gates et al. 2005, Yeom \& Watson 2009). A personhood-promoting interaction as Kitwood (1997) recommended for people with dementia cannot be performed under time pressure.

\section{Burden for caregivers and consequences for the caregiver-resident-relationship}

Participants of this study experience especially physical attacks as severely stressing. Almost $30 \%$ of them suffered from minor physical injuries. This corresponds with results in studies by Aström et al. (2004) and Tak et al. (2010), in which almost one third of the participants report about minor injuries and hematoma due to residents' aggressive behaviour. A close 
correlation between nursing interventions, involving physical contact, e.g. mobilisation, and the risk of being injured, could be revealed by Myers et al. (2005).

Besides physical injuries, consequences of aggressive incidents on caregiver's emotional experience are also significant. In the present study caregivers were asked exclusively about the intensity of the burden they felt, without further specification. It is well known that emotions like powerlessness, anger, disappointment, self-doubt, sadness as well as physical or psychical exhaustion are common in caregivers after aggressive incidents (Aström et al. 2004, Josefsson et al. 2007, Chapman et al. 2009, Franz et al. 2010). The emotional burden of caregivers caused by aggressive behaviour is proven also in other clinical areas (Needham et al. 2005b).

In this study over $20 \%$ of the participants told that aggressive incidents evoked fear in them. This percentage is higher than in the study by Josefsson et al. (2007), in which $15 \%$ of the participants reported about fear of aggressive behaviour. In a literary review by Needham et al. (2005b) fear is also perceived as one of the most common emotional consequences. It was experienced by 12.4 to $49 \%$ of all caregivers affected by aggression. In the present study fear about the unpredictability of the situation is most frequently mentioned. If aggressive behaviour hurts caregivers without prior warning, they experience it as especially fear-inducing. They did not recognize any warning signs of aggression. Fear about their own uncertainty was the third most frequently mentioned consequence and indicates the excessive demand on caregivers at this moment. The possibility to reassure residents and to react adequately in this situation is decreasing. Answers like ,fear of losing control' or ,fear of becoming aggressively myself' emphasize the excessive strain at the moment of the aggressive incident. There is a risk for inducing a mutual process of escalation, leading to aggression (Gates et al. 2003). This is associated with negative consequences for residents. Fear about the unpredictability of the situation probably points at a lack of knowledge concerning early warning signs of an aggressive incident. It is unknown how often assessment scales, e.g. the Bröset-Scale (Almvik et al. 2007), are used in Swiss nursing homes.

Results concerning caregiver' s emotional response to residents' aggression indicate a strained relationship with residents. It can be assumed that aggressive behavior negatively influences caring for residents (Arnetz \& Arnetz 2001). Antipathy, ignoring the needs of residents and rejecting their questions are reactions of caregivers to aggressive behavior, described in the study by Aström et al. (2004). Assuming that aggressive behavior could be an expression of unfulfilled and unrecognized needs, a strained caregiver-resident-relationship may have a serious impact on residents.

The present study has several limitations, which should be considered when interpreting the results. One limiting factor is the performance of this study with an accidental sampling. Data about non-participating persons are not available. Characterizations of residents are 
exclusively based on the data of caregivers. Additionally, aggressive incidents and particular interventions were asked retrospectively. Consequently, recall bias is possible. It was intended to reduce this problem by limiting the experiences to the past seven working days. It is not known whether caregivers with very frequent or with very few experiences of aggressive behaviour took part in the study. The high prevalence-figures lead to the assumption that in participating institutions aggressive behaviour is a relevant theme. This may bias the results and restrict the representativity of this study. Despite these restrictions, this explorative study provides insight into the experiences of caregivers and their response to aggressive behaviour of residents in nursing homes in the German-speaking part of Switzerland and reveals that aggression is a relevant theme for caregivers in this setting.

\subsection{Conclusions}

As the results of this study show, caregivers in nursing homes are to a high extent confronted with residents' aggressive behaviour. Aggressive incidents particularly often occur during interventions involving physical contact. The strategies of caregivers are primarily directed at calming the situation by a reassuring conversation or keeping themselves at a distance. In extreme cases caregivers leave the room, in the hope that the resident will calm down after a certain time. Caregivers perceive resident aggression as burdensome, especially if they are exposed to physical attacks. Some caregivers feel frightened, especially if aggressions occur without prior warning. The question arises if caregivers probably do not recognize early warning signs of aggression or possible situational triggers and therefore are not able to protect themselves or apply de-escalating techniques.

The results indicate, that the caregiver-resident-relationship can be negatively affected and some caregivers reduce their contact with residents. This entails the risk that residents' needs, which eventually could cause aggressive behaviour, are not recognized, because caregivers keep themselves at a distance. In aggression management training programs caregivers should be prepared to confront aggression with de-escalating techniques. Additionally, an in-depth consideration should be promoted with regard to possible reasons of aggressive behaviour, as mentioned in the general recommendations (Bundesministerium für Gesundheit 2006). 


\subsection{References}

Algase DL, Beck C, Kolanowski A, Whall A, Berent S, Richards K \& Beattie E (1996) Needdriven dementia-compromised behavior: An alternative view of disruptive behavior. American Journal of Alzheimer's Disease and Other Dementias 11, 10-19.

Almvik R, Woods P \& Rasmussen K (2007) Assessing risk for imminent violence in the elderly: the Brøset Violence Checklist. International Journal of Geriatric Psychiatry 22, 862-867.

Arnetz JE \& Arnetz BB (2001) Violence towards health care staff and possible effects on the quality of patient care. Social Science and Medicine 52, 417-427.

Aström S, Bucht G, Eisemann M, Norberg A \& Saveman B (2002) Incidence of violence towards staff caring for the elderly. Scandinavian Journal of Caring Sciences 16, 66-72.

Aström S, Karlsson S, Sandvide A, Bucht G, Eisemann M, Norberg A \& Saveman B (2004) Staff's experience of and the management of violent incidents in elderly care. Scandinavian Journal of Caring Sciences 18, 410-416.

Boström AM, Squires JE, Mitchell A, Sales AE \& Estabrooks CA (2011) Workplace aggression experienced by frontline staff in dementia care. Journal of Clinical Nursing.

Bundesministerium für Gesundheit (2006) Rahmenempfehlungen zum Umgang mit herausforderndem Verhalten bei Menschen mit Demenz in der stationären Altershilfe (Guidelines regarding handling of challenging behaviour by persons with dementia in residential facilities). Available at: https://www.bundesgesundheitsministerium.de/fileadmin/dateien/ Publikationen/Pflege/Berichte/Bericht_Rahmenempfehlungen_zum_Umgang_mit_ herausforderndem_Verhalten_bei_Menschen_mit_Demenz_in_der_stationaeren_Altenhil fe.pdf [accessed 01 June 2012].

Camerino D, Estryn-Behar M, Conway P, van Der Heijden BIJM \& Hasselhorn H (2008) Workrelated factors and violence among nursing staff in the European NEXT study: a longitudinal cohort study. International Journal of Nursing Studies 45, 35-50.

Chapman R, Perry L, Styles I \& Combs S (2009) Consequences of workplace violence directed at nurses. British Journal of Nursing (Mark Allen Publishing) 18, 1256-1261.

Farrell G, Bobrowski C \& Bobrowski P (2006) Scoping workplace aggression in nursing: findings from an Australian study. Journal of Advanced Nursing 55, 778-787.

Franz S, Zeh A, Schablon A, Kuhnert S \& Nienhaus A (2010) Aggression and violence against health care workers in Germany--a cross sectional retrospective survey. BMC Health Services Research 10, 51. 
Gates D, Fitzwater E \& Succop P (2003) Relationships of stressors, strain, and anger to caregiver assaults. Issues in Mental Health Nursing 24, 775-793.

Gates D, Fitzwater E \& Succop P (2005) Reducing assaults against nursing home caregivers. Nursing Research 54, 119-127.

Gates D, Fitzwater E, Telintelo S, Succop P \& Sommers M (2004) Preventing assaults by nursing home residents: nursing assistants' knowledge and confidence-a pilot study. Journal of the American Medical Directors Association 5, S16-21.

Gerberich SG, Church TR, McGovern PM, Hansen HE, Nachreiner NM, Geisser MS, Ryan AD, Mongin. S. J. \& Watt GD (2006) An epidemiological study of the magnitude and consequences of work related violence: the Minnesota Nurses' Study. Occupational and Environmental Medicine 61, 495-503.

Glaus Hartmann M (2006) Aggressionsmuster erkennen und Auslöser reduzieren (Recognizing aggression and relieving stress). Krankenpflege 99, 24-26.

Graneheim U, Isaksson U, Ljung I \& Jansson L (2005) Balancing between contradictions: the meaning of interaction with people suffering from dementia and "behavioral disturbances". International Journal of Aging \& Human Development 60, 145-157.

Hahn S, Hantikainen V, Needham I, Kok G, Dassen T \& Halfens RJ (2012) Patient and visitor violence in the general hospital, occurrence, staff interventions and consequences: $a$ cross-sectional survey. Journal of Advanced Nursing 68, 2685-2699.

Hahn S, Müller M, Needham I, Dassen T, Kok G \& Halfens R (2011) Measuring patient and visitor violence in general hospitals: feasibility of the SOVES-G-R, internal consistency and construct validity of the POAS-S and the POIS. Journal of Clinical Nursing 20, 2519-2530.

Hahn S, Zeller A, Needham I, Kok G, Dassen T \& Ruud RJ (2008) Patient- and visitor violence in general hospitals: a systematic review. Journal of Aggression and Violent Behavior 13, 431-441.

Hall KA \& O'Connor DW (2004) Correlates of aggressive behavior in dementia. International Psychogeriatrics 16, 141-158.

Hegney D, Tuckett A, Parker D \& Eley R (2010) Workplace violence: differences in perceptions of nursing work between those exposed and those not exposed: a cross-sector analysis. International Journal of Nursing Practice 16, 188-202.

Höwler E (2008) Herausforderndes Verhalten bei Menschen mit Demenz: Erleben und Strategien Pflegender (Challenging behaviour in people with dementia: caregivers experiences and strategies). Kohlhammer, Stuttgart. 
Isaksson U, Graneheim UH, Richter J, Eisemann M \& Aström S (2008) Exposure to violence in relation to personality traits, coping abilities, and burnout among caregivers in nursing homes: a case-control study. Scandinavian Journal of Caring Sciences 22, 551-559.

Josefsson K, Sonde L \& Wahlin T (2007) Violence in municipal care of older people in Sweden as perceived by registered nurses. Journal of Clinical Nursing 16, 900-910.

Kitwood T (1997) Dementia reconsidered. The person comes first. Open University Press, Buckingham.

Kolanowski AM (1999) An overview of the need-driven dementia-compromised behavior model. Journal of Gerontological Nursing 25, 7-9.

Maechler M, Rousseeuw P, Struyf A, Hubert M \& Hornik K (2011) cluster: Cluster Analysis Basics and Extensions. Available at: http://cran.r-project.org/web/packages/cluster/ [accessed 01.06.2012].

McKenna K (2004) Study of work-related violence. Committee on Workplace Violence. North Eastern Health Board, Ireland.

Myers D, Kriebel D, Karasek R, Punnett L \& Wegman D (2005) Injuries and assaults in a longterm psychiatric care facility: an epidemiologic study. AAOHN Journal : Official Journal of the American Association of Occupational 53, 489-498.

Needham I, Abderhalden C, Halfens RJG, Dassen T, Haug HJ \& Fischer JE (2005a) The Impact of Patient Aggression on Carers Scale: instrument derivation and psychometric testing. Scandinavian Journal of Caring Sciences 19, 296-300.

Needham I, Abderhalden C, Halfens RJG, Fischer JE \& Dassen T (2005b) Non-somatic effects of patient aggression on nurses: a systematic review. Journal of Advanced Nursing 49, 283-296.

R Development Core Team (2011) R: A Language and Environment for Statistical Computing. $R$ Foundation for Statistical Computing. Available at: http://www.R-project.org [accessed 01.06.2012].

Rodney V (2000) Nurse stress associated with aggression in people with dementia: its relationship to hardiness, cognitive appraisal and coping. Journal of Advanced Nursing 31, 172-180.

Sandvide A, Aström S, Norberg A \& Saveman BI (2004) Violence in institutional care for elderly people from the perspective of involved care providers. Scandinavian Journal of Caring Sciences 18, 351-357. 
Scott A, Ryan A, James I \& Mitchell EA (2011) Perceptions and implications of violence from care home residents with dementia: a review and commentary. International Journal of Older People Nursing 6, 110-122.

Skovdahl K, Kihlgren AL \& Kihlgren M (2003) Dementia and aggressiveness: video recorded morning care from different care units. Journal of Clinical Nursing 12, 888-898.

Snyder L, Chen P \& Vacha-Haase T (2007) The underreporting gap in aggressive incidents from geriatric patients against certified nursing assistants. Violence and Victims 22, 367379.

Somboontanont W, Sloane PD, Floyd FJ, Holditch-Davis D, Hogue CC \& Mitchell CM (2004) Assaultive Behavior in Alzheimer's Disease: Identifying Immediate Antecedents During Bathing. Journal of Gerontological Nursing 30, 22-29.

Steinert T (1995) Aggression bei psychisch Kranken (Aggression in mentally ill). Ferdinand Enke Verlag, Stuttgart.

Tak S, Sweeney M, Alterman T, Baron S \& Calvert G (2010) Workplace assaults on nursing assistants in US nursing homes: a multilevel analysis. American Journal of Public Health 100, 1938-1945.

Testad I, Aasland AM \& Aarsland D (2007) Prevalence and correlates of disruptive behavior in patients in Norwegian nursing homes. International Journal of Geriatric Psychiatry 22, 916-921.

Therneau TM \& Atkinson B (2011) rpart: Recursive Partitioning. Available at: http://cran.rproject.org/web/packages/rpart/index.html [accessed 01.06.2012].

Voyer P, Verreault R, Azizah G, Desrosiers J, Champoux N \& Bedard A (2005) Prevalence of physical and verbal aggressive behaviours and associated factors among older adults in long-term care facilities. BMC Geriatrics 5, 13.

Whall A, Colling K, Kolanowski A, Kim H, Son H, DeCicco B, Ronis D, Richards K, Algase D \& Beck C (2008) Factors associated with aggressive behavior among nursing home residents with dementia. The Gerontologist 48, 721-731.

Yeom H \& Watson NM (2009) Patterns of Antecedents of Catastrophic Reactions in Nursing Home Residents with Dementia in the United States. Asian Nursing Research 3, 99-110.

Zeller A, Dassen T, Kok G, Needham I \& Halfens RJG (2011) Nursing home caregivers' explanations for and coping strategies with residents' aggression: a qualitative study. Journal of Clinical Nursing 20, 2469-2478. 
Zeller A, Hahn S, Needham I, Kok G, Dassen T \& Halfens R (2009) Aggressive behavior of nursing home residents toward caregivers: a systematic literature review. Geriatric Nursing 30, 174-187. 


\section{Chapter 5}

Dealing with aggressive behaviour in nursing homes: caregivers' use of recommended measures

Zeller A, Müller M, Needham I, Dassen T, Kok G \& Halfens RJG (submitted in the Journal of Clinical Nursing 2013) Dealing with aggressive behaviour in nursing homes: caregivers' use of recommended measures 


\subsection{Abstract}

\section{Aims and objectives}

This study identifies groups of caregivers in terms of their use of measures for dealing with resident aggression and the differences between these groups related to their characteristics.

\section{Background}

Caregivers in nursing home are confronted with a major challenge when faced with the aggressive behaviour of residents. Therefore, the application of recommended measures is important in supporting caregivers and promoting safety for residents.

\section{Design}

A cross-sectional survey was conducted.

\section{Methods}

A total of 804 caregivers working in 21 Swiss nursing homes provided data. The questionnaire used was based on published recommendations regarding management of aggressive behaviour and amendments by experts.

\section{Results}

The most widely used measure aimed to calm down the resident and to understand the meaning of aggressive behaviour. Physical activities were applied by around $50 \%$ of the respondents and interdisciplinary case reviews as well as standardised instruments for assessment and documentation were used by less than $50 \%$.

Caregiver characteristics such as employment level, support from superiors, institutionalised support for affected caregivers, and training in aggression management are associated with their use of recommended measures. Furthermore, caregivers' competence in empathising with the residents' perspective in connection with their professional experience has a positive influence on applying recommended measures.

\section{Conclusion}

Caregivers use multifaceted measures in understanding the meaning of underlying aggression but there is a certain failure to use standardised instruments.

Caregivers differ significantly in the frequency of their application of recommended measures. Support from superiors and assistance for affected caregivers positively influences their use of measures, whereas training in aggression management leads to less use.

\section{Relevance to clinical practice}

Findings show the importance of support from superiors and institutionalised assistance for affected caregivers. Caregiver competence in empathising with the residents' perspective is important in using person-centred approaches in the care of residents with aggressive behaviour. 


\subsection{Introduction}

Dealing with aggressive behaviour from residents is a complex and challenging task for health care staff in nursing homes. The risk of health care staff experiencing aggression by nursing home residents is high, with prevalence rates for health care staff averaging $60-80 \%$ (Gerberich et al. 2006, Camerino et al. 2008, Franz et al. 2010). Several studies found that residents with a cognitive impairment show more aggressive behaviour (Talerico et al. 2002, Voyer et al. 2005, Testad et al. 2007). Oh et al. (2004) compared aggressive with nonaggressive residents and found that aggressive residents had significantly more cognitive impairment, more pain, and had stayed longer in the nursing home than non-aggressive residents (Oh et al. 2004).

A recently conducted study in Swiss nursing homes found that $80 \%$ of the caregivers had experienced aggressive behaviour in the last twelve months and $38 \%$ in the week prior to data collection (Zeller et al. 2012). Previous studies demonstrated that caring for residents with aggressive behaviour is associated with high burden and stress for caregivers in nursing homes (Gates et al. 2003, Morgan et al. 2005). Possible emotions of caregivers experiencing resident aggression are anxiety, shame, guilt, anger or resignation (Gates et al. 2003, Needham et al. 2005b, Lundström et al. 2007). As a consequence, caregivers may sometimes become aggressive towards residents and neglect residents' wishes and/or needs (Aström et al. 2004). Graneheim et al. (2005) describe the interaction with people suffering from dementia and behavioural disturbances as a balancing act between contradictory positions; namely, meeting the person in my versus her/his world, feeling powerless versus capable, and feeling rejected versus accepted.

In supporting caregivers and promoting safety for residents it is important that caregivers use recommended, evidence based measures when confronted with aggression. The aim of this study is to identify groups of caregivers regarding their use of different measures for dealing with resident aggression and to determine if these groups differ in their basic characteristics.

\section{Recommended measures}

To provide appropriate care and support for residents with aggressive behaviour in nursing homes is a challenging task for caregivers. The recommendations developed for the Germanspeaking countries can support caregivers in dealing with resident aggression (Bundesministerium für Gesundheit 2006).

These recommendations focus on residents suffering from dementia and showing aggressive behaviour. As there are no general guidelines for the German-speaking countries available and almost half of residents in nursing homes have dementia and display aggres- 
sion, these guidelines are relevant for nursing homes (Bundesministerium für Gesundheit 2006).

They contain the following recommendations: As a basic intervention they recommend the use of 'understanding diagnostic' which puts the perspective of the person with aggressive behaviour in the centre of the care process with the aim of understanding residents' behaviour and identifying reasons for resident aggression. The process of using an 'understanding diagnostic' can be conducted by means of the Need-Driven, Dementiacompromised Behaviour Model (NDB-Model) (Algase et al. 1996). Furthermore, the authors recommend the use of assessment instruments for recording aggressive behaviour on the grounds that instruments are helpful in objectifying caregivers' observations. Validation therapy (Feil 1993) and reminiscence work (Zanetti et al. 2002) are also part of the recommendations. The aim of validation therapy is to confirm residents' emotions and to understand the inner world of persons suffering from dementia, whereas reminiscence work supports the well-being of residents by recollecting past experiences or events. Further suggestions in these guidelines are physical touch and basic stimulation, which can be understood as an attempt to establish communication with other people. Contact is supplied by touch and movement with the aim of addressing basic somatic senses like vestibular and vibratory perception (Bienstein \& Fröhlich 2012).

The last recommendation in the guidelines refers to 'physical activities'. They suggest integrating physical activities and the promotion of body consciousness in all daily activities; passive sequences of movements are also helpful. However, there is limited evidence that physical activities reduce aggression in nursing home residents' diagnosed with Alzheimer's disease (Verkaik et al. 2005, National Collaborating Centre for Mental Health 2006, revised 2011).

\section{Background}

Zeller et al. (2011) found in a qualitative study that caregivers endeavour to find out residents' habits and needs, they continue the quest for new solutions and try to pacify and distract when aggressive behaviour occurs in care situations. Confronting residents with their behaviour is used in some situations and coercive measures are used when caregivers see no other alternatives. The study, however, yielded no information on whether caregivers apply a systematic approach in caring for residents with aggressive behaviour or whether they plan long-term measures as described in the recommendations, with the aim of preventing or reducing aggressive behaviour whenever possible. Therefore, in a next step, we conducted a survey among caregivers in which the use of the above mentioned measures, the results of the qualitative investigation and amendments suggested by experts in the field of long-term care had been taken into account. The purpose of this study was to describe how often care- 
givers in Swiss nursing homes use the recommended measures in caring for residents displaying aggression and if there is an association between the approaches used and the sociodemographic characteristics of caregivers.

There are many definitions and descriptions of behavioural problems among nursing home residents. In this study aggressive behaviour is conceptualized according to the operationalization of McKenna (2004), which delineates verbal aggression as the use of abusive or offensive language (including sexually abusive language), derogatory remarks, or profane or obscene comments; threats as warnings of intent to injure another person with or without an object or weapon; harassment (including sexual); and physical intimidation and physical assault, including slapping, pinching, pushing, shoving, spitting, or kicking, with or without the use of weapons.

\subsection{Method}

\section{Design}

In a retrospective cross-sectional survey participants were asked how often they use recommended measures for managing resident aggression with the aim of identifying different groups of caregivers regarding the frequency of measures used and related characteristics.

\section{Participants and data collection}

In total 21 nursing homes, located in urban and rural regions in the German-speaking part of Switzerland participated in the study. With regard to their legal and economic status, 14 institutions were funded by public funding and seven institutions by private sponsorship. They were recruited by means of an announcement in two national nursing journals. The nursing homes differed in size between 25 and 705 beds. The inclusion criteria were caregivers' informed consent, caregivers' direct contact with residents, and an adequate command of the German language.

The data collection for the study was conducted between November 2010 and April 2011. The data were collected by means of a questionnaire. The questionnaires and written information regarding the study and its aims were sent to the directors of the nursing homes for distribution on the wards. After consultation with the directors, the caregivers of all wards in 14 nursing homes and in seven nursing homes of one to three wards were recruited. Accordingly, 1,572 questionnaires were distributed to potential respondents in the 21 nursing homes. Each questionnaire was in an open, stamped envelope, which participants filled in and returned directly and anonymously to the principal researcher. Participating nursing homes were coded to check the response rate. 


\section{Instrument}

The questionnaire used in this survey consists of two parts. The first part pertains to staff characteristics, e.g. gender, educational level, professional experience, employment level, training in aggression management and exposure to aggressive behaviour. The second part refers to the German-language recommendations (Bundesministerium für Gesundheit 2006). Due to the fact that no proper tool was available to measure caregivers' use of these recommendations and to the authors' knowledge also no instrument in another language is consistent with the research question, a measurement tool was developed by the first author.

This tool consists of 22 items and was referred to as the 'Resident Aggression Management Inventory' (RAMI). The items on the questionnaire were designed to depict 1) the operationalization of the recommendations described in the introduction as well as 2) the measures mentioned in a qualitative study (Zeller et al. 2011). The first draft of the questionnaire was critically assessed by seven experts in the field of long-term care in nursing homes regarding completeness of content and comprehensibility. The expert-group added seven Items which 3) reflect important measures in caring for resident with aggressive behaviour (see Table 2). The questionnaire employs a Likert-type format with four choices representing the frequency of self-reported measures ('always', 'frequently', 'sometimes', 'never'). Subsequently, pilot testing of the questionnaire with regard to clarity and completeness of the content was conducted in a nursing home not participating in the study. In this pilot test, 135 caregivers completed the questionnaire and attested that the questionnaire gave a broad overview of measures used in dealing with resident aggression. Thus, no further changes in the questionnaire were required.

\section{Ethical considerations}

This study was approved by the ethics committees of the cantons of the participating nursing homes. Nursing homes that were willing to participate received written information regarding the study aims, methods, questionnaire and the voluntary nature of participation. Confidentiality and anonymity were ensured.

\section{Analysis}

Standard descriptive statistics for describing and summarizing the data were calculated using IBM SPSS Version 19 (IBM Inc., Armonk, NY, USA). To identify groups of caregivers based on their answers to the RAMI, a hierarchical agglomerative cluster analysis by Ward's method was carried out. This analysis and the subsequent multiple regression analysis were performed with the R statistical package Version 2.12.1 (R Development Core Team 2012) and the additional $\mathrm{R}$ package cluster (Maechler et al. 2011). Stepwise variable selection in the 
regression analysis was based on the Akaike information criterion (AIC). Interactions were also tested and the usual residual plots were checked to detect possible violations of the model assumptions.

\subsection{Results}

\section{Participants}

The questionnaire was returned by 814 caregivers from 21 nursing homes, which corresponds to a response rate of $51.8 \%$. The response rate varied among participating nursing homes from $32.6 \%$ to $92.5 \%$. Ten questionnaires were incomplete; thus 804 questionnaires were used for data analysis. $42.9 \%$ registered nurses participated in the study, $41.7 \%$ had more than 15 years experience in health care; $58.8 \%$ worked full-time and $72.8 \%$ spent over $60 \%$ of their working hours in direct contact with residents. In all, $44.3 \%$ of the participants were trained in the management of aggressive behaviour and $81.6 \%$ had been exposed to aggressive behaviour twelve months prior to data collection. The participants who had experienced aggression in the last twelve months were requested to fill in the RAMI. Further characteristics of participants are shown in Table 5.1.

Table 5.1: Characteristics of the sample

\begin{tabular}{llrl}
\hline \multirow{2}{*}{ Demographic characteristics } & & \multicolumn{2}{c}{ Total $(\mathrm{n}=804)$} \\
\cline { 2 - 4 } Gender & Female & $\mathrm{n}$ & $(\%)$ \\
& Male & 749 & $(93.2)$ \\
& Missing & 50 & $(6.2)$ \\
Age (years) & & 5 & $(0.6)$ \\
& $<17$ & & \\
& $18-29$ & 13 & $(1.6)$ \\
& $30-45$ & 179 & $(22.3)$ \\
& $>46$ & 250 & $(31.1)$ \\
Educational level & Missing & 358 & $(44.5)$ \\
including nurses in & & 4 & $(0.5)$ \\
training & Registered nurses & & \\
& Enrolled nurses* & 345 & $(42.9)$ \\
& Nursing assistants & 207 & $(25.7)$ \\
Professional experience in & Other caregivers & 212 & $(26.4)$ \\
health care (years) & Missing & 35 & $(4.4)$ \\
& & 5 & $(0.6)$ \\
& $5-9$ & & \\
& $10-15$ & 127 & $(15.8)$ \\
& $>15$ & 150 & $(18.7)$ \\
& Missing & 187 & $(23.2)$ \\
& & 335 & $(41.7)$ \\
& & 5 & $(0.6)$ \\
\hline
\end{tabular}




\begin{tabular}{|c|c|c|c|}
\hline \multirow{5}{*}{$\begin{array}{l}\text { Experience in present posi- } \\
\text { tion (years) }\end{array}$} & $<1$ & 98 & $(12.2)$ \\
\hline & $1-4$ & 315 & (39.2) \\
\hline & $5-10$ & 213 & (26.5) \\
\hline & $>10$ & 172 & (21.4) \\
\hline & Missing & 6 & $(0.7)$ \\
\hline \multirow[t]{4}{*}{ Employment level (\%) } & $80-100$ & 473 & $(58.8)$ \\
\hline & $51-79$ & 180 & (22.4) \\
\hline & $\leq 50$ & 147 & (18.3) \\
\hline & Missing & 4 & $(0.5)$ \\
\hline \multirow{4}{*}{$\begin{array}{l}\text { Proportion of time per day } \\
\text { spent in direct contact } \\
\text { with resident (\%) }\end{array}$} & $<30$ & 29 & (3.6) \\
\hline & $30-60$ & 184 & (22.9) \\
\hline & $>60$ & 585 & $(72.8)$ \\
\hline & Missing & 6 & $(0.7)$ \\
\hline \multirow{3}{*}{$\begin{array}{l}\text { Trained in management of } \\
\text { aggressive behaviour }\end{array}$} & Yes & 356 & (44.3) \\
\hline & No & 445 & (55.3) \\
\hline & Missing & 3 & $(0.4)$ \\
\hline $\begin{array}{l}\text { Exposed to aggressive be- } \\
\text { haviour in the past } 12 \\
\text { months }\end{array}$ & & 656 & (81.6) \\
\hline
\end{tabular}

*Caregivers with a two- or three-year education not at diploma level

\section{Caregivers' application of recommended measures}

Descriptive results on the frequency of application of recommended measures are shown in Table 5.2. From the participants' point of view 'calming down the resident' and 'searching for reasons explaining aggressive behaviour' are the most commonly used measures, with around $90 \%$ of caregivers mentioning that they always or frequently use these measures. Further commonly used measures reported by around $80 \%$ to $87 \%$ of participants were 'taking the residents' perspective in order to understand the meaning of the behaviour', 'integrating biographical information', and 'finding out underlying physical reasons for aggressive behaviour'. Roughly $80 \%$ stated that they describe aggressive behaviour in the nursing report or in an aggression protocol and around 75\% applied measures for validation and always or frequently adapted the daily structure to residents' needs.

Measures used always or frequently by approximately $50 \%$ of participants were 'carrying out activities for memory stabilization', 'performing interdisciplinary case reviews', 'obtaining information from relatives', 'enhancing mobilization and physical activities', and 'meeting aggression with humour'. As can be seen in Table 2, less than $30 \%$ of participants reported that they 'distract resident by singing', 'change the environment', or 'use a standardized report form for documentation of aggressive behaviour' as measures for dealing with resident aggression. Aromatherapy is always or frequently applied by around $10 \%$ and 'exercising physical restraint towards residents' was mentioned by only $4.6 \%$ of participants. 
This measure is not a recommendation in guidelines, but experts in the field recommended including this point in the questionnaire. Further descriptive results regarding application of measures for management of resident aggression are shown in Table 5.2. 


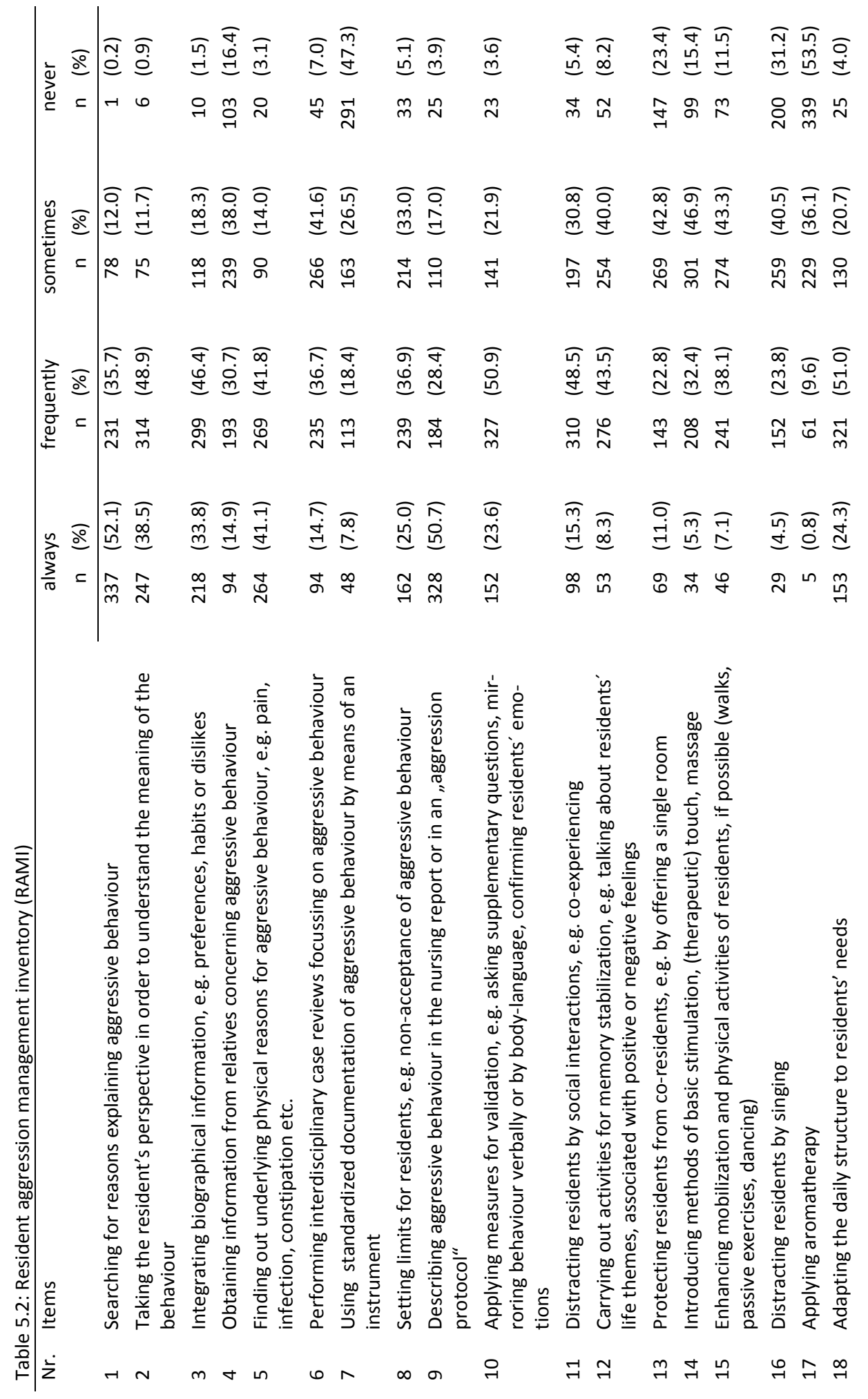




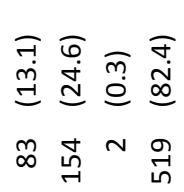

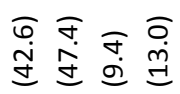

오송ำ

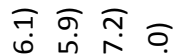

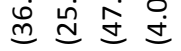

్ㅗ웜

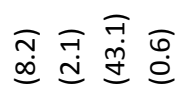

กำ 욧

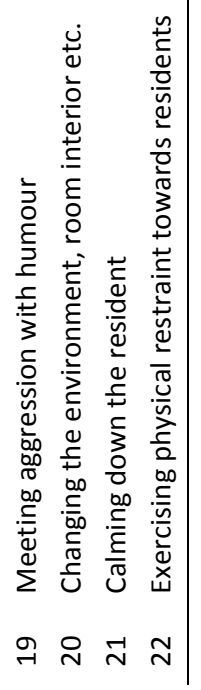




\section{Caregiver characteristics associated with the use of recommended measures}

Cluster analysis was used to classify caregivers into groups according to their answers on suggested measures on a scale coded from 1 (never) to 4 (always). The dendrogram of respondents obtained by the Ward's method is shown in Figure 5.1. Two well differentiated clusters can be seen. The two groups did not differ in the sorts of measures they use, but they do differ in the frequency of application of these measures. The sum of the scores on the individual 22 items, coded from 1 to 4 , was therefore calculated. The difference of this sum score between the two groups was highly significant $(p<.001)$. This indicates that some caregivers apply recommended measures far more often than others.

In the next step a multiple regression analysis was conducted with the sum score as the response variable. All demographic variables, caregiver's confidence in managing aggressive behaviour and institutional factors such as support from a superior were used as explanatory variables. The explanatory variables of the final model are shown in Table 5.3. Caregivers with an employment level of over $80 \%$ apply the recommended measures significantly more often. This is also the case among caregivers who receive support from superiors and when institutionalised assistance for affected caregivers is available. Caregivers who do not know if their institution has a reporting system for aggressive incidents apply recommended measures significantly more frequently than those without a reporting system. Further, caregivers' judgement of the importance of training in aggression management seems to be a predicting factor for their application of recommended measures as well as caregiver's confidence in managing aggressive behaviour $(p<.01)$.

Finally, there is an interaction between caregivers' perceived competence in empathising with residents' perspective and their professional experience in health care. For caregivers with short professional experience, competence in empathising with residents' perspective has no influence on applying recommended measures. However, there is a positive relationship between competence in empathising with residents' perspective and applying recommended measures for caregivers with more than nine years of professional experience $(5-9$ years $=p \leq .01,10-15$ years $=p<.001,>15$ years $=p<.001)$. A significant negative association with the application of recommended measures is reflected in the results for other caregivers $(p<.05)$ and for caregivers trained in aggression management $(p<.05)$. 


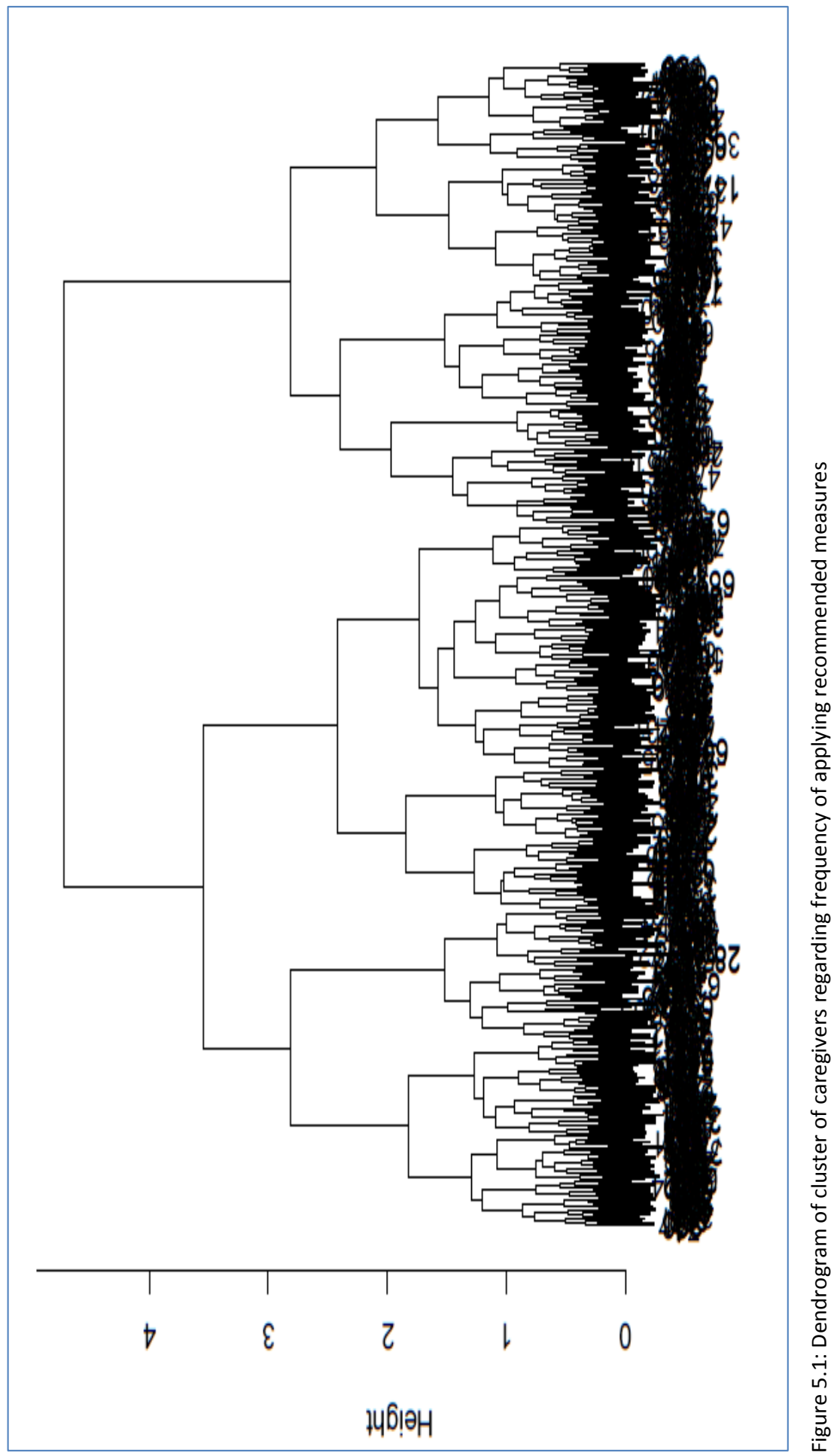




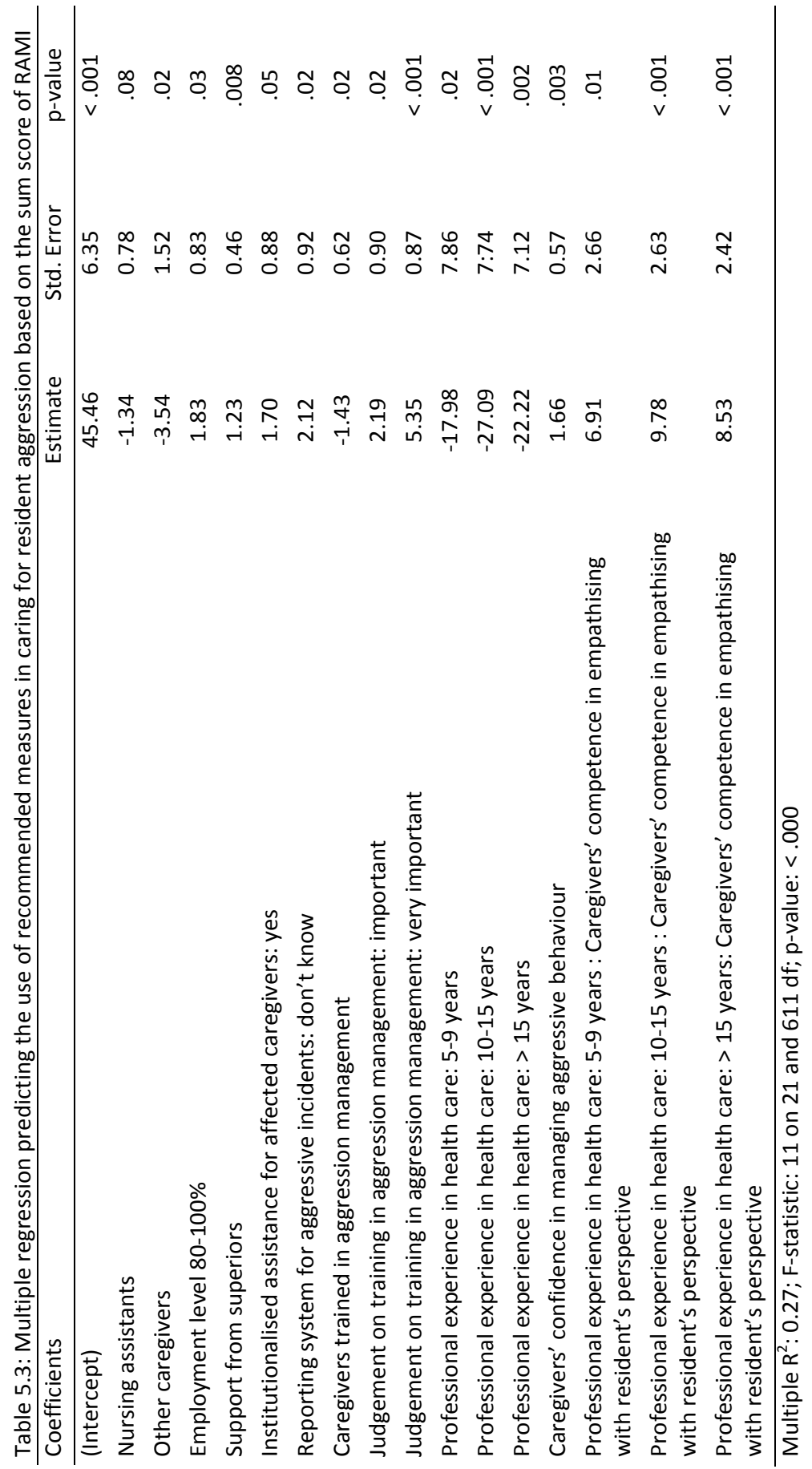




\subsection{Discussion}

The aim of this study was to identify different groups of caregivers in Swiss nursing homes regarding the frequency of measures used and related characteristics.

\section{Caregivers' application of recommended measures}

The results show that 'calming down the resident' is the most widely used measure in dealing with aggressive behaviour by residents. This finding is in line with a qualitative investigation of caregivers in Swiss nursing homes in which participants mentioned that they try first and foremost to pacify the situation (Zeller et al. 2011), and also with a prospective study in which more than $80 \%$ of caregivers tried to stop aggressive behaviour with calming talk and calming measures, like distracting (Glaus Hartmann 2006). Pryor (2006) also emphasised the calming approach as an essential element of all interactions with patients who show aggressive behaviour. Nevertheless, it should be taken into account that this answer could be based on social desirability.

Furthermore, a high percentage of participants stated that they take residents' perspective to understand the meaning underlying aggression and integrate biographical information. These results indicate that participating caregivers endeavoured to gain insight into the resident's world with the aim of understanding his or her behaviour. In a framework of optimal therapeutic interventions for managing verbal and behavioural aggression among patients with dementia, Finfgeld-Connet (2009) described 'entering in the patients' world' as an important measure within the scope of patient-centred care. Caregivers are encouraged to become a part of the patient's lived experience and to strive for mutual understanding and action (Miller 1997, Finfgeld-Connett 2009, Zeller et al. 2011). Also, frequently mentioned interventions like searching for explanatory reasons, and finding out underlying physical reasons for aggressive behaviour can be interpreted as caregiver attempts to understand a resident's aggression by viewing aggression as a part of his or her condition. An unsurprising result is that about two-thirds of participants mentioned that they use validation, as in the last few years many caregivers in Swiss nursing homes received training in validation. Moreover, in the study by Jervis (2002), validation was a common approach used in dealing with residents' aggression. Although research results regarding the effectiveness of validation are inconsistent, this approach is integrated in the recommendation as a basis for the care of people with dementia who show challenging behaviour (Bundesministerium für Gesundheit 2006).

Considerably less frequently reported measures were 'performing interdisciplinary case reviews' and 'obtaining information from relatives'. Although these measures contribute to obtaining a comprehensive picture of residents' situation and to identifying possible reasons 
for aggressive behaviour (Foley et al. 2003), caregivers seem not to use these measures routinely. Despite the fact that the benefit of case reviews is based primarily on experience, the recommendations (Bundesministerium für Gesundheit 2006) advise the implementation for residents who, due to their aggressive behaviour, are at risk of receiving inappropriate care.

Even measures like 'enhancing mobilisation and physical activities' and 'carrying out activities for memory stabilisation' were used always or frequently by only about half of participants. As physical activities are clearly recommended as an intervention to reduce aggression in nursing home residents diagnosed with Alzheimer's disease (Verkaik et al. 2005, Desai et al. 2012), caregivers should be supported in undertaking such activities as a preventive intervention for residents who show aggressive behaviour.

A surprising result is the apparent reluctance to use standardised documentation of aggressive behaviour by means of an instrument. This indicates either those instruments regarding assessment and standardised documentation related to aggressive incidents are not widely used in Swiss nursing homes or that caregivers are unwilling to use available instruments. In a study by Morgan et al. (2008), caregivers stated that when they reported experiencing aggressive behaviour from a resident they felt that they were blamed for the incident. In light of the fact that about $80 \%$ of participants mentioned describing aggressive behaviour in the nursing report, we can assume the lack of appropriate tools to be a reason for this low rate of routinely used standardised documentation of aggressive behaviour. Several guidelines recommend a comprehensive assessment and documentation of the characteristics of those residents who display aggressive behaviour (Vickland et al. 2012), and the study by Glaus-Hartmann (2006) underlines the importance of standardised documentation, as it allows the discovery of patterns in aggressive behaviour which support targeted care planning for affected residents. Kovach et al. (2006) note the frequency of caregivers who treated aggressive behaviour without conducting prior assessment as worrisome: assessment is fundamental to the nursing process, and emphasised as the cornerstone of all care.

The use of physical restraint on residents showing aggressive behaviour seems to be very rare. It is possible that this result reflects the policy in Swiss nursing homes against the use of physical restraint. Some studies reveal that caregivers use physical restraint as a last resort (Foley et al. 2003, Zeller et al. 2011). Nevertheless, we have to take the problem of the social desirability response bias into consideration. It is well known that residents exhibiting aggressive behaviour are at risk of experiencing physical restraint (Kirkevold et al. 2004, Bredthauer et al. 2005), despite the fact that physical restraint can increase resident aggression (Ryden et al. 1999, Foley et al. 2003). Although the rate of caregivers who use physical restraint is very low, it is important to pay attention to the frequency of this measure, as it is not consistent with appreciative care and respect for residents' dignity. 


\section{Caregiver characteristics associated with application of recommended measures}

The results show a high rate of application of recommended measures among caregivers who have an employment level of over $80 \%$, get support from their superiors and work in an institution where assistance for affected caregivers is available. Support from superiors is important for caregivers who have to deal with aggressive behaviour from residents, as a study by Skovdahl et al. (2003) underlines: Caregivers who felt supported by colleagues and the management described their work as stimulating and challenging despite the fact that aggressive behaviour could arise. They felt that they worked in an innovative climate, and continuously exchanged experiences regarding the care of affected residents and supported each other. They spent a great deal of time on residents who needed attention due to aggressiveness, or on the aim of preventing aggressive behaviour (Skovdahl et al. 2003). It is conceivable that caregivers with an employment level of over $80 \%$ are more involved in an exchange of experience with colleagues, and have more practice in dealing with residents' aggression. A further reason for the higher use of recommended measures by this caregivergroup may be higher participation in nursing home internal trainings related to this topic compared with caregivers with a lower employment level.

A controversial result is that caregivers who judge training in aggression management to be important and feel confident in managing this behaviour use recommended measures significantly more often, whereas caregivers who received training in aggression management use it significantly less. The assumption is that there is a relationship between the way caregivers view residents and the way they manage aggression (Chrzescijanski et al. 2007). Kitwood (1997) maintained that the essence of person-centred care is a focus on the person with dementia rather than the disease. This approach can open the perceptions of caregivers to various causes of resident aggression and may result in applying a greater variety of measures. The assumption is that caregivers' views on residents who display aggressive behaviour play a more important role related to the use of measures in dealing with aggressive behaviour than training in aggression management. This may be an explanation for the result that caregivers who are motivated to attend training in aggression management or feel confident in dealing with aggressive behaviour are more engaged in the use of the recommendations mentioned because of their attitude towards affected residents.

Furthermore, the results suggest that training in aggression management is no guarantee that recommendations will be used. It should be noted that, to the authors' knowledge, aggression management training in Switzerland is not specified in situations of aggressive resident behaviour in nursing homes. The training programme was developed in the context of mental health problems and the recommended measures are only a small part of the training (Needham et al. 2005a, Zeller et al. 2006). 
The result that caregivers with professional experience of over 5 years who feel competent in empathising with residents' perspective apply the recommended measures more often than those with less professional experience underlines the assumption that a comprehensive view of the resident's situation leads to an increased use of various measures for dealing with resident aggression. Furthermore the result indicates that professional experience is an important factor in combination with caregivers' judgement of their ability to empathise with a resident's' perspective. Nakahira et al. (2009) elicited a positive association between caregiver attitudes to resident aggression and the use of need-based approaches to minimise aggression as well as the positive influence of years of professional experience. In contrast a recent study by Morgan et al. (2012) reports that caregivers who attributed most aggressive behaviour to resident-related factors, particularly dementia or cognitive impairment, were not optimistic that anything could be done to prevent further aggression, or that they personally could control or change the cause of aggression. This result underlines the importance of the caregivers' view of residents' situation and their competence 'to go into residents' world'

The group of 'other caregivers' who used recommended measures significantly less often consisted of people like auxiliary personnel or people of other occupational groups, such as occupational therapists who are partly involved in resident care. Therefore it is not surprising that this group use the recommended measures considerably less frequently.

\subsection{Conclusion}

This study provides insight into caregivers' application of recommended measures in dealing with resident aggression in nursing homes. The results demonstrate that participants in this study use multifaceted measures which enable them to calm the situation as well as to understand the meaning of residents' aggressive behaviour. Therefore we can assume that caregivers in Swiss nursing homes pursue a person-centred approach, as recommended for dealing with aggressive behaviour (Bundesministerium für Gesundheit 2006, Enmarker et al. 2011).

Nevertheless, improvements should be taken into consideration, namely, the implementation of interdisciplinary case reviews, the use of instruments for standardised assessments and documentation of residents' aggression as well as the increased application of measures to enhance mobilisation and physical exercises. Furthermore, this study reveals a significant difference among caregivers in how frequently they apply the recommended measures. Important factors which encourage caregivers in the use of recommended measures are support from superiors and available assistance for caregivers who are confronted with aggres- 
sive behaviour. Even caregivers' professional experience and their competence to empathise with the resident's perspective are relevant factors influencing use of the measures under investigation. Nursing homes should take these factors into consideration when they develop their care concepts. Training programmes for aggression management should be critically reviewed regarding their content related to resident aggression. In further research the results of this study should be compared with observations.

\section{Limitations}

One limitation of this study is the use of a nonprobability sample. Despite the satisfying response rate, it is possible that those caregivers most interested in their practice responded to the survey and their view may differ from that of non-respondents. A further potential limitation is the first use of the RAMI which was based only on face validity. The contents of the instrument need further development regarding caregivers' practice in dealing with aggressive behaviour as well as further testing in practice with regard to validity and reliability. The use of a self-report instrument is a further limitation, as self-report instruments highlight what respondents say they do but may not reflect actual practice. Although participants' anonymity may have reduced this effect, it is suggested that future research should include an observation of caregivers' actual practice regarding application of recommended measures, thus reducing this potential limitation.

\section{Relevance to clinical practice}

The findings show the importance of support from superiors and assistance in the use of recommended measures for nursing home caregivers who have to deal with resident aggression. Therefore these findings should be taken into consideration in the development of care concepts in nursing homes. Caregivers' competence in empathising with the resident's perspective should be encouraged because it increases the use of so-called person-centred approaches in dealing with aggressive behaviour. A critical result is the failure to use instruments for standardised assessments and documentation of residents' aggression and the less frequent application of the recommended measures by caregivers trained in aggression management. 


\section{Acknowledgements}

The authors thank all participants of the study who completed the survey.

\section{Contributions}

Study design: AZ, RJGH, TD; data collection and analysis: $A Z, M M$ and manuscript preparation: AZ, MM, IN; TD, GK, RJGH.

\section{Conflict of interest}

None. 


\subsection{References}

Algase DL, Beck C, Kolanowski A, Whall A, Berent S, Richards K \& Beattie E (1996) Needdriven dementia-compromised behavior: An alternative view of disruptive behavior. American Journal of Alzheimer's Disease and Other Dementias 11, 10-19.

Aström S, Karlsson S, Sandvide A, Bucht G, Eisemann M, Norberg A \& Saveman B (2004) Staff's experience of and the management of violent incidents in elderly care. Scandinavian Journal of Caring Sciences 18, 410-416.

Bundesministerium für Gesundheit (2006) Rahmenempfehlungen zum Umgang mit herausforderndem Verhalten bei Menschen mit Demenz in der stationären Altershilfe (Guidelines regarding handling of challenging behaviour by persons with dementia in residential facilities). Available at: https://www.bundesgesundheitsministerium.de/fileadmin/dateien/ Publikationen/Pflege/Berichte/Bericht_Rahmenempfehlungen_zum_Umgang_mit_ herausforderndem_Verhalten_bei_Menschen_mit_Demenz_in_der_stationaeren_Altenhilfe.pdf [accessed 01 June 2012].

Bienstein C \& Fröhlich A (2012) Basale Stimulation ${ }^{\circledR}$ in der Pflege. Die Grundlagen, 7th edn. Hans Huber, Bern.

Bredthauer D, Becker C, Eichner B, Koczy P \& Nikolaus T (2005) Factors relating to the use of physical restraints in psychogeriatric care: a paradigm for elder abuse. Zeitschrift für Gerontologie und Geriatrie 38, 10-18.

Camerino D, Estryn-Behar M, Conway P, van Der Heijden BIJM \& Hasselhorn H (2008) Workrelated factors and violence among nursing staff in the European NEXT study: a longitudinal cohort study. International Journal of Nursing Studies 45, 35-50.

Chrzescijanski D, Moyle W \& Creedy D (2007) Reducing dementia-related aggression through a staff education intervention. Dementia 271, 271-286.

Desai AK, Schwartz L \& Grossberg GT (2012) Behavioral disturbance in dementia. Current Psychiatry Reports 14, 298-309.

Enmarker I, Olsen R \& Hellzen O (2011) Management of person with dementia with aggressive and violent behaviour: a systematic literature review. International Journal of Older People Nursing 6, 153-162.

Feil N (1993) The Validation breakthrough. Simple techniques for communicating with people with Alzheimer's - Type Dementia. Health Professions Press, Baltimore.

Finfgeld-Connett D (2009) Management of aggression among demented or brain-injured patients. Clinical Nursing Research 18, 272-287. 
Foley KL, Sudha S, Sloane PD \& Gold DT (2003) Staff perceptions of successful management of severe behavioural problems in dementia special care units. Dementia 2, 105-124.

Franz S, Zeh A, Schablon A, Kuhnert S \& Nienhaus A (2010) Aggression and violence against health care workers in Germany - a cross sectional retrospective survey. BMC Health Services Research 10, 51.

Gates D, Fitzwater E \& Succop P (2003) Relationships of stressors, strain, and anger to caregiver assaults. Issues in Mental Health Nursing 24, 775-793.

Gerberich SG, Church TR, McGovern PM, Hansen HE, Nachreiner NM, Geisser MS, Ryan AD, Mongin. S. J. \& Watt GD (2006) An epidemiological study of the magnitude and consequences of work related violence: the Minnesota Nurses' Study. Occupational and Environmental Medicine 61, 495-503.

Glaus Hartmann M (2006) Aggressionsmuster erkennen und Auslöser reduzieren (Recognizing aggression and relieving stress). Krankenpflege 99, 24-26.

Graneheim U, Isaksson U, Ljung I \& Jansson L (2005) Balancing between contradictions: the meaning of interaction with people suffering from dementia and "behavioral disturbances". International Journal of Aging \& Human Development 60, 145-157.

Jervis LL (2002) Contending with "problem behaviors" in the nursing home. Archives of Psychiatric Nursing 16, 32-38.

Kirkevold O, Sandvik L \& Engedal K (2004) Use of constraints and their correlates in Norwegian nursing homes. International Journal of Geriatric Psychiatry 19, 980-988.

Kitwood T (1997) Dementia reconsidered. The person comes first. Open University Press, Buckingham.

Kovach CR, Kelber ST, Simpson M \& Wells T (2006) Behaviors of nursing home residents with dementia: examining nurse responses. Journal of Gerontological Nursing 32, 13-21.

Lundstrom M, Saveman B, Eisemann M \& Astrom S (2007) Prevalence of violence and its relation to caregivers' demographics and emotional reactions: an explorative study of caregivers working in group homes for persons with learning disabilities. Scandinavian Journal of Caring Sciences 21, 84-90.

Maechler M, Rousseeuw P, Struyf A, Hubert M \& Hornik K (2011) cluster: Cluster Analysis Basics and Extensions. Available at: http://cran.r-project.org/web/packages/cluster/ [accessed 01 June 2012].

McKenna K (2004) Study of work-related violence. Committee on Workplace Violence, North Eastern Health Bord, Ireland. 
Miller MF (1997) Physical aggressive resident behavior during hygienic care. Journal of Gerontological Nursing 23, 24-39.

Morgan DG, Cammer A, Stewart NJ, Crossley M, D'Arcy C, Forbes DA \& Karunanayake C (2012) Nursing aide reports of combative behavior by residents with dementia: results from a detailed prospective incident diary. Journal of the American Medical Directors Association 13, 220-227.

Morgan DG, Crossley MF, Stewart NJ, D'Arcy C, Forbes DA, Normand SA \& Cammer AL (2008) Taking the hit: focusing on caregiver "error" masks organizational-level risk factors for nursing aide assault. Qualitative Health Research 18, 334-346.

Morgan DG, Stewart NJ, D'Arcy C, Forbes D \& Lawson J (2005) Work stress and physical assault of nursing aides in rural nursing homes with and without dementia special care units. Journal of Psychiatric and Mental Health Nursing 12, 347-358.

Nakahira M, Moyle W, Creedy D \& Hitomi H (2009) Attitudes toward dementia-related aggression among staff in Japanese aged care settings. Journal of Clinical Nursing 18, 807816.

National Collaborating Centre for Mental Health (2006 revised 2011) Dementia. Supporting people with dementia and their carers in health and social care. NICE clinical guideline 42. Available at: http://www.nice.org.uk/nicemedia/live/10998/30317/30317.pdf. [accessed 01 December 2012].

Needham I, Abderhalden C, Halfens RJG, Dassen T, Haug HJ \& Fischer JE (2005a) The effect of a training course in aggression management on mental health nurses' perceptions of aggression: a cluster randomised controlled trial. International Journal of Nursing Studies $\mathbf{4 2}$, 649-655.

Needham I, Abderhalden C, Halfens RJG, Fischer JE \& Dassen T (2005b) Non-somatic effects of patient aggression on nurses: a systematic review. Journal of Advanced Nursing 49, 283-296.

Oh H, Eom M \& Kwon Y (2004) A study on aggressive behavior among nursing home residents with cognitive impairment. Taehan Kanho Hakhoe Chi 34, 1451-1459.

Pryor J (2006) What do nurses do in response to their predictions of aggression? Journal of Neuroscience Nursing 38, 177-182.

R Development Core Team (2012) R: A Language and Environment for Statistical Computing. $R$ Foundation for Statistical Computing. Available at: http://www.R-project.org [accessed 01 June 2012]. 
Ryden MB, Feldt KS, Oh HL, Brand K, Warne M, Weber E, Nelson J \& Gross C (1999) Relationships between aggressive behavior in cognitively impaired nursing home residents and use of restraints, psychoactive drugs, and secured units. Archives of Psychiatric Nursing 13, 170-178.

Skovdahl K, Kihlgren AL \& Kihlgren M (2003) Different attitudes when handling aggressive behaviour in dementia - narratives from two caregiver groups. Aging \& Mental Health 7, 277-286.

Talerico K, Evans L \& Strumpf N (2002) Mental health correlates of aggression in nursing home residents with dementia. The Gerontologist 42, 169-177.

Testad I, Aasland AM \& Aarsland D (2007) Prevalence and correlates of disruptive behavior in patients in Norwegian nursing homes. International Journal of Geriatric Psychiatry 22, 916-921.

Verkaik R, van Weert JCM \& Francke AL (2005) The effects of psychosocial methods on depressed, aggressive and apathetic behaviors of people with dementia: a systematic review. International Journal of Geriatric Psychiatry 20, 301-314.

Vickland V, Chilko N, Draper B, Low L, O'Connor D \& Brodaty H (2012) Individualized guidelines for the management of aggression in dementia - Part 2: appraisal of current guidelines. International Psychogeriatrics / IPA 24, 1125-1132.

Voyer P, Verreault R, Azizah G, Desrosiers J, Champoux N \& Bedard A (2005) Prevalence of physical and verbal aggressive behaviours and associated factors among older adults in long-term care facilities. BMC Geriatrics 5, 13.

Zanetti O, Oriani M, Geroldi C, Binetti G, Frisoni GB, Di Giovanni G \& Vreese LP de (2002) Predictors of cognitive improvement after reality orientation in Alzheimer's disease. Age and Ageing 31, 193-196.

Zeller A, Needham I \& Halfens R (2006) Effekt einer Schulung in Aggressionsmanagement bei Schülerinnen und Schülern in der Pflegeausbildung (Effect of a training course in management of aggression and violence on nursing students). Pflege 19, 251-258.

Zeller A, Dassen T, Kok G, Needham I \& Halfens RJG (2011) Nursing home caregivers' explanations for and coping strategies with residents' aggression: a qualitative study. Journal of Clinical Nursing 20, 2469-2478.

Zeller A, Dassen T, Kok G, Needham I \& Halfens RJ (2012) Factors associated with resident aggression toward caregivers in nursing homes. Journal of Nursing Scholarship 44, 249257. 


\section{Chapter 6}

\section{Factors associated with resident aggression toward}

caregivers in nursing homes

Zeller A, Dassen T, Kok G, Needham I \& Halfens RJ (2012) Factors Associated With Resident Aggression Toward Caregivers in Nursing Homes. Journal of Nursing Scholarship 44, 249257. 


\subsection{Abstract}

\section{Purpose of the article}

Caregivers in nursing homes often experience aggressive behaviour of residents. The aim of this study was to explore the caregivers' experiences with aggressive behaviour from residents and to identify environmental factors as well as caregiver and resident characteristics related to aggressive behaviour in Swiss nursing homes.

Design: A retrospective cross-sectional survey was conducted between November 2010 and April 2011 with a sample of caregivers working in various nursing homes in the German-speaking part of Switzerland. In total 814 caregivers (response rate $51.8 \%$ ) of 21 nursing homes participated in the study.

\section{Methods}

Data were collected using the German version of the Survey of Violence Experienced by Staff (SOVES-G-R). Standard descriptive statistics were used to describe and summarize the date. To identify risk factors related to the experience of aggression by residents, multilevel logistic regression analysis was applied.

\section{Findings}

The prevalence of participants reporting an aggressive incident during the 12 months period prior to data collection was $81.6 \%$. Of these, $76.5 \%$ had experienced verbal aggression, $27.6 \%$ threats and $54.0 \%$ physical aggression. The predictive variables in the multiple regression model for physical aggression were: staff education level $(O R=1.82)$, gender ( $O R=1.82)$, age $(<30$ years vs. $>30-45$ years: $O R=1.46,<30$ years vs. $>45$ years: $O R=2.13$ ) and confidence in managing physical aggression $(O R=1.49)$. The predictive variables for threatening behaviour were staff education level (registered nurses vs. non-registered nurses: $O R=1.70$, non-student vs. student: $\mathrm{OR}=1.89$ ) and age ( $<30$ years vs. $>30-45$ years: $O R=2.00,<30$ years vs. $>45$ years: $O R=2.04)$.

\section{Conclusions}

Caregivers in nursing homes are at high risk to experience aggressive behaviour. The identified risk factors are in line with earlier investigations but also some contradictory results appear.

\section{Clinical relevance}

The high risk for registered nurses exposed to aggressive behaviour and the increased risk for caregivers who feel confident in managing aggressive behaviour cast a critical light on the content and aim on present programmes for management of aggressive behaviour. Caregivers in nursing homes should be qualified understanding resident aggression in a comprehensive way. A critical point in this topic seems to be the interaction between caregiver and resident during basic care activities. This topic should be investigated in further research projects. 


\subsection{Introduction}

Caregivers in nursing homes often experience aggressive behaviour of residents. As Franz et al. (2010) showed, $83.3 \%$ of the caregivers in German nursing homes have experienced physical aggression, and $90.3 \%$ have been exposed to verbal aggression during the previous twelve months. An investigation in US nursing homes focussing on physical aggression toward nursing assistants revealed that a total of $34 \%$ of nursing assistants experienced physical injuries from assaults by residents (Tak et al. 2010). Moreover, the results of the European Nurses Early Exit Study (NEXT-Study) have demonstrated that nursing staff in geriatric wards experience the third highest frequency of aggression of all clinical settings; only nurses in psychiatric and emergency wards were more often confronted with aggression (Camerino et al. 2008). The importance of the topic for caregivers has been underlined by a literature review of Zeller et al. (2009) which demonstrates caregivers' high risk of exposition to residents' aggression in nursing homes.

While caregivers are challenged to implement measures to reduce aggressive behaviour among residents (Zeller et al. 2011), more in-depth knowledge about factors leading to aggressive behaviour of residents is important for the development of such measures. Based on current research in this field it can be assumed that aggressive behaviour of residents towards their caregivers is multifaceted and emphasizes the characteristics of caregiver, environment, and resident (Gates et al. 2003).

Caregiver characteristics that might be relevant for aggressive behaviour were examined by Isaksson et al. (2008a). As their results show, caregivers who are more exposed to aggression had higher burnout scores than less exposed caregivers, whereas no major differences were found with regard to caregivers' defence style, their temperament, and aspects of their character. Regarding the higher burnout scores of exposed caregivers it is difficult to say whether caregivers with high burnout scores have a higher risk to experience aggressive behaviour or if burnout emerges as a consequence of experienced aggression from residents.

The study of Gates et al. (2003) showed significant correlations between the incidence of aggression and staffing ratios, age, occupational strain, as well as occupational stressors like role ambiguity and role insufficiency. Workers with a high role ambiguity may report that they are experiencing conflicting demands from supervisors. Role insufficiency measures the extent to which the individual's competencies and experiences are appropriate to the job requirements. In the qualitative investigation of Zeller et al. (2011) caregivers assumed that 'working under pressure', 'lack of thoughtfulness', and 'fear of the resident' are factors which influence the relationship between caregiver and resident and may trigger residents' aggression. 
Less knowledge is available regarding the influence of environmental factors on resident aggression. A few studies have reported that older people suffering from dementia are sensitive to changes in their environment and that such changes can trigger aggressive behaviour (Hall \& O'Connor 2004). Morgan et al. (2005) found that there is significantly less aggressive behaviour in special care units (SCU) than in non-SCU facilities. This was explained by the fact that working in an SCU facility was related to staff's lower job strain and higher work autonomy. Moreover, mandatory overtime and the lack of time for appropriate support of residents in activities of daily living result in a significantly higher proportion of physical assaults (Tak et al. 2010).

Deeper insight into environmental factors is offered in a study by Yeom and Watson (2009) which depicted two patterns of environmental context which can trigger aggressive behaviour: stimulants like public location, olfactory stimulation or media use as part of the physical environment, and basic care activities or demands of tasks in a dementia unit as mixed components of the physical and social environment. It can be assumed that caregiver characteristics and environmental factors are associated because caregivers shape or create residents' environment due to their way of performing care and other activities in nursing homes. The mode of routine daily care activities significantly affects aggressive behaviour and quality of life of people with dementia (Dettmore et al. 2009).

As residents suffering from dementia often exhibit aggressive behaviour, dementia seems to be the main risk factor in nursing homes (Testad et al. 2007). Similarly, Voyer et al. (2005) found significant associations between aggressive behaviour and cognitive impairment, male gender, use of neuroleptic drugs, insomnia, physical distress, and physical restraints. Talerico et al. (2002) demonstrated associations between impaired communication and all forms of aggressive behaviour, between depression and physical aggression, as well as between disorientation and verbal aggression. Despite these findings there is still a lack of knowledge concerning predictive factors of aggressive behaviour among residents in nursing homes (Isaksson et al. 2008b).

Aggressive behaviour and associated factors have scarcely been investigated in Swiss nursing homes. The results of a first prospective study in Swiss nursing homes showed an incidence rate of aggression about 1.2 per day in all nursing homes participating in the study (Glaus Hartmann 2006), which can be deemed considerably high. For this reason, nursing homes are interested in developing strategies for preventing and dealing with aggression as well as conducting training programmes for their staff. To this end research-based knowledge about risk and predictive factors is needed.

Therefore, the aim of this study was to explore caregivers' experiences with aggressive behaviour of residents and to identify environmental factors as well as caregiver and resident characteristics related to aggressive behaviour in a sample of Swiss nursing homes. 
In this study aggressive behaviour is conceptualised according to the operationalization of McKenna (2004) which delineates verbal aggression as the use of abusive or offensive language (including sexually abusive language), derogatory remarks or profane and/or obscene comments; threats as warnings of intent to injure another person with or without an object or weapon; harassment (also sexually); physical intimidation and physical assault including slapping, pinching, pushing, shoving, spitting or kicking, with or without the use of weapons.

\subsection{Methods}

\section{Design and Setting}

A retrospective cross-sectional survey was conducted with a sample of caregivers working in various nursing homes in the German-speaking part of Switzerland. Given that this is the first study investigating residents' aggression in Swiss nursing homes the method of a crosssectional survey was deemed appropriate to explore this issue.

\section{Sample}

A non-probability purposive sampling strategy by means of an announcement in two national nursing journals was used for the recruitment of nursing homes. In total directors of 23 nursing homes replied to the announcement. Two nursing homes agreeing only to participate in a survey among registered nurses were excluded in order not to jeopardise the representativeness of the mix of educational levels among staff in Swiss nursing homes.

The remaining 21 directors gave their approval to conduct the survey among the caregivers in their institutions. The 21 nursing homes, located in urban and rural regions in the German-speaking part of Switzerland, differed in size between 25 and 705 beds. The inclusion criteria were participants' informed consent, caregivers' direct contact with residents, and an adequate command of the German language.

\section{Data collection}

Given that every nursing home had a different time frame for data collection the study was conducted between November 2010 and April 2011. The data were collected by means of a questionnaire. The questionnaires and written information regarding the study and its aims were sent to the directors of the nursing homes for distribution on the wards. In 14 nursing homes staff of all wards participated and in seven nursing homes staff of one to three wards. Accordingly, 1,572 questionnaires were distributed to potential respondents in each of the 21 nursing homes. An open, stamped envelope containing the questionnaire was dispatched 
which participants filled in and returned directly and anonymously to the principal researcher. Participating nursing homes were coded to control the response rate.

\section{Instrument}

The questionnaire used was the German version of the Survey of Violence Experienced by Staff (SOVES-G-R). This questionnaire was developed by McKenna (2004). Content validity of the SOVES was ascertained by a panel of eight experts form the European Violence in Psychiatry Research Group, who agreed with its content. In addition, the SOVES underwent a trial run by 44 health care staff and was used in a study with 812 health care staff. The subscales of the SOVES achieved good levels of internal consistency (Cronbach's alpha 0.870.91). The questionnaire was translated into German as well as investigated on feasibility and face-validity by Hahn et al. (2011) in a general hospital. The instrument shows good feasibility and allows clinical practitioners to understand the questions appropriately.

The SOVES-G-R consists of seven sections pertaining to the following subjects: A) staff characteristics; B) experiences of verbal aggression, threats or physical aggression of residents during their professional life; $\mathrm{C}$ ) experiences of aggression in the last twelve months; D) experiences of aggressive behaviour during the last seven working days, characteristics of the perpetrator and their impairments in activities of daily living, medical diagnoses, the performed care activity prior to the aggression incident, possible triggers and measures to respond to resident aggression; E) questions related to the consequences and burden of experienced aggression on caregivers and available post-aggression support systems; F) documentation and formal reporting-systems for aggressive incidents; $G$ ) experiences pertaining to training in management of aggressive behaviour.

To employ the questionnaire in nursing homes instead of hospitals some adaptations were necessary. The term 'patient' was changed to 'resident', and items related to patients' diagnoses were modified to more specific diagnoses of residents in nursing homes and their cognitive and/or physical impairments. These changes in the questionnaire were reviewed by seven experts in the field of long term-care in nursing homes. They judged the changes as relevant and comprehensible. Subsequently pilot testing of the questionnaire was conducted in a nursing home not participating in the study. In this pilot testing 135 caregivers completed the questionnaire, judged the questionnaire as comprehensive and feasible, and attested

that the survey instrument gives a broad overview about the issue of residents' aggression in nursing homes. Thus, no further changes in the questionnaire were required.

\section{Ethical considerations}

This study was approved by the ethics commissions of the various cantons of the participating nursing homes. Nursing homes willing to participate received written information regard- 
ing the study aims, methods, questionnaire and the voluntary nature of participation. Confidentiality and anonymity was ensured.

\section{Analysis}

Standard descriptive statistics were used to describe and summarise the data. To identify risk-factors related to experiencing aggression of residents, multilevel logistic regression analysis was applied. Outcome variables were 'experiences of aggression in the past 12 months and in the past week' (yes or no). As our sample consists of institutions and nurses within institutions, data show a multilevel structure. Multilevel models include a random factor for the institution to take account for this structure. We started with a model including all available explanatory variables and selected variables based on the Akaike Information Criterion (AIC). Data analysis was conducted using IBM SPSS Statistics Version 19 (IBM Inc., Armonk, NY, USA) and the R statistical package Version 2.12.1 (R Development Core Team 2012). A p value of less than 0.05 was considered to indicate statistical significance.

\subsection{Results}

\section{Participants}

The questionnaire was returned by 814 caregivers from 21 nursing homes giving rise to an overall response rate of $51.8 \%$ with response rates varying from $32.6 \%$ to $92.5 \%$ across the participating nursing homes. Ten questionnaires were incomplete and thus 804 questionnaires were used for data analysis. The participants were predominantly female (93.2\%) and over 46 years old (44.5\%). More than $40 \%$ of the participants were qualified as registered nurses with over 15 years of experience in health care service. Most participants (58.8\%) work full-time and spend over $60 \%$ of their working hours in direct contact with residents (72.8\%). Less than half of the participants (44.3\%) are trained in the management of aggressive behaviour. Further characteristics of participants are shown in Table 6.1. 
Table 6.1

Characteristics of the sample

\begin{tabular}{|c|c|c|c|}
\hline \multirow{2}{*}{ Demographic characteristics } & & \multicolumn{2}{|c|}{ Total $(n=804)$} \\
\hline & & $\mathrm{n}$ & (\%) \\
\hline \multirow[t]{3}{*}{ Gender } & Female & 749 & (93.2) \\
\hline & Male & 50 & $(6.2)$ \\
\hline & Missing & 5 & $(0.6)$ \\
\hline \multirow[t]{5}{*}{ Age (years) } & $<17$ & 13 & (1.6) \\
\hline & $18-29$ & 179 & (22.3) \\
\hline & $30-45$ & 250 & (31.1) \\
\hline & $>46$ & 358 & (44.5) \\
\hline & Missing & 4 & $(0.5)$ \\
\hline \multirow{5}{*}{$\begin{array}{l}\text { Educational level } \\
\text { including nurses in } \\
\text { training }\end{array}$} & Registered nurses & 345 & (42.9) \\
\hline & Enrolled nurses* & 207 & (25.7) \\
\hline & Nursing assistants & 212 & (26.4) \\
\hline & Other caregivers & 35 & (4.4) \\
\hline & Missing & 5 & $(0.6)$ \\
\hline \multirow{5}{*}{$\begin{array}{l}\text { Professional experience in } \\
\text { health care (years) }\end{array}$} & $<4$ & 127 & (15.8) \\
\hline & $5-9$ & 150 & (18.7) \\
\hline & $10-15$ & 187 & (23.2) \\
\hline & $>15$ & 335 & (41.7) \\
\hline & Missing & 5 & $(0.6)$ \\
\hline \multirow{5}{*}{$\begin{array}{l}\text { Experience in present posi- } \\
\text { tion (years) }\end{array}$} & $<1$ & 98 & (12.2) \\
\hline & $1-4$ & 315 & (39.2) \\
\hline & $5-10$ & 213 & (26.5) \\
\hline & $>10$ & 172 & (21.4) \\
\hline & Missing & 6 & $(0.7)$ \\
\hline \multirow[t]{4}{*}{ Employment level (\%) } & $80-100$ & 473 & $(58.8$ \\
\hline & $51-79$ & 180 & (22.4) \\
\hline & $\leq 50$ & 147 & (18.3) \\
\hline & Missing & 4 & $(0.5)$ \\
\hline \multirow{4}{*}{$\begin{array}{l}\text { Proportion of time per day } \\
\text { spent in direct contact } \\
\text { with resident (\%) }\end{array}$} & $<30$ & 29 & (3.6) \\
\hline & $30-60$ & 184 & (22.9) \\
\hline & $>60$ & 585 & (72.8) \\
\hline & Missing & 6 & $(0.7)$ \\
\hline \multirow{3}{*}{$\begin{array}{l}\text { Trained in management of } \\
\text { aggressive behaviour }\end{array}$} & Yes & 356 & (44.3) \\
\hline & No & 445 & (55.3) \\
\hline & Missing & 3 & (0.4) \\
\hline
\end{tabular}

\footnotetext{
* Caregivers with a 2- or 3-year education not at diploma level
} 


\section{Prevalence of aggressive behaviour}

Almost all participants (96\%) had experienced aggressive behaviour during their professional career in the health care system. Furthermore, $81.6 \%(n=656)$ had experienced aggressive behaviour during the 12 -months period prior to data collection. Of these, $76.5 \%$ had experienced verbal aggression, $27.6 \%$ threats and $54.0 \%$ physical aggression. In the week prior to data collection $38.2 \%(n=307)$ of the participants had experienced aggressive behaviour. The most salient incident in this week was verbal aggression for $49.8 \%$, physical aggression for $42.7 \%$ and threatening behaviour for $7.5 \%$ (Table 6.2 ).

Table 6.2

Aggressive behaviour experienced by caregivers

\begin{tabular}{|c|c|c|c|c|c|}
\hline \multirow[b]{2}{*}{$\begin{array}{l}\text { Exposed to aggressive } \\
\text { behaviour, } \mathrm{n}(\%)\end{array}$} & & \multicolumn{2}{|c|}{$\begin{array}{l}\text { Past } 12 \text { months }^{\mathrm{a}} \\
\quad(\mathrm{n}=804)\end{array}$} & \multicolumn{2}{|c|}{$\begin{array}{l}\text { Past week }^{b} \\
(n=804)\end{array}$} \\
\hline & & 656 & $(81.6)$ & 307 & $(38.2)$ \\
\hline \multirow[t]{3}{*}{ Aggression from residents, $\mathrm{n}(\%)$} & Verbal & 615 & $(76.5)$ & 153 & (49.8) \\
\hline & Threats & 222 & (27.6) & 23 & (7.5) \\
\hline & Physical & 434 & (54.0) & 131 & (42.7) \\
\hline
\end{tabular}

${ }^{a}$ Multiple responses possible. ${ }^{b}$ Figures related to the most salient incident in the past working week.

\section{Factors associated with aggressive behaviour}

A multiple regression model was fitted for factors associated with aggressive behaviour experienced during the past 12 months and the past week. In the model related to the past week no significant risk factors were identified. Based on the model related to the past 12 months, the variable selection process resulted in a multiple regression model for physical aggression and threatening behaviour experienced in the past 12 months. The factors are described in Table 3 and 4 . In the final model for physical aggression the predictive variables were educational level of staff, gender, age, and confidence in managing physical aggression.

Table 6.3 shows that trained staff had experienced physical aggression more often during the past 12 months $(O R=1.82, p<0.05)$ than students. As the results show, female caregivers were more often confronted with physical aggression than male caregivers $(O R=1.82$, n. s.). For staff under 30 years the odds were more than doubled (OR=2.13, $p<0.001)$ compared with staff over 45 years. Confidence in managing physical aggression increased the estimated odds one and a half fold $(\mathrm{OR}=1.49, \mathrm{p}<0.01)$.

In the model for threatening behaviour (Table 6.4) the predictive variables were staff educational level and age. Related to the educational level the results show that registered nurses $(O R=1.70, p<0.01)$ as well as trained nurses $(O R=1.89, p<0.05)$ experience more threatening behaviour compared with non-registered nurses and students. The results regarding age are approximately similar compared with the regression model on physical ag- 
gression. The odds for staff under 30 years old were more than doubled $(O R=2.00, p<0.01$; $\mathrm{OR}=2.04, p<0.01$ ) compared with staff above the age of 30 . Environmental factors like support from superiors, reporting systems for aggressive incidents or institutionalised assistance for affected caregivers as well as resident characteristics were not significant factors in the multiple regression models.

Table 6.3

Multiple regression model for physical aggression in nursing homes in the past 12 month

\begin{tabular}{lccc}
\hline Variables & OR & $95 \% \mathrm{Cl}$ & $\mathrm{p}$-value \\
\hline Staff education level: non-student vs. student & 1.82 & $1.06-3.03$ & $.0296^{*}$ \\
Staff gender: female vs. male & 1.82 & $0.94-3.45$ & .0746 \\
Staff age: under 30 vs. 30-45 years & 1.46 & $0.99-2.27$ & .0858 \\
Staff age: under 30 vs. over 45 years & 2.13 & $1.41-3.23$ & $.0004^{* * *}$ \\
Staff confidence in managing physical aggression & 1.49 & $1.12-1.99$ & $.0057^{* *}$ \\
\hline
\end{tabular}

Note. $\mathrm{OR}=$ odds ratio; $\mathrm{Cl}=$ confidence interval. ${ }^{*} \mathrm{p}<.05 ;{ }^{* *} \mathrm{p}<.01 ;{ }^{* * *} \mathrm{p}<.001$.

Table 6.4:

Multiple regression analysis predicting risk factors with threatening behaviour in nursing homes in the past 12 months

\begin{tabular}{lccc}
\hline Variables & OR & $95 \% \mathrm{Cl}$ & $\mathrm{p}$-value \\
\hline Staff education level: & 1.70 & $1.22-2.37$ & $.0017^{* *}$ \\
registered nurses vs. non-registered nurses & & & \\
Staff education level: non-student vs. student & 1.89 & $1.03-3.45$ & $.0390^{*}$ \\
Staff age: under 30 vs. 30-45 years & 2.00 & $1.27-3.13$ & $.0027^{* *}$ \\
Staff age: under 30 vs. over 45 years & 2.04 & $1.33-3.13$ & $.0011^{* *}$ \\
\hline
\end{tabular}

Note. $\mathrm{OR}=$ odds ratio; $\mathrm{Cl}=$ confidence interval. ${ }^{*} \mathrm{p}<.05 ;{ }^{* *} \mathrm{p}<.01 ;{ }^{* * *} \mathrm{p}<.001$ 


\subsection{Discussion}

The aim of this study was to explore caregivers' experiences of aggressive behaviour in nursing homes and to identify associated factors. This study underlines existing evidence that aggressive behaviour from residents towards their caregivers is also a significant problem in Swiss nursing homes(Gates et al. 2004, Zeh et al. 2009). Isaksson et al. (2008a) describe that $68.4 \%$ of caregivers had been exposed to aggressive behaviour in the past 12 months, whereas in our study the prevalence-rate with $81.6 \%$ of affected participants during the past 12 months is higher. Franz et al. (2010) report similar results with $83.9 \%$ of employees having experienced physical aggression during the last 12 months.

The results of the factor educational level as a potential risk factor for experiencing aggressive behaviour indicate that trained caregivers, particularly registered nurses, experienced more aggression than students or caregivers with lower educational level such as nursing assistants or enrolled nurses. Magnavita and Heponiemi (2011) also found a higher risk of physical assaults for registered nurses than for students and explained this difference on the basis of the tasks of registered nurses which entail more unpleasant personal stimulations (e.g. injections or wound care) which may lead to disputes and aggression. Furthermore, a lower level of perceived organisational justice and social support as well as greater levels of work-related stress were associated with higher rates of aggression (Magnavita \& Heponiemi 2011). By contrast, the studies of Myers et al. (2005) and Hegney et al. (2010) show a higher aggression risk for nursing aides and nursing assistants than for registered nurses. Myers et al. (2005) show a significant association between the physical lifting of residents and the risk of injury, a task which is mostly performed by nursing assistants in the institution where the study was conducted. This result is corroborated by the study of Hegney et al. (2010) who observed that caregivers providing most of the clinical care are at the greatest risk to experience aggression.

Aström et al. (2002) also reported more aggression towards nursing assistants than registered nurses. No significant differences between professional levels were found by Isaksson et al. (2008a). The explanations for these contradictory results perhaps relate to different working-conditions in nursing homes, e.g. mentorship programs for students. In Swiss nursing homes all students are accompanied by experienced nurses and are normally not alone in situations in which aggression occurs. In Switzerland it is also common to allocate registered nurses to residents with multiple health problems, and more pretentious care, or difficult behaviour such as aggression.

These contradictory results concerning educational level of caregivers and their risk to experience aggressive behaviour leads to the tentative assumption, that caregivers' experiences of aggression may depend more on the allocation of care activities than on education- 
al level. The more caregivers are charged with basic care activities, the higher the risk to experience aggression from residents.

In our study female caregivers are more often exposed to physical aggression than male caregivers. This result is in line with the studies of Tak et al. (2010) and Myers et al. (2005) which indicate also a higher prevalence of aggression and risk of assault against female caregivers. In contrast, Aström et al. (2002) report that more male respondents experience aggression and Hegney et al. (2010) found no significant difference in reported workplace violence regarding caregivers' gender. There are no conceivable reasons described for the gender-gap concerning exposition to aggressive behaviour. However, a possible explanation for the higher female aggression risk for female caregivers could be that residents possibly have higher respect for male caregivers and are thus less aggressive. In some nursing homes in Switzerland is it common to involve male caregivers in the care of aggressive residents because in some cases they are less aggressive than towards female caregivers. A further tentative explanation for the gender difference in experiencing aggression refers to intimate care activities like dressing, bathing, and toileting which are often performed by female caregivers whereas male caregivers are often more involved in management tasks.

Further results of this study show that younger caregivers (under 30 years old) are more often confronted with aggressive behaviour compared with caregivers over 30 years old. This result does not correspond to the studies of Myers et al. (2005) and Hegney et al. (2010) who found no significant association between age and risk of reported aggressive behaviour. The results of Isaksson et al. (2008a) indicate a higher exposure of caregivers under 50 years to aggression, but these results are not directly comparable because of differences in the coding of age groups in the study. In keeping with the findings of the present study Aström et al. (2002) report that staff younger than 40 years of age was significantly more exposed than staff over 40 years. Based on available investigations we can ascertain that younger caregivers are at higher risk to experience aggressive behaviour from residents. A possible explanation for this difference may be less experience and routine in dealing with difficult or complex resident situations as well as aggressive behaviour at the beginning of caregivers' professional career. Given that aggressive behaviour by residents is a multifactorial phenomenon triggered by different reasons it is reasonable to conclude that the care of these residents necessitates high abilities in critical thinking and clinical skills (Yeom \& Watson 2009). This becomes apparent in considering the qualitative findings of Graneheim et al. (2005) who describe the challenge of caregivers to manage and balance out contradictory feelings - feeling rejected versus feeling accepted or feeling powerless versus feeling capable - in caring for residents.

The higher risk of experiencing aggressive behaviour by caregivers who feel confident in managing physical aggression contradicts our expectation. The use of specialised techniques 
in aggression management is becoming more and more common in nursing homes in Switzerland with one of the expectations being that trained caregivers are able to reduce aggressive incidents. Studies investigating the effect of such training programs indicate an improvement in knowledge about aggression and confidence in the ability to prevent and handle aggressive situations (Gates et al. 2005, Zeller et al. 2006, Richter \& Needham 2007). However, there is no reduction in the number of aggressive incidents after the implementation of training (Gates et al. 2005, Richter \& Needham 2007). Richter und Needham (2007) assumed that caregivers trained in aggression management are more aware of aggressive behaviour. A further consequence of training might be that trained staff is more deployed to situations with aggressive behaviour because of their greater knowledge. Other critical points that may influence the effect of training programmes include the lack of sufficient repetition and the lack of reinforcement by using immediate feedback to caregivers due to high workload in nursing homes.

A common criticism of studies about caregivers' experiences of residents' aggression refers to different definitions of aggressive behaviour and different measurement methods which makes comparisons difficult. Although a definition of aggressive behaviour was given, participants' subjective interpretations must be taken into account. Furthermore, participants who are often exposed to aggression are more likely than others to respond to the survey, and this may bias the results. A further limitation of this study relates to the representativeness of the sample. Due to the fact that every Swiss canton has its own regulations regarding educational requirements of staff in nursing homes we cannot guarantee if the sample is representative for all Swiss nursing homes. In addition, we have to consider that the findings are based on self-reported measures. However, due to the utilisation of a validated instrument and the satisfactory response rate we can assume that the results offer a good approximation of the situation in Swiss nursing homes.

\subsection{Conclusions}

Our study demonstrates that aggressive behaviour of residents in Swiss nursing homes is a serious problem for caregivers. The results corroborate previous international reports of investigations in nursing homes. The identified risk factors are partially in line with similar investigations but we found also contradictory results especially related to trained caregivers as registered nurses who have a significantly higher risk of experiencing aggressive behaviour than students or caregivers with a lower educational level. The fact that registered nurses are more exposed to aggressive behaviour should be taken into consideration regarding their skills in aggression management and their professional tasks or roles in their teams. Based on the results of the present study we can assume that the allocation of care activi- 
ties, especially basic care activities, is a more potent mediating factor for experiencing resident aggression than the educational level.

Furthermore, the increased risk of caregivers who feel more confident in managing aggressive behaviour cast doubts on the content and aims of training programmes as well as to the instruments used to measure the effect of such training programmes. Given that the success of these training programmes is usually associated with decreased aggressive incidents after the training, we may have to reconsider this outcome measure and should possibly focus on content which can improve caregivers' knowledge and understanding about possible emotions underlying aggressive behaviour. A further point in these programmes is the training in assessment skills which can enable caregivers to deal with aggressive behaviour in a more comprehensive way than just striving for the reduction of manifest aggression.

Finally, it was not possible in this study to detect further associations between caregivers' experiences of aggression and environmental factors or resident characteristics. This stresses the need for further studies to identify risk factors relevant to the development and improvement of working conditions for caregivers in nursing homes. 


\subsection{References}

Aström S, Bucht G, Eisemann M, Norberg A \& Saveman B (2002) Incidence of violence towards staff caring for the elderly. Scandinavian Journal of Caring Sciences 16, 66-72.

Camerino D, Estryn-Behar M, Conway P, van Der Heijden BIJM \& Hasselhorn H (2008) Workrelated factors and violence among nursing staff in the European NEXT study: a longitudinal cohort study. International Journal of Nursing Studies 45, 35-50.

Dettmore D, Kolanowski A \& Boustani M (2009) Aggression in persons with dementia: use of nursing theory to guide clinical practice. Geriatric Nursing (New York, N 30, 8-17.

Franz S, Zeh A, Schablon A, Kuhnert S \& Nienhaus A (2010) Aggression and violence against health care workers in Germany--a cross sectional retrospective survey. BMC Health Services Research 10, 51.

Gates D, Fitzwater E \& Succop P (2003) Relationships of stressors, strain, and anger to caregiver assaults. Issues in Mental Health Nursing 24, 775-793.

Gates D, Fitzwater E \& Succop P (2005) Reducing assaults against nursing home caregivers. Nursing Research 54, 119-127.

Gates D, Fitzwater E, Telintelo S, Succop P \& Sommers M (2004) Preventing assaults by nursing home residents: nursing assistants' knowledge and confidence-a pilot study. Journal of the American Medical Directors Association 5, S16-21.

Glaus Hartmann M (2006) [Recognizing aggression and relieving stress] Aggressionsmuster erkennen und Auslöser reduzieren. Krankenpflege 99, 24-26.

Graneheim U, Isaksson U, Ljung I \& Jansson L (2005) Balancing between contradictions: the meaning of interaction with people suffering from dementia and "behavioral disturbances". International Journal of Aging \& Human Development 60, 145-157.

Hahn S, Müller M, Needham I, Dassen T, Kok G \& Halfens R (2011) Measuring patient and visitor violence in general hospitals: feasibility of the SOVES-G-R, internal consistency and construct validity of the POAS-S and the POIS. Journal of Clinical Nursing 20, 2519-2530.

Hall KA \& O'Connor DW (2004) Correlates of aggressive behavior in dementia. International Psychogeriatrics 16, 141-158.

Hegney D, Tuckett A, Parker D \& Eley R (2010) Workplace violence: differences in perceptions of nursing work between those exposed and those not exposed: a cross-sector analysis. International Journal of Nursing Practice 16, 188-202. 
Isaksson U, Aström S, Sandman P \& Karlsson S (2008b) Factors associated with the prevalence of violent behaviour among residents living in nursing homes. Journal of Clinical Nursing 18, 972-980.

Isaksson U, Graneheim UH, Richter J, Eisemann M \& Aström S (2008a) Exposure to violence in relation to personality traits, coping abilities, and burnout among caregivers in nursing homes: a case-control study. Scandinavian Journal of Caring Sciences 22, 551-559.

Magnavita N \& Heponiemi T (2011) Workplace Violence Against Nursing Students and Nurses: An Italian Experience. Journal of Nursing Scholarship 43, 203-210.

McKenna K (2004) Study of work-related violence. Committee on Workplace Violence, North Eastern Health Board, Ireland, pp.1-121.

Morgan DG, Stewart NJ, D'Arcy C, Forbes D \& Lawson J (2005) Work stress and physical assault of nursing aides in rural nursing homes with and without dementia special care units. Journal of Psychiatric and Mental Health Nursing 12, 347-358.

Myers D, Kriebel D, Karasek R, Punnett L \& Wegman D (2005) Injuries and assaults in a longterm psychiatric care facility: an epidemiologic study. AAOHN Journal : Official Journal of the American Association of Occupational 53, 489-498.

R Development Core Team (2012) R: A Language and Environment for Statistical Computing. $R$ Foundation for Statistical Computing. Available at: http://www.R-project.org.

Richter D \& Needham I (2007) [Effects of aggression management trainings for mental health care and disability care staff-systematic review]. Effekte von mitarbeiterbezogenen Trainingsprogrammen zum Aggressionsmanagement in Einrichtungen der Psychiatrie und Behindertenhilfe-Systematische Literaturübersicht. Psychiatrische Praxis 34, 7-14.

Tak S, Sweeney M, Alterman T, Baron S \& Calvert G (2010) Workplace assaults on nursing assistants in US nursing homes: a multilevel analysis. American Journal of Public Health 100, 1938-1945.

Talerico K, Evans L \& Strumpf N (2002) Mental health correlates of aggression in nursing home residents with dementia. The Gerontologist 42, 169-177.

Testad I, Aasland AM \& Aarsland D (2007) Prevalence and correlates of disruptive behavior in patients in Norwegian nursing homes. International Journal of Geriatric Psychiatry 22, 916-921.

Voyer P, Verreault R, Azizah G, Desrosiers J, Champoux N \& Bedard A (2005) Prevalence of physical and verbal aggressive behaviours and associated factors among older adults in long-term care facilities. BMC Geriatrics 5, 13. 
Yeom H \& Watson NM (2009) Patterns of Antecedents of Catastrophic Reactions in Nursing Home Residents with Dementia in the United States. Asian Nursing Research 3, 99-110.

Zeh A, Schablon A, Wohlert C, Richter D \& Nienhaus A (2009) [Violence and aggression in care-related jobs-a literature overview] Gewalt und Aggression in Pflege- und Betreuungsberufen-Ein Literaturüberblick. Gesundheitswesen (Bundesverband der Ärzte des Öffentlichen Gesundheitsdienstes 71, 449-459.

Zeller A, Dassen T, Kok G, Needham I \& Halfens RJG (2011) Nursing home caregivers' explanations for and coping strategies with residents' aggression: a qualitative study. Journal of Clinical Nursing 20, 2469-2478.

Zeller A, Hahn S, Needham I, Kok G, Dassen T \& Halfens R (2009) Aggressive behavior of nursing home residents toward caregivers: a systematic literature review. Geriatric Nursing 30, 174-187.

Zeller A, Needham I \& Halfens R (2006) Effekt einer Schulung in Aggressionsmanagement bei Schülerinnen und Schülern in der Pflegeausbildung (Effect of a training course in management of aggression and violence on nursing students). Pflege 19, 251-258. 
Chapter 7

General discussion 


\subsection{Introduction}

The main goal of this dissertation was to explore caregivers' experiences with resident aggression in nursing homes and to examine their dealing with aggressive behaviour as well as related factors. In the following sections the findings of the different studies, the literature review, the qualitative investigation and the cross-sectional survey, are summarised and discussed in accordance with the research questions presented in chapter 1 . After a critical appraisal of strengths and limitations of the research, the chapter ends with implications for clinical practice and suggestions for future research.

\subsection{Main results}

\section{Prevalence and types of resident aggression}

The prevalence and types of resident aggression was investigated as part of the literature review and the cross-sectional survey. The literature review showed that prevalence rates of resident aggression were reported in two ways: in retrospective studies focused on caregivers reporting, or in prospective studies which gather aggressive incidents involving residents. The results revealed a broad variance. Approximately $11 \%$ to $70 \%$ of caregivers in nursing homes experienced resident aggression in the course of one year. The results of our retrospective cross sectional survey in Swiss nursing homes show that almost all participants (96\%) had experienced aggressive behaviour during their professional career in the health care system. Furthermore, $81.6 \%(n=656)$ had experienced aggressive behaviour during the 12-month period prior to data collection and 38.2\% $(n=307)$ in the last week prior to the survey. Furthermore, the results show that caregivers were confronted with physical and verbal aggression as well as threatening behaviour, of which verbal aggression was the most commonly experienced type of aggressive behaviour with $76.4 \%$ in the past 12 months and 49.8 in the past working week. Physical aggression was experienced by $54 \%$ of the participants during the previous 12 months and by $42.7 \%$ in the week prior to data collection.

\section{Context of resident aggression}

Context factors encompass aspects and conditions which encourage or trigger aggressive behaviour of residents in nursing homes. In the literature review several factors on different levels were identified: the interaction between caregiver and resident during personal care, psychosocial stress of the resident and organisational and policy aspects that affect caregivers' working conditions and attitude. These factors were partially in line with the results of our qualitative study in which participants mentioned two main factors which contribute to 
aggression: resident related factors like their loss of faculties or suffering from intrusion into their personal space and caregiver related factors such as working under pressure or lacking thoughtfulness. The findings of our cross-sectional survey conducted in 21 nursing homes show that most of residents with aggressive behaviour were cognitively impaired and suffered from impaired mobility, elimination and communication. The most frequently mentioned diagnosis of residents involved was dementia and/or depression. In $60 \%$ of all cases a nursing intervention with physical contact was conducted when aggression broke out. As a trigger for aggressive behaviour participants predominantly assumed 'non-understanding and excessive demands' on residents.

\section{Caregivers' strategies in dealing with resident aggression and use of measures recom- mended by guidelines}

The question regarding caregivers' strategies in dealing with resident aggression depicted different approaches. Summarised in the results from the literature review, these strategies can be categorised as follows: strategies aiming to prevent or detect aggressive behaviour at an early stage, calming and de-escalating strategies when signs of aggressive behaviour occur, repressive or sanctioning interventions, medical treatment, and policy-based strategies. In the qualitative investigation caregivers mentioned two ways of dealing with resident aggression: firstly, measures used in direct contact with affected residents, like pacifying and distracting or confronting residents with their behaviour; secondly, measures for selfprotection and coping with experienced aggression such as being calm in the situation or pulling themselves together after the experience. In the cross-sectional survey, reassuring conversation and keeping oneself at a distance were the most often used measures reported in the acute situation when aggression occurs. Furthermore, $41.2 \%$ of participants leave the room and around $30 \%$ request residents to change their behaviour. Applying coercion is seen as a last resort for handling aggressive behaviour for participants in the qualitative study as well as in the cross-sectional survey.

Findings focusing on measures caregivers use in general in the care of people with aggressive behaviour show that interventions with the aim of understanding reasons underlying aggression were mentioned by $80 \%$ to $90 \%$ of participants. Physical activities were applied by around $50 \%$ of respondents and interdisciplinary case reviews as well as standardized instruments for assessment and documentation were used by less than $50 \%$. A cluster analyses revealed two groups of caregiver who differ in their frequency of used measures, which indicates that some caregivers apply recommended measures far more often than others. Multiple regression analysis show the following predicting factors regarding caregivers' use of recommended measures: caregivers' employment level, support from superiors, and institutionalised support for affected caregivers. Furthermore, caregivers' confidence in 
managing behaviour has a positive influence whereas caregivers trained in aggression management use recommended measures significantly less. Caregivers' competence in empathising with the residents' perspective in connection with their professional experience has a positive influence on applying recommended measures.

\section{Consequences of resident aggression for caregivers and residents}

Results show that caregivers perceive aggression-related burden differently depending on the type of experienced aggression. Physical attacks were perceived as a moderate or strong burden by $43.6 \%$ of the participants, whereas verbal aggression was burdening for around $30 \%$ of affected caregivers. Threatening behaviour was moderately or strongly burdening for 37.8 of participants.

Fear of aggressive behaviour from residents was mentioned by 23.4 of participants, particularly when it occurred without warning and $6.6 \%$ of these respondents were afraid of becoming aggressive towards the care recipient. As a consequence of aggression $12.3 \%$ of participants who were exposed to resident aggression experienced a disruption in the relationship with the resident and $4 \%$ avoided contact with residents after an aggressive incident.

\section{Factors associated with caregivers' risk of experiencing resident aggression}

A multiple regression model was fitted for factors associated with aggressive behaviour experienced during the past 12 months and past week. Whereas in the model related to the past week, no significant risk factors could be identified, the model related to the past 12 months revealed the following risk factors for physical aggression and threatening behaviour: education level of staff, gender, age and confidence in managing physical aggression. The predictive variables for threatening behaviour were education level and age.

\subsection{Discussion of the results}

\section{Definition of resident aggression}

As mentioned in the first chapter resident aggression is differently defined and up to now there is no agreement regarding a common definition among researchers or among professionals in nursing homes. This problem makes discussion difficult and hampered findings of prevalence rates, the interpretation of possible reasons of these behaviours as well as the development of measures. For this reason an operationalized definition which describes all forms of aggressive behaviour with examples (McKenna 2004) was included in this thesis with the aim of supporting participants in their judgement about experienced aggression. 
Nevertheless, we have to take into consideration that the term 'challenging behaviour' has been used more and more in recent years to describe resident behaviour in the context of nursing homes. Challenging behaviour is defined as culturally abnormal behaviour of such intensity, frequency or duration that the physical safety of the persons or others is placed in serious jeopardy, or behaviour which is likely to seriously limit or deny access to the use of ordinary community facilities (Emerson 2001). The term originally came from the learning disability literature and was introduced in order to shift the focus of attention away from individual pathology towards an understanding that caregivers have to find solutions to the problem behaviour (Blunden and Allen 1987).

James (2011, p. 12) changed the term and suggested 'behaviour that challenges'. He described behaviour that challenges as actions that detract from the well-being of individuals due to the physical or psychological distress they cause within the settings they are performed. The individuals affected may be either the instigators of the acts or those in their immediate surroundings (James 2011). The assumption is that challenging behaviours reflect some form of need or are related to distress. Neurological impairment is just one of numerous factors which can lead to this behaviour. Furthermore, what caregivers perceived to be "challenged" will differ between settings, with some onlookers, being more tolerant than others (James, 2011, p. 12).

Aggressive behaviour, the phenomenon under investigation in this study, is one type of behaviour which is subsumed under the broad construct of challenging behaviour (James, 2001, p. 14) and similarly operationalized as in McKenna (2004). According to the statement of James (2011) we have to take into consideration that caregivers' judgements about experienced aggression remain subjective.

\section{Prevalence and consequences of resident aggression}

Participants in this study reported a high prevalence of experienced aggression by residents, with $81.6 \%$ who had been confronted with it during the 12 -month period and $38.2 \%$ in the week prior to data collection. These results were comparable to studies by Franz et al. (2010) and Zeh et al. (2009), which reported similar high prevalence rates in the nursing home setting. The study by Franz et al. was conducted in Germany and it can be assumed that working conditions and the general state of health of residents are comparable to the situation in Swiss nursing homes. In contrast to these results the prevalence rates in two studies conducted in Sweden are considerably lower with around 40\% (Aström et al. 2002, Josefsson et al. 2007) of affected caregivers in the same time frame. In both studies comparable definitions of aggression were used. As further information, e.g. about working conditions or residents' state of health in these studies is not given, is it not possible to explain the difference between prevalence rates. 
A comparison of the prevalence in a Swiss general hospital setting, conducted with the same instrument, revealed a considerably lower prevalence rate with $50.5 \%$ of affected health care staff in the previous 12 months and $13.5 \%$ in the week prior to data collection (Hahn et al. 2012). In the setting of mental health care, $72.4 \%$ of the respondents felt once or repeatedly seriously threatened in their professional lives and about $70 \%$ were once or repeatedly physically attacked (Abderhalden et al. 2002). Abderhalden et al. (2002) did not use the same instrument but the response categories are similar to our instrument. In this comparison of different settings, caregivers in nursing homes reported the highest prevalence of experienced aggression. Our survey among caregivers in nursing homes in German-speaking Switzerland was the first study of this kind in the area and the results underline the relevance of this issue and for the first time allow comparisons with other health care settings as well as countries.

Furthermore, the results of this study show the influence of resident aggression on caregivers and care recipients. First of all physical attacks were perceived as strongly burdening compared with verbal aggression or threatening behaviour. Studies by Aström et al. (2004) or Chapmann et al. (2009) show impressively that caregivers exposed to resident aggression experience emotions like insufficiency, powerlessness, insult and fear. Even in our study around $20 \%$ of respondents reported fear of resident aggression where the unpredictability of the situation was the most commonly mentioned reason for caregivers' fear. In $6.6 \%$ of the cases participants mentioned that they are afraid of becoming aggressive towards the care recipient. Caregivers who were frequently exposed to resident aggression reported a significantly lower quality of general health, reduced workability and high burnout levels (Schmidt et al. 2012). Moreover, resident aggression had an influence on the relationship between caregiver and care recipient as the results in our study show. Participants reported a disruption in the relationship after an aggressive incident and some of them avoid contact with the resident concerned. Aström et al. (2004) shows that ignoring care recipients' need for help, giving no answer to care recipients' questions or bringing food or coffee first to other care recipients are possible behaviours of caregivers after an aggressive incident.

Chapman et al. (2009) investigated in their study consequences of workplace violence directed at nurses and identified factors regarding the organisation, the perpetrator and the caregivers themselves. Focused on the consequences on the perpetrator, the results of Chapman et al. (2009) were comparable to the results of our study as they also described an affected interpersonal relationship and patient avoidance after aggressive incidents. In this situation the risk of resident abuse can arise (Cooper et al. 2013). 


\section{Context of resident aggression}

Several studies described that resident aggression occurs in the majority of cases during care activities with physical contact and this is also confirmed by the results of our study. As a trigger caregivers suggested most often that residents do not understand the situation and were overwhelmed, whereas violation of residents' private sphere was considerably less often mentioned as a possible trigger. These results indicate that caregivers relate aggression more often to dementia and rarely to nursing intervention or caregiver-related factors like interactional aspects which can influence the situation between caregiver and resident during personal care activities.

These findings are in line with the study of Morgan et al. (2012), where participants also suggested resident-related factors such as cognitive impairment and did not want to see care as a main cause of aggressive behaviour (Morgan et al. 2012). Interestingly they continued to provide care in $89 \%$ of the incidents.

With reference to the theoretical framework of this thesis, which takes a broad view of the causes of aggressive behaviour both in the general aggression model (Anderson \& Bushman 2002) and in the need-driven dementia-compromised behaviour model (NDBModel) (Algase et al. 1996), the results of this study lead to the conclusion that caregivers still focus on stable or non-modifiable factors such as cognitive impairment and take factors like caregiver-resident interaction less into consideration. According to the GAM (Anderson \& Bushman 2002), input variables - categorised as features of the situation or as features of the person in the situation - influence the outcome behaviour. Two-thirds of aggression incidents in the week prior to data collection were perpetrated by residents suffering from cognitive impairment which can cause a strain in simple daily activities such as in personal care. Given this situation combined with a disturbed interaction between caregiver and resident aggressive behaviour may be triggered. That one-sided assumptions about dementia-related causes of resident aggression are limited is shown by the findings in the study by Josefsson et al. (2007), which revealed no significant difference regarding caregivers' exposure to resident aggression between groups specialized on dementia care and those working in general elder care where older people have different diagnoses. Despite the fact that the degenerative nature of dementia predisposes sufferers to aggressive behaviour, aggression should be seen as a process influenced not only by specific factors, but also by situational and structural factors in the context (Josefsson et al. 2007). 


\section{Caregivers' strategies in dealing with resident aggression and use of approaches recom- mended by guidelines}

The results of our study regarding caregivers' strategies in dealing with resident aggression refer, on the one hand, to measures caregivers use in the situation when aggression occurs and, on the other, to measures they use in general and with a more preventive intention when they have to care for resident who displays aggressive behaviour. In the acute situation caregivers primarily intend to de-escalate the situation with calmative talk (55.5\%), to distance themselves from the aggressive resident (51.5\%) or to leave the room (41.2\%). With these measures caregivers expect a calming of the situation. However, based on the NDBModel (Algase et al. 1996) whereby aggressive behaviour is viewed as a way to express or communicate needs, it might be problematic if caregivers leave the room.

Furthermore, the study gives no information on how caregivers perform calmative talk in an escalating situation, as this could be very demanding and requires good communication and interactive skills. It can be assumed that interactive skills are the basis for taking a person-centred approach, which is recommended for the care of people suffering from dementia as well as for dealing with aggressive behaviour (Kitwood 1997, Vickland et al. 2012). According to the model of interactive behaviour of residents by Höwler (2008), caregivers try to convey the idea that they are able to manage these challenging situations and do not talk about their failure. In this field further research is necessary, e.g. with observational methods, to gain information about the quality and performance of caregiver communication skills. The measure of "distancing oneself" is on the one hand a useful reaction to protect caregivers themselves or to avoid further provocation; on the other hand Höwler (2008) judged these strategies as emotion-focused. They include a distancing behaviour toward residents and do not change aggressive behaviour. According to Höwler (2008) caregivers rely on these strategies because they fear losing control over the situation.

A further question in this thesis was to ask caregivers about their use of measures recommended by guidelines and to identify differences between caregivers in terms of their use of these measures. The results show that measures like validation therapy, finding out underlying reasons for aggressive behaviour or taking the resident's perspective to understand the meaning of the behaviour were frequently used measures. Kitwood's (1997) theory of personhood emphasizes viewing the person with dementia as a social being with an individual experience. In this person-centred view, understanding the world from the perspective of the person with dementia is essential for the successful management of aggression. However, measures like performing interdisciplinary case reviews or the use of standardized report forms for documentation were applied by less than half of respondents. $A$ recently published review regarding the effect of case conferences on people with challenging behaviour came to the conclusion that case conferences can reduce challenging behav- 
iour (Reuther et al. 2012). Moreover, case conferences support caregivers with recurring care problems and approach cases analytically within a team and facilitate critical thinking. This is the basis for a sustainable improvement in caring for people with aggressive behaviour (Reuther et al. 2012).

The analysis regarding differences between caregivers revealed two groups who did not differ in the sort of measures they use but in the frequency of application of these measures. Factors which support caregivers in the use of recommended measures were an employment level of over $80 \%$, support from superiors and institutionalised assistance for affected caregivers.

A controversial result is that caregivers who judge training in aggression management to be important and feel confident in managing this behaviour use recommended measures significantly more often, whereas caregivers who received training in aggression management use it significantly less. The assumption is that caregivers' views on residents who display aggressive behaviour play a more important role related to the use of measures in dealing with aggressive behaviour than training in aggression management. This may be an explanation for the result that caregivers who are motivated to attend training in aggression management or feel confident in dealing with aggressive behaviour are more engaged in the use of the recommendations mentioned because of their attitude towards affected residents. Furthermore, the results suggest that training in aggression management is no guarantee that recommendations will be used. The content of training programmes should be reviewed critically in the light of these results.

A further finding is that there is a positive relationship between caregivers' judgement of their competence in empathising with residents' perspectives and their years of professional experience. Höwler (2008) mentioned in her model that caregivers with mental stability and psycho-social skills like empathy and self-reflection in connection with a personcentred attitude are able to apply problem-focused strategies with residents who show aggressive behaviour. Careful interpretations of our results lead to the assumption that the development of these competencies is influenced by years of professional experience.

\section{Factors associated with caregivers' risk of experiencing aggression}

In this study it was not possible to identify risk factors regarding environmental aspects or resident characteristics. The findings of a multiple regression analyses reveal caregiverrelated risk factors such as educational level of staff, gender, age, and confidence in managing physical aggression. As age and gender of caregivers are hardly controllable factors, this discussion focuses on staff educational level and confidence in managing aggressive behaviour. 
In our study registered nurses experience significantly more aggression compared with nonregistered nurses and students. As compared to other studies this result is a further contribution to contradictory findings which describe either a higher risk for registered nurses (Magnavita \& Heponiemi 2011), or a higher risk for non-registered caregivers (Aström et al. 2002, Myers et al. 2005, Hegney et al. 2010), or no differences between professional levels (Isaksson et al. 2008). Furthermore, there is an association between care activities with physical contact and the risk of experiencing resident aggression (Myers et al. 2005, Hegney et al. 2010). This is in line with the results of our study which also show that aggression breaks out most often during a nursing intervention with physical contact.

These contradictory results concerning educational level lead to the tentative assumption that caregivers' experiences of aggression may depend more on the allocation of care activities than on educational level. The more caregivers are charged with basic care activities, the higher their risk of experiencing resident aggression. Starting from the premise that caring for residents with aggressive behaviour is a demanding task we can assume that registered nurses are more involved due to their education/training than caregivers with a lower level of education. However, we do not know whether or how they were prepared for this task during their training. Oh et al. (2004) detected in their study that a considerable proportion of nursing staff responded to aggressive behaviour inadequately.

A surprising result was the higher risk of experiencing aggression for caregivers who feel confident in managing aggressive behaviour. In our study $44.3 \%$ of the participants mentioned that they were trained in aggression management but there is no information available about the content of training programmes. An easily comprehensible rationale for this result could be that trained caregivers are more often deployed to situations with aggressive behaviour and we can also expect that trained caregivers are more aware of aggressive behaviour. The increased risk for caregivers trained in aggression management casts doubt on the content and aims of training programmes.

\subsection{Methodological aspects}

Methodological strengths and limitations of the different studies in this thesis were discussed in the previous chapters. To summarize, they can be considered as follows:

The strengths of this thesis are the use of a qualitative approach as a first step to gain an insight into caregivers' situation regarding their experience of resident aggression in Swiss nursing homes. The knowledge gained from the qualitative study flowed into the planning and conduct of the cross-sectional survey, especially for the adaption of the questionnaire to the nursing home setting. 
The qualitative study was conducted with focus group interviews, which allow exploration and confirmation of ideas with a wide range of participants on a predefined set of issues. Interviews with focus groups incite an associative thinking process amongst the participants and therefore help to uncover the maximal amount of variance on a topic, which may lead to an increased understanding of the subject matter.

However, some limitations have to be taken into consideration: Due to the fact that the participants know each other it is possible that the participants may have felt inhibited in expressing their own opinions and sharing their experience with their co-workers. Furthermore, some degree of social acceptance cannot be excluded.

The strengths of our cross-sectional survey are the use of an instrument which was well validated in the context of the Swiss health care system and where only adaptions regarding the setting in nursing homes were necessary. Even the participation of 21 nursing homes located in rural and urban regions with differing size and ownership and the satisfactory response rate leads to the assumption that the results offer a good approximation of the situation in Swiss nursing homes.

The limitations of the survey are the retrospective time frame, which could lead to a recall bias and the use of a nonprobability sample. Furthermore it is not possible to draw causal conclusions from a cross-sectional survey, e.g. we cannot say if factors associated with resident aggression are the cause or the result of aggression. The missing information regarding the characteristics of non-responders are a further limitation and therefore results should be interpreted with caution. The results of the cross-sectional survey based on selfreport of the participants and thus the problem of social desirability response bias should be taken into consideration. The viewpoint of residents is included in this study.

Furthermore, in the cross-sectional survey a newly developed questionnaire regarding caregivers' use of measures recommended by guidelines, the Resident Aggression Management Inventory (RAMI), were included. The RAMI consists of operationalization of recommended measures and added items by an expert-group. As the RAMI is based only on face validity and was used for the first time in this study, the questionnaire needs further testing in practice with regard to validity and reliability.

Despite these limitations a cross-sectional design is an approved method for describing the status of phenomena like resident aggression and for examining relationships among phenomena under investigation. 


\subsection{Implications for caregivers and clinical practice}

The results of this study demonstrate that the prevalence of experienced resident aggression is high for caregivers in nursing homes. However, we have to take recall bias into consideration due to the retrospective design. Therefore a prospective measure of aggression incidents should be conducted to verify the results of this study.

Respondents perceive resident aggression as burdening and mentioned its adverse influence on the relationship between caregiver and care recipient. A critical review is necessary regarding the content of nursing curricula and training programmes on aggression management not least because of the high risk of experiencing aggression for registered nurses. The findings of this study reveal a need for action regarding the development of caregivers' competencies in a comprehensible assessment of conditions and factors which can contribute to resident aggression. In this context the use of case reviews and other suitable instruments as tools for a systematic assessment and development of individual targeted measures should be encouraged. In addition caregivers' assumptions regarding their rationales of resident aggression have to be critically reviewed with respect to available guidelines.

The results suggest that nurses tend to assume that especially dementia-related factors underlie aggressive behaviour and pay less attention to environmental and caregiver-related factors. It is widely recommended that caregivers who have to care for residents with aggressive behaviour should be able to identify, monitor and address environmental, physical health and psychosocial factors that may influence aggressive behaviour (Bundesministerium für Gesundheit 2006, National Collaborating Centre for Mental Health 2007). These recommendations support the use of comprehensible models like the NDB-Model (Algase et al. 1996) for assessing the needs and conditions of affected residents. According to the NICESCIE Guidelines the skills needed for individualised assessment and intervention are rare, and most referrals come at a crisis point, where it is difficult for caregivers to take on board a different approach, as their own levels of distress have reached a breaking point (National Collaborating Centre for Mental Health 2007).

For that reason, attention should be given to caregivers' type of interaction with residents, especially during care activities with physical contact, due to the fact that aggression most often erupts in these moments. As results of our study show, caregivers tend in these situations to use emotion-focused strategies, e.g. leaving the resident and the situation. Training in aggression management should focus on caregivers' development of preventive strategies such as sharpening their awareness of care activities which violate residents' sense of privacy.

Moreover, the use of problem-focused strategies and development of competencies in applying person-centred interactions as well as creating and maintaining a therapeutic rela- 
tionship with residents even if they behave aggressively should be part of training programmes.

However, the management of nursing homes should also be required to give attention to this issue. The results of our study strongly suggest that support from superiors and institutionalised assistance for affected caregivers improve caregivers' use of measures in managing resident aggression recommended by guidelines.

\subsection{Implications for future research}

This explorative study gives a broad overview of several aspects of aggressive behaviour among nursing home residents. Based on the results discussed above future research should focus on the following issues:

A growing number of studies have been published in the last decade that offer data about the prevalence of resident aggression in nursing homes, one among them is also part of this thesis. Based on the fact that the prevalence of resident aggression is high and a further increase can be expected due to the increase of people suffering from dementia in coming years, further research should focus on factors such as environmental features and caregiver-related factors that influence the occurrence of aggressive behaviour. There is a lack of studies investigating the factors proposed in terms of their cause.

A further point for future research is the critical review of available programmes for training in aggression management. Training of health care staff in aggression management is widely recommended but we are groping in the dark regarding evidence based elements of training programmes which contribute to the development of caregivers' social and communication skills needed in managing resident aggression, both preventive and in acute situations when aggression breaks out.

Furthermore, measures for dealing with resident aggression should be critically examined regarding their use and effectiveness.

A neglected aspect in research in this field is the involvement of residents as experienced service users. This is probably deliberate, as people suffering from dementia are a vulnerable group and their inclusion in research projects is difficult for ethical reasons. However, with regard to the results presented in chapter 4 of this thesis, a group of residents demonstrating aggressive behaviour but with no cognitive impairment could be identified. This indicated that not only residents with cognitive impairment are involved in aggressive incidents and a survey among these residents could be a promising approach to improving knowledge about risk factors and prevention of resident aggression. 


\subsection{References}

Abderhalden C, Needham I, Friedli TK, Poelmans J \& Dassen T (2002) Perception of aggression among psychiatric nurses in Switzerland. Acta Psychiatrica Scandinavica 106, 110117.

Algase DL, Beck C, Kolanowski A, Whall A, Berent S, Richards K \& Beattie E (1996) Needdriven dementia-compromised behavior: An alternative view of disruptive behavior. American Journal of Alzheimer's Disease and Other Dementias 11, 10-19.

Anderson CA \& Bushman BJ (2002) Human aggression. Annual review of psychology 53, 2751.

Aström S, Bucht G, Eisemann M, Norberg A \& Saveman B (2002) Incidence of violence towards staff caring for the elderly. Scandinavian Journal of Caring Sciences 16, 66-72.

Bundesministerium für Gesundheit (2006) Rahmenempfehlungen zum Umgang mit herausforderndem Verhalten bei Menschen mit Demenz in der stationären Altershilfe (Guidelines regarding handling of challenging behaviour by persons with dementia in residential facilities). Available at: https://www.bundesgesundheitsministerium.de/fileadmin/dateien/ Publikationen/Pflege/Berichte/Bericht_Rahmenempfehlungen_zum_Umgang_mit_ herausforderndem_Verhalten_bei_Menschen_mit_Demenz_in_der_stationaeren_Altenhilfe.pdf [accessed 01 June 2012].

Blunden R \& Allen D (1987) Facing the challenge: an ordinary life for people with learning difficulties and challenging behaviour. King's Fund, London.

Chapman R, Perry L, Styles I \& Combs S (2009) Consequences of workplace violence directed at nurses. British Journal of Nursing 18, 1256-1261.

Cooper C, Dow B, Hay S, Livingston D \& Livingston G (2013) Care workers' abusive behavior to residents in care homes: a qualitative study of types of abuse, barriers, and facilitators to good care and development of an instrument for reporting of abuse anonymously. International Psychogeriatrics, 1-9.

Emerson E (2001) Challenging behaviour: analysis and intervention in people with severe intellectual disabilities. Cambridge University Press, Cambridge.

Franz S, Zeh A, Schablon A, Kuhnert S \& Nienhaus A (2010) Aggression and violence against health care workers in Germany--a cross sectional retrospective survey. BMC Health Services Research 10, 51. 
Hahn S, Hantikainen V, Needham I, Kok G, Dassen T \& Halfens RJ (2012) Patient and visitor violence in the general hospital, occurrence, staff interventions and consequences: a cross-sectional survey. Journal of Advanced Nursing 68, 2685-2699.

Hegney D, Tuckett A, Parker D \& Eley R (2010) Workplace violence: differences in perceptions of nursing work between those exposed and those not exposed: a cross-sector analysis. International Journal of Nursing Practice 16, 188-202.

Höwler E (2008) Herausforderndes Verhalten bei Menschen mit Demenz: Erleben und Strategien Pflegender (Challenging behaviour in people with dementia: caregivers experiences and strategies). Kohlhammer, Stuttgart.

Isaksson U, Aström S, Sandman P \& Karlsson S (2008) Factors associated with the prevalence of violent behaviour among residents living in nursing homes. Journal of Clinical Nursing 18, 972-980.

James Al (2011) Understanding behaviour in dementia that challenges. A guide to assessment and treatment. Jessica Kingsley Publishers, London, Philadelphia.

Josefsson K, Sonde L \& Wahlin T (2007) Violence in municipal care of older people in Sweden as perceived by registered nurses. Journal of Clinical Nursing 16, 900-910.

Kitwood T (1997) Dementia reconsidered. The person comes first. Open University Press, Buckingham.

Magnavita N \& Heponiemi T (2011) Workplace violence against nursing students and nurses: an Italian experience. Journal of Nursing Scholarship 43, 203-210.

McKenna K (2004) Study of work-related violence. Committee on Workplace Violence, North Eastern Health Board, Ireland.

Morgan DG, Cammer A, Stewart NJ, Crossley M, D'Arcy C, Forbes DA \& Karunanayake C (2012) Nursing aide reports of combative behavior by residents with dementia: results from a detailed prospective incident diary. Journal of the American Medical Directors Association $13,220-227$.

Myers D, Kriebel D, Karasek R, Punnett L \& Wegman D (2005) Injuries and assaults in a longterm psychiatric care facility: an epidemiologic study. AAOHN Journal : Official Journal of the American Association of Occupational 53, 489-498.

National Collaborating Centre for Mental Health (2007) Dementia: The NICE-SCIE Guideline on Supporting People with Dementia and their Carers in Health and Social Care. The NICESCIE Guideline on Supporting People with Dementia and Their Carers in Health and Social Care. British Psychological Society. 
Oh H, Eom M \& Kwon Y (2004) A study on aggressive behavior among nursing home residents with cognitive impairment. Journal of Korean Academy of Nursing 34, 1451-1459.

Reuther S, Dichter MN, Buscher I, Vollmar HC, Holle D, Bartholomeyczik S \& Halek M (2012) Case conferences as interventions dealing with the challenging behavior of people with dementia in nursing homes: a systematic review. International Psychogeriatrics / IPA 24, 1891-1903.

Schmidt SG, Dichter MN, Palm R \& Hasselhorn HM (2012) Distress experienced by nurses in response to the challenging behaviour of residents - evidence from German nursing homes. Journal of Clinical Nursing 21, 3134-3142.

Vickland V, Chilko N, Draper B, Low L, O'Connor D \& Brodaty H (2012) Individualized guidelines for the management of aggression in dementia - Part 1: key concepts. International Psychogeriatrics 24, 1112-1124.

Zeh A, Schablon A, Wohlert C, Richter D \& Nienhaus A (2009) Gewalt und Aggression in Pflege- und Betreuungsberufen - Ein Literaturüberblick [Violence and aggression in carerelated jobs - a literature overview]. Gesundheitswesen (Bundesverband der Ärzte des Öffentlichen Gesundheitsdienstes 71, 449-459. 


\section{Chapter 8}

\section{Summary}

Aggressive behaviour on the part of nursing home residents is a challenging task for caregivers. Studies have demonstrated that nursing staff in geriatric wards experience the third highest frequency of aggression after psychiatric and emergency wards. Researchers in this field agree that causes of resident aggression are multifaceted and take several factors into consideration, such as resident factors, characteristics and competencies of the caregiver, and environmental aspects. The relation between dementia and aggressive behaviour is one of the most widely discussed aspects, whereas the relation between caregiver characteristics and environmental factors has been only sparsely investigated. People suffering from dementia are sensitive to changes in their environment. There is some evidence that caregivers with more clinical experience and a higher level of professional training more often use need-based approaches to minimize aggression. A further aspect is caregivers' lack of time for appropriate support of residents in activities of daily living, which results in a significantly higher proportion of physical assaults.

Furthermore, it is well known that caring for residents with aggressive behaviour is associated with high burden and stress for caregivers in nursing homes. The interaction with people suffering from dementia and displaying aggression is described as a balancing act between contradictory positions, namely, meeting the person in my world versus her/his world, feeling powerless versus capable and feeling rejected versus accepted. Yet, despite the well-known increase in people suffering from dementia and the expected increase in aggressive behavioural symptoms, aggression has been sparsely investigated in Swiss nursing homes. Therefore, this dissertation addresses caregivers' experiences with resident aggression in nursing homes. It investigates caregivers' experience as well as their strategies and measures for dealing with aggression. Moreover, factors associated with the occurrence of resident aggression are examined.

The definition of resident aggression is an important point in research in this field, as varying definitions exist with an overlap in their descriptions. Therefore a clear operationalization of aggressive behaviour was used in this thesis; it delineates verbal aggression as the use of abusive or offensive language (including sexually abusive language), derogatory remarks, or profane or obscene comments; threats as warnings of intent to injure another person with or without an object or weapon; harassment (including sexual); and physical intimidation and physical assault, including slapping, pinching, pushing, shoving, spitting, or kicking, with or without the use of weapons. As theoretical framework for this thesis the General Aggression Model (GAM) and the need-driven dementia-compromised behaviour model 
(NDB-Model) were used to explain the multifaceted factors involved in the occurrence of resident aggression. For the reflection of caregivers' handling of resident aggression, the model of interactive behaviour of caregivers was integrated in the theoretical framework of this thesis.

With the intention of summarising available scientific knowledge of resident aggression, a literature review was conducted. The literature was reviewed regarding types and prevalence of aggressive behaviour that caregivers in nursing homes experience as well as situations in which aggressive behaviour occurs and caregivers' strategies for managing aggressive behaviour. The results of the review are presented in chapter two and refer to the first research question of this thesis. With an extensive search of electronic databases in Medline, Cumulative Index of Nursing and Allied Health Literature (CINAHL), PsycINFO, and supplemented by screening citations, references, and unpublished manuscripts, 72 publications were identified. After application of the exclusion criteria and an independent critical appraisal by two reviewers (first and second author), 21 publications remained for further analysis. Thirteen publications were based on a quantitative and eight on a qualitative research design. The most frequently used quantitative method was a retrospective crosssectional survey, with only two publications using a prospective approach. One publication was an observational study. Of the eight qualitative publications, two employed a phenomenological hermeneutic approach, one used grounded theory methodology and one was an ethnographic investigation; four publications gave only minor information regarding their methodology. The description of aggressive behaviour and related terms used fall into two main categories: verbal aggression and physical aggression. The prevalence of aggressive behaviour was prospectively or retrospectively measured in 13 quantitative publications using various instruments. A considerable variance in the prevalence rates of aggression, ranging from 1.2 incidents per day to 1 to 4 incidents per year, was reported. Despite the difficulty in comparing the prevalence rates due to different measurement methods, the figures underline the importance of the topic for caregivers in nursing homes.

The publications reviewed described the situations in which aggressive behaviour occurs at various levels. Some articles focused on the interaction between caregivers and residents during personal care as well as psychosocial stress of the resident as a trigger for aggressive behaviour. Another approach to causes of aggressive behaviour involves organisational or policy aspects that affect the staff's attitudes and the interaction between caregiver and resident. The demanding nursing home environment provides the context for aggression toward staff, with residents, their families, and administration placing multiple and simultaneous demands on caregivers, creating an atmosphere in which residents' care is often rushed and limited to the task at hand. 
In summarising the results on caregivers' strategies for dealing with aggressive behaviour, five categories could be identified: 1) strategies aiming to prevent or detect aggressive behaviour at an early stage, 2) calming and de-escalating strategies when signs of aggressive behaviour appear, 3) repressive or sanctioning interventions, 4) medical treatment, and 5) policy based strategies. The results of this literature review demonstrated the difficulty in establishing exact prevalence rates of resident aggression and explained the complex interplay between several factors contributing to aggressive behaviour. It would seem that resident aggression depends on the interplay between resident and the environment, including interpersonal style of interaction and organizational factors. Beside the lack of evidence on the effectiveness of various approaches, there is also a lack of data on the preferred measures that caregivers use in practice to deal with resident aggression.

Therefore as a next step a qualitative study was conducted with the aim of exploring caregivers' perspectives regarding the conditions and situations of resident aggression and practical strategies caregivers use to deal with aggression. This study addressed research questions two, three and four, and the results were presented in chapter three in this thesis. Five focus group interviews, with a total of 30 participants, were undertaken, employing a semi-structured interview guideline. Qualitative content analyses of the data produced three main-themes with additional sub-themes.

One main-theme concerns the explanations of the caregivers in regard to the occurrence of aggressive behaviour. This theme is subdivided into two areas: a) the contributory resident-related factors such as residents realizing their loss of faculties, their failing to understand and being overwhelmed, or aggression as residents' way of expressing themselves, and $b$ ) caregiver-related factors such as working under pressure, lacking thoughtfulness and their fear of residents who show aggressive behaviour. The measures for handling resident aggression are illustrated in the second theme 'dealing with residents' which includes getting to know residents' habits and needs, continuing the quest for new solutions or confronting residents with their behaviour. The third theme refers to the strategies of caregivers when confronted with resident aggression - 'self-protection' and 'coping with the situation'. With this study we obtained an insight into caregivers' perspectives on factors leading to aggression and their strategies for dealing with it.

The results showed that caregivers use a broad spectrum of interventions for reducing aggression, some of which are recommended by guidelines but often ignore the link between aggressive behaviour and physiological issues like pain or elimination. The caregivers only very rarely linked their practical knowledge about aggressive behaviour with theoretical knowledge. Moreover, caregivers do not apply a systematic approach in the management of aggressive behaviour. The anxiety of caregivers involved in aggression incidents and the effect of this on their managing of aggressive behaviour is an underexamined area. 
Chapter four reports the results of an exploratory descriptive cross-sectional survey in 21 Swiss nursing homes in which 814 caregivers participated. This study refers to research questions three, four, five and six. Data collection was carried out by means of a questionnaire, the German version of the 'Survey of Violence Experienced by Staff' (SOVES-G). The study results described, for the first time in Swiss nursing homes, that about $80 \%$ of the participants reported aggressive incidents during the last 12 months and $38.2 \%$ were confronted with resident aggression in the period of the last seven working days. Data about the most impressing aggressive incident showed that the participants were particularly confronted with verbal insults and physical attacks. Most of the residents involved had impaired cognitive abilities, impaired mobility and communication or suffered from incontinence. In almost $60 \%$ of all cases aggressive behaviour occurred during a nursing intervention involving physical contact.

As triggers for aggressive behaviour participants predominately assumed 'nonunderstanding and excessive demand' of residents. Reassuring conversation and keeping oneself at a distance were most often used to calm the situation. Almost half of the participants reported that no long-term measures were applied in dealing with resident aggression. In order to recognize patterns in the most impressive aggressive incident, a cluster analysis was carried out, which revealed three clearly separated clusters. Cluster one contains a group of residents with intact cognitive abilities. In cluster two residents mostly had impaired communicative abilities and the aggression occurred during nursing interventions involving physical contact. In cluster three residents also suffered from impaired cognitive capacities, but their communicative abilities were intact.

Furthermore, results show that the caregiver's burden is experienced differently, depending on the type of aggression. Approximately $40 \%$ of participants experienced physical attacks as especially distressing and about $23 \%$ were frightened, particularly when aggressive behaviour occurred without warning. Almost $4 \%$ of the participants avoided contact with residents after an aggressive incident and around $12 \%$ perceived a disturbed relationship.

As the results of this study show, caregivers in nursing homes are confronted with residents' aggressive behaviour to a great extent. Caregivers perceived resident aggression as burdensome, especially if they were exposed to physical attacks: they felt frightened, particularly when aggression occurred without prior warning. The question arises whether caregivers might not recognize early warning signs of aggression or possible situational triggers and therefore are not able to protect themselves or apply de-escalating techniques. The results indicate that the caregiver-resident relationship can be negatively affected. This entails the risk that residents' needs, which could possibly cause aggressive behaviour, are not recognized, because caregivers keep themselves at a distance. 
Chapter five focusses on caregivers' use of recommended measures in dealing with resident aggression with reference to the seventh research question. The aim of this study was to identify groups of caregivers in terms of their use of measures for dealing with resident aggression and the differences between these groups related to their characteristics. The questionnaire used was developed by the first author and based on published recommendations regarding management of aggressive behaviour and amendments by experts. This instrument was part of the questionnaire used in the cross-sectional survey mentioned in chapter four. The results of this study demonstrate that caregivers use multifaceted measures which enable them to calm the situation as well as to understand the meaning of residents' aggressive behaviour. Therefore we can assume that caregivers in Swiss nursing homes pursue a person-centred approach in caring for residents who display aggressive behaviour. Nevertheless, the results indicate that further improvements should be considered, namely, the implementation of interdisciplinary case reviews and the use of instruments for standardised assessments and documentation of resident aggression.

Furthermore, this study revealed a significant difference among caregivers in how frequently they apply the recommended measures. Important factors which encourage caregivers to use recommended measures are support from superiors and available assistance for caregivers who are confronted with aggressive behaviour. Even caregivers' professional experience and their competence in empathising with the resident's perspective are relevant factors influencing use of the measures under investigation. Nursing homes should take these factors into consideration when they develop their care concepts. Training programmes for aggression management should be critically reviewed regarding their content related to resident aggression due to the fact that caregivers who received training in aggression management use recommended measures significantly less. In subsequent research the results of this study should be compared with observations to objectivise it.

The study in chapter six focusses on research question eight, which addresses factors associated with resident aggression toward caregivers in nursing homes. Data for this study were also collected in the cross-sectional survey mentioned in chapter four. Based on caregivers' experience with resident aggression in the past twelve months, the variable selection process resulted in a multiple regression model for physical aggression and threatening behaviour. Findings show that trained staff experienced more physical aggression during the past twelve months than students, and female caregivers were more often confronted with physical aggression than male caregivers. For staff under 30 years of age, the odds were more than double compared with staff over 45 years. Confidence in managing physical aggression increased the estimated odds one and half-fold. In the model for threatening behaviour the predictive variables were staff educational level and age. Registered nurses ex- 
perience more threatening behaviour compared with non-registered nurses and students, and the results regarding age are similar to the regression model on physical aggression.

The identified risk factors are partially in line with similar investigations, but we also found contradictory results, especially related to trained caregivers such as registered nurses, who have a significantly higher risk of experiencing resident aggression than students or caregivers with a lower educational level. The fact that registered nurses are more exposed to aggressive behaviour should be taken into consideration regarding their skills in aggression management and their professional tasks or roles in their teams. Based on the results of this study we can assume that the allocation of care activities, especially basic care activities, is a more potent mediating factor for experiencing resident aggression than educational level. Furthermore, it was not possible in this study to detect further associations between caregivers' experiences of aggression and environmental factors or resident characteristics. This stresses the need for further studies to identify risk factors relevant to the development and improvement of working conditions for caregivers in nursing homes.

Finally, in chapter seven the main findings of the thesis are summarised and discussed with respect to the methodological limitations of the studies. The results of this study demonstrated that the prevalence of experienced resident aggression is high for caregivers in Swiss nursing homes. Respondents perceive it as burdensome and mention its adverse influence on the relationship between caregiver and care recipient. The findings of this thesis lead to the conclusion that there is a need for action regarding the development of caregivers' competencies in a comprehensive assessment of conditions and factors which contribute to resident aggression. Furthermore, the results strongly suggest that support from superiors and institutionalised assistance for affected caregivers improve caregivers' use of measures in managing resident aggression recommended by guidelines.

In consideration of the results and limitations of the studies, recommendations for further research are made. These recommendations relate to factors that influence the occurrence of resident aggression, the elements and effectiveness of available programmes for training in aggression management as well as the effectiveness of applied measures for dealing with resident aggression and, finally, the involvement of residents as experienced service users as a promising approach to improving knowledge about risk factors and prevention of resident aggression. 


\section{Samenvatting}

Agressief gedrag door verpleeghuisbewoners is een uitdagende taak voor zorgverleners. Onderzoek heeft aangetoond dat het verplegend personeel in geriatrische afdelingen de hoogste frequentie van agressie ervaren na psychiatrische en spoedeisende hulp afdelingen. Onderzoekers op dit gebied zijn het erover eens dat de oorzaken van de agressie veelzijdig zijn en nemen verschillende factoren in overweging zoals de bewonersfactoren, eigenschappen en competenties van de zorgverlener en omgevingsfactoren. De relatie tussen dementie en agressief gedrag is een van de meest besproken relaties, terwijl de relatie tussen de kenmerken van de zorgverlener en de kenmerken van de omgevingsfactoren nauwelijks is onderzocht. Mensen die lijden aan dementie zijn gevoelig voor veranderingen in hun omgeving. Onderzoek toont aan dat zorgverleners met meer klinische ervaring en een hogere beroepsopleiding vaker gebruik maken op behoeftegebaseerde benaderingen om agressie te minimaliseren. Een ander aspect is dat zorgverleners gebrek aan tijd hebben voor de juiste ondersteuning van bewoners bij activiteiten van het dagelijks leven, wat resulteert in een significant groter aandeel van lichamelijk geweld.

Bovendien is het algemeen bekend dat de zorg voor bewoners met agressief gedrag wordt geassocieerd met een hoge belasting en stress voor zorgverleners in verpleeghuizen. De interactie met mensen die lijden aan dementie en het tonen van agressie wordt beschreven als een evenwichtsoefening tussen tegenstrijdige posities, namelijk het voldoen aan de persoon in mijn wereld versus haar/zijn wereld, gevoel van machteloosheid tegenover bekwaam en het gevoel afgewezen versus geaccepteerd. Ondanks de bekende toename van mensen met dementie en de verwachte toename van agressieve gedragssymptomen is agressie schaars onderzocht in Zwitserse verpleeghuizen. Om deze reden behandelt dit proefschrift de ervaringen van zorgverleners met aggressie van bewoners in verpleeghuizen. Het onderzoek richt zich op de ervaringen van zorgverleners alsmede hun strategieën en maatregelen voor het omgaan met agressie. Ook worden de factoren die samenhangen met de agressie van bewoners onderzocht. De definitie van agressie door bewoner is een belangrijk onderwerp in onderzoek op dit gebied omdat er uiteenlopende definities bestaan met een overlap in hun beschrijvingen. Daarom is een duidelijke operationalisering van agressief gedrag gebruikt in dit proefschrift; het schetst verbale agressie zoals het gebruik van grove of beledigende taal (waaronder seksueel beledigende taal), denigrerende opmerkingen, of godslasterlijke of obscene opmerkingen; bedreigingen als waarschuwingen om iemand met opzet te verwonden met of zonder een voorwerp of wapen, intimidatie (waaronder seksueel intimidatie) en fysieke intimidatie en fysiek geweld zoals slaan, knijpen, duwen, trekken, spugen of schoppen, met of zonder het 
gebruik van wapens. Als theoretisch kader voor dit proefschrift zijn General Aggression Model (GAM) en need-driven dementia-compromised behaviour model (NDB-model) gebruikt om de veelzijdige factoren bij het ontstaan van de aggressie van de bewoners te verklaren. Voor de reflectie van de behandeling van bewonersagressie door zorgverleners werd het model of interactive behaviour of caregivers geïntegreerd in het theoretisch kader van dit proefschrift.

Een literatuurstudie werd uitgevoerd met als doel het samenvatten van de beschikbare wetenschappelijke literatuur over de agressie van bewoners. De gevonden literatuur werd beoordeeld op soorten en prevalentie van agressief gedrag die zorgverleners in verpleeghuizen ervaren, op situaties waarin agressief gedrag optreedt en op de strategieën die zorgverleners gebruiken voor het omgaan met agressief gedrag. De resultaten van de literatuurstudie worden gepresenteerd in hoofdstuk twee en hebben betrekking op de eerste onderzoeksvraag van dit proefschrift. Met een uitgebreid onderzoek in de elektronische databanken: Medline, Cumulatieve Index of Nursing en Allied Health Literature (CINAHL), PsycINFO, aangevuld met citaten, verwijzingen, en niet-gepubliceerde manuscripten, werden er 72 publicaties gevonden. Na toepassing van de exclusiecriteria en een onafhankelijke kritische beoordeling door twee reviewers (eerste en tweede auteur), werden 21 publicaties meegenomen voor verdere analyse. Dertien publicaties waren gebaseerd op een kwantitatieve onderzoekdsdesign en acht op een kwalitatief onderzoeksdesign.

De meest gebruikte kwantitatieve methode was een retrospectief crosssectioneel onderzoeksdesign; twee publicaties met behulp van een prospectief onderzoeksdesign. Een publicatie was een observationele studie. Van de acht kwalitatieve publicaties, bebruikten twee publicaties een fenomenologisch hermeneutische benadering, een publicatie een grounded theory methodologie en een publicatie een etnografisch onderzoek. Vier publicaties gaven slechts geringe informatie over hun methodologie. De beschrijving van agressief gedrag en gerelateerde begrippen valt in twee hoofdcategorieën uiteen: verbale agressie en fysieke agressie. De prevalentie van agressief gedrag was prospectief of retrospectief gemeten in 13 kwantitatieve publicaties met behulp van diverse instrumenten. De prevalente van agressief gedrag is aanzienlijk verschillend in de gevonden publicaties; tussen 1.2 voorvallen per dag tot 1-4 incidenten per jaar. Ondanks de moeilijkheden bij het vergelijken van de prevalentie door verschillende meetmethodes, onderstrepen de cijfers het belang van het onderwerp voor zorgverleners in verpleeghuizen. De publicaties beschrijven in welke situaties agressief gedrag optreedt op verschillende niveaus. Sommige artikelen zijn gericht op de interactie tussen zorgverleners en bewoners tijdens de persoonlijke verzorging, alsmede psychosociale stress van de bewoner als een trigger voor agressief gedrag. Een andere benadering van de oorzaken van agressief gedrag impliceert 
organisatorische of beleidsmatige aspecten die invloed hebben op de houding van de zorgverleners en de interactie tussen zorgverlener en de bewoner. De veel eisende verpleeghuisomgeving biedt de context voor agressie naar zorgverlener, met bewoners, hun familie, en de organisatie. Meervoudige en gelijktijdige eisen aan zorgverleners zorgen voor een sfeer waarin in zorg voor bewoners te gehaast en te beperkt kan plaats vinden. De resultaten over de strategieën voor zorgverleners voor het omgaan met agressief gedrag, kunnen worden samengevat in vijf categorieën: 1) strategieën gericht om agressief gedrag in een vroeg stadium te voorkomen of op te sporen, 2) kalmerende en de-escalerende strategieën als tekenen van agressief gedrag verschijnen, 3) repressieve of sanctionering interventies, 4) medische behandeling, en 5) op beleid gebaseerde strategieën.

De resultaten van dit literatuuronderzoek geven weer de moeilijkheid bij het vaststellen van de exacte prevalentie van de agressie van de bewoners en de complexe wisselwerking tussen verschillende factoren die bijdragen aan agressief gedrag. Het lijkt erop dat bewonersagressie afhangt van het samenspel tussen bewoner en het omgeving, waaronder interpersoonlijke stijl van interactie en organisatorische factoren. Naast het gebrek aan bewijs voor de effectiviteit van verschillende benaderingen is er ook een gebrek aan gegevens over de gewenste maatregelen die zorgverleners gebruiken in de praktijk voor bewoners met agressie.

De volgende stap was een kwalitatieve studie naar de mogelijkheden voor zorgverleners naar de voorwaarden en situaties van bewonersagressie en naar praktische strategieën die zorgverleners gebruiken in de omgang met agressie. Deze studie richt zich om onderzoeksvragen twee, drie en vier en de resultaten worden gepresenteerd in hoofdstuk drie in dit proefschrift. Vijf focusgroepinterviews zijn uitgevoerd met een totaal van 30 deelnemers en met semi-gestructureerde interviewrichtlijnen. Een kwalitatieve content analyse werd uitgevoerd met als resultaat drie-thema's met extra sub-thema's. Het hoofdthema betreft de uitleg van de zorgverleners over het voorkomen van agressief gedrag. Dit thema is onderverdeeld in twee delen: a) de bewoners-gerelateerde factoren die bijdragen aan agressie, zoals de realisatie van verlies van vermogens, het niet begrijpen en overweldigd voelen of agressie als een manier om zich uit te drukken, en b) zorgverlenergerelateerde factoren zoals werken onder druk, het ontbreken van bedachtzaamheid en de angst voor bewoners die agressief gedrag vertonen.

De maatregelen voor de behandeling van agressie door bewoners worden geïllustreerd in het tweede thema 'omgaan met de bewoners', die bestaat uit het leren kennen van de gewoontes en behoeften van de bewoners, het voortdurend zoeken naar nieuwe oplossingen of het confronteren van bewoners met hun gedrag. Het derde thema verwijst naar de strategieën van de zorgverleners als ze geconfronteerd worden met de agressie van bewoners: 'zelfbescherming' en 'omgaan met de situatie'. Met dit onderzoek verkregen we 
een inzicht in perspectieven van zorgverleners, de factoren die leiden tot agressie en strategieën voor het omgaan met deze agressie. De resultaten toonden aan dat zorgverleners gebruik maken van een breed spectrum van interventies voor het verminderen van agressie, waarvan sommige worden aanbevolen door de richtlijnen, maar vaak wordt het verband tussen agressief gedrag en fysiologische problemen genegeerd, zoals pijn of eliminatie. De zorgverleners linken zelden hun praktische kennis over agressief gedrag met theoretische kennis. Bovendien, de zorgverleners hebben een niet systematische aanpak bij de controle over agressief gedrag. De angst van de zorgverleners die betrokken zijn bij de agressie incidenten en het effect hiervan op het omgaan met agressief gedrag is een gebied wat nauwelijks is onderzocht.

Hoofdstuk vier beschrijft de resultaten van een verkennend beschrijvende crosssectionele vragenlijst in 21 Zwitserse verpleeghuizen waaraan 814 zorgverleners deelnamen. Deze studie heeft betrekking op onderzoeksvragen drie, vier, vijf en zes. Het verzamelen van gegevens werd uitgevoerd door middel van een vragenlijst, de Duitse versie van de 'Survey of Violence Experienced by Staff' (SOVES-G). De studie resultaten beschreven, voor het eerst in Zwitserse verpleeghuizen, dat ongeveer $80 \%$ van de deelnemers incidenten van agressie van bewoners rapporteren tijdens de laatste 12 maanden en 38,2\% werden geconfronteerd met de agressie van bewoners in de periode van de laatste zeven werkdagen. Uit gegevens over het incident van agressie met de meeste impact, bleek dat de deelnemers vooral werden geconfronteerd met verbale beledigingen en fysiek geweld. De meeste van de betrokken bewoners hadden verminderde cognitieve vaardigheden, verminderde mobiliteit en communicatie of hadden last van incontinentie. In bijna $60 \%$ van alle gevallen kwam agressief gedrag voort tijdens een verpleegkundige handeling met lichamelijk contact. Deelnemers gingen ervan uit dat de aanleidingen voor agressief gedrag door bewoners voortkwam uit 'het niet-begrijpen en een te grote verwachtingen'. Geruststellende gesprekken en afstand houden werden meestal gebruikt om de situatie te kalmeren. Bijna de helft van de deelnemers meldde dat er geen maatregelen op lange termijn werden toegepast in het omgaan met agressie van de bewoner. Om de patronen te herkennen in de agressieve incidenten die het meeste indruk hebben gemaakt, werd een clusteranalyse uitgevoerd, waarvan drie duidelijk clusters werden onthuld. Cluster een bevat een groep bewoners met intacte cognitieve vaardigheden. In cluster twee zaten bewoners die meestal verminderde communicatieve vaardigheden hadden en waar de agressie zich tijdens verpleegkundige interventies met lichamelijk contact plaats vond. In cluster drie zaten bewoners die last hadden van verminderde cognitieve capaciteiten, maar hun communicatieve vaardigheden waren intact.

Verder tonen de resultaten de last die zorgverleners ondervinden afhankelijk van het type agressie. Ongeveer $40 \%$ van de deelnemers ervaren fysieke aanvallen als bijzonder 
stressvol en ongeveer $23 \%$ waren bang, vooral als agressief gedrag heeft plaatsgevonden zonder waarschuwing. Bijna $4 \%$ van de deelnemers vermeden contact met bewoners na een agressief incident en ongeveer $12 \%$ contateerde een verstoorde relatie.

De resultaten van deze studie laten zien dat zorgverleners in verpleeghuizen te maken hebben met aggressief gedrag op een grote schaal. Zorgverleners ervaren bewonersagressie als belastend als ze werden blootgesteld aan fysieke aanvallen en waren bang, vooral wanneer agressie voorkwam zonder voorafgaande waarschuwing. De vraag is of zorgverleners vroege signalen agressief gedrag of bepaalde omstandigheden niet herkennen en dus niet in staat zijn om zichzelf te beschermen of om de-escalerende technieken toe te passen. De resultaten geven aan dat de bewoner-zorgverlener relatie negatief kan worden beïnvloed. Met als risico dat de behoeften van de bewoners, die eventueel kan leiden tot agressief gedrag, niet worden herkend, omdat zorgverleners zich op een afstand houden.

Hoofdstuk vijf richt zich op het gebruik door zorgverleners van de aanbevolen maatregelen in het omgaan met agressie bewoners aan de hand van onderzoeksvraag zeven. Het doel van deze studie was om groepen zorgverleners te identificeren na gebruik van maatregelen voor de omgang met de agressie van bewoners en de verschillen tussen deze groepen en hun eigenschappen. De gebruikte vragenlijst is ontwikkeld door de eerste auteur en gebaseerd op gepubliceerde aanbevelingen met betrekking voor het beheren van agressief gedrag en adviezen van deskundigen. De vragenlijst bestaat ui een deel van de gebruikte materialen in het cross-sectionele onderzoek van de in hoofdstuk vier genoemde vragenlijst. De resultaten van deze studie tonen aan dat zorgverleners veelzijdige maatregelen gebruiken die hen in staat stellen om de situatie te kalmeren en om de betekenis van agressief gedrag van de bewoners te begrijpen. Daarom kunnen we aannemen dat zorgverleners in Zwitserse verpleeghuizen streven naar een persoonsgerichte aanpak in de zorg voor bewoners die agressief gedrag vertonen. Toch wijzen de resultaten erop dat verdere verbeteringen moeten worden overwogen, namelijk de invoering van interdisciplinaire case-beoordelingen en het gebruik van instrumenten voor gestandaardiseerde evaluaties en documentatie van de agressie van bewoners.

Bovendien is er in deze studie een significant verschil gevonden bij de zorgverleners in hoe vaak ze de aanbevolen maatregelen toepassen. Belangrijke factoren die zorgverleners stimuleren de aanbevolen maatregelen te gebruiken zijn steun van meerderen en beschikbare hulp voor zorgverleners die zijn geconfronteerd met agressief gedrag. Ook zorgverleners met beroepservaring, hun bekwaamheid en het kunnen inleven in het perspectief van bewoners zijn relevante factoren voor het gebruik van de onderzochte maatregelen. Verpleeghuizen moeten deze factoren in overweging nemen wanneer ze zorgconcepten ontwikkelen. Trainingsprogramma's voor agressie-management moeten kritisch worden beoordeeld op hun inhoud gerelateerd tot bewonersagressie; zorgverleners 
die een opleiding hebben gekregen in het omgaan met agressie gebruiken de aanbevolen maatregelen aanzienlijk minder. Toekomstig onderzoek moeten de resultaten van dit onderzoek worden vergeleken met waarnemingen om het te objectiveren.

Het onderzoek in hoofdstuk zes richt zich op onderzoeksvraag acht met factoren samenhangen met bewonersagressie naar zorgverleners in verpleeghuizen. De gegevens voor deze studie werden ook verzameld in de cross-sectionele survey die in hoofdstuk vier wordt vermeld. Gebaseerd op de ervaringen van zorgverleners agressie van bewoners in de afgelopen twaalf maanden, resulteerde de variabele selectieprocedure in een multiple regressie model voor fysieke agressie en bedreigend gedrag. De resultaten tonen aan dat opgeleid personeel meer fysieke agressie ervaren tijdens de afgelopen twaalf maanden dan studenten; en vrouwelijke zorgverleners werden vaker geconfronteerd met fysieke agressie dan mannelijke zorgverleners. Voor zorgverleners jonger dan 30 jaar, waren de kansen op fysieke agressie meer dan het dubbele in vergelijking met zorgverleners ouder dan 45 jaar. Vertrouwen in het omgaan met fysieke agressie vergrootte de kans op agressie met een factor anderhalf. In het model for threathening behaviour waren de voorspellende variabelen opleidingsniveau van het personeel en leeftijd. Geregistreerde verpleegkundigen ervaren meer bedreigend gedrag in vergelijking met niet-geregistreerde verpleegkundigen en studenten; en de resultaten met betrekking tot leeftijd zijn vergelijkbaar met het regressiemodel van fysieke agressie.

De geïdentificeerde risicofactoren zijn deels in lijn met soortgelijke onderzoeken, maar er werden ook tegenstrijdige resultaten gevonden, vooral bij getrainde zorgverleners zoals geregistreerde verpleegkundigen. $\mathrm{Zij}$ hebben een significant hoger risico op de agressie van bewoners dan studenten of zorgverleners met een lager opleidingsniveau. Het feit dat geregistreerde verpleegkundigen meer worden blootgesteld aan agressief gedrag moet in overweging worden genomen bij hun vaardigheden in het omgaan met agressie en hun professionele taken of rollen in hun teams. Op basis van de resultaten van dit onderzoek kunnen we aannemen dat met name de basis zorgactiviteiten grotere invloedrijke factor zijn voor het ervaren van agressie van bewoners dan opleidingsniveau. Bovendien was het niet mogelijk in deze studie verdere associaties tussen ervaringen van agressie en omgevingsfactoren of bewonerskenmerken te achterhalen. Dit benadrukt de noodzaak van verdere studies naar het indentificeren van relevante risicofactoren voor de ontwikkeling en verbetering van de arbeidsomstandigheden van zorgverleners in verpleeghuizen.

Tenslotte worden in hoofdstuk zeven de belangrijkste bevindingen van dit proefschrift samengevat en worden de methodologische beperkingen van de studies besproken. De resultaten van deze studie toonden aan dat de prevalentie van ervaren agressie van bewoners door zorgverleners in Zwitserse verpleeghuizen hoog is. De zorgverleners zien agressief gedrag door bewoners als belastend en vermelden een nadelige invloed op de 
relatie tussen zorgverlener en bewoner. De bevindingen van dit proefschrift leiden tot de conclusie dat er behoefte is aan onderzoek naar de competenties van de zorgverleners met betrekking tot omstandigheden en factoren die bijdragen aan de agressie van bewoners. Bovendien suggereren de resultaten dat de steun van meerderen en geïnstitutionaliseerde hulp voor getroffen zorgverleners, het gebruik van de maatregelen van de aanbevolen richtlijnen door zorgverleners in het omgaan van de agressie van bewoners verbeteren.

Rekening houdend met de resultaten en beperkingen van de studies worden aanbevelingen voor verder onderzoek gedaan. Deze aanbevelingen hebben betrekking op factoren die van invloed zijn op agressie door bewoners, op de factoren en de doeltreffendheid van de beschikbare programma's voor de opleiding in het omgaan met agressie, alsook de effectiviteit van de toegepaste maatregelen voor het omgaan met agressie.Ten slotte; het betrekken van de bewoners van diensten als een veelbelovende aanpak ter verbetering van kennis over risicofactoren en preventie van agressie door bewoners van verpleeghuizen. 


\section{Zusammenfassung}

Die Betreuung von Bewohnenden mit aggressivem Verhalten ist eine anspruchsvolle Aufgabe für Pflegende. Studien haben gezeigt, dass Pflegefachpersonen in geriatrischen Abteilungen am dritthäufigsten Aggression erleben. Nur in psychiatrischen Abteilungen und Notfallstationen sind Pflegende noch öfter mit aggressiven Verhaltensweisen konfrontiert.

Die Forschenden in diesem Gebiet sind sich einig hinsichtlich der vielfältigen Aggressionsursachen. Sie betonen, dass mehrere Perspektiven berücksichtigt werden sollten, beispielsweise bewohnerbezogene Faktoren, Charakteristika und Kompetenzen der Pflegenden sowie Umgebungseinflüsse. Einer der meistdiskutierten Aspekte ist der Zusammenhang zwischen Demenz und aggressivem Verhalten. Die Charakteristika der Pflegenden und die Umgebungseinflüsse wurden jedoch noch wenig untersucht.

Menschen, die an einer Demenz leiden, reagieren empfindlich auf Veränderungen in ihrer Umgebung. Ein wichtiger Aspekt im Zusammenhang mit Aggression ist zudem der Mangel an Zeit für eine angemessene Unterstützung der Bewohnenden in den Aktivitäten des täglichen Lebens. Dies führt zu einer Zunahme körperlicher Angriffe gegen Pflegende. Es gibt einige Hinweise darauf, dass Pflegefachpersonen mit mehrjähriger klinischer Erfahrung und einem höheren Ausbildungsniveau häufiger bedürfnisorientierte Methoden einsetzen, um aggressives Verhalten zu minimieren.

Darüber hinaus ist bekannt, dass die Pflege von Bewohnenden, die aggressives Verhalten zeigen, mit hoher Belastung und Stress verbunden ist. Die Interaktion mit dieser Personengruppe wird als Balanceakt zwischen widersprüchlichen Positionen beschrieben: Einerseits möchten die Pflegenden die Bewohnerinnen und Bewohner in ihrer eigenen Welt respektieren, andererseits sind sie gezwungen, für das Wohl aller Beteiligten zu sorgen. Kommt es zu einem aggressiven Ereignis, fühlen sie sich in diesem Augenblick oft ohnmächtig, möchten aber doch die Kontrolle behalten und die schwierige Situation kompetent meistern. Pflegende erfahren von den Bewohnenden Ablehnung und Zurückweisung, im nächsten Moment jedoch suchen diese ihre Hilfe und schätzen die Unterstützung, die sie erhalten.

Trotz der zu erwartenden steigenden Anzahl von Menschen mit Demenz und dem damit verbundenen Herausforderungen, wurde Aggression in Schweizer Pflegeheimen bis heute nur wenig erforscht. Aus diesem Grund untersucht diese Dissertation die Erfahrungen Pflegender mit aggressivem Verhalten von Bewohnenden sowie ihre Strategien und Maßnahmen im Umgang damit. Darüber hinaus werden Risikofaktoren im Zusammenhang mit dem Auftreten von Aggression ermittelt.

Die Definition von Aggression ist ein wichtiger Aspekt in diesem Forschungsbereich. Es existiert eine Vielzahl an Begriffen mit inhaltlich ähnlichen Definitionen. Daher wurde in dieser 
Arbeit folgende operationalisierte Beschreibung aggressiven Verhaltens verwendet: verbale Beschimpfung (z. B. beleidigende Sprache, persönliche Angriffe, Fluchen oder obszöne Kommentare), Bedrohung (z. B. Äußerung der Verletzungsabsicht, belästigendes oder schikanierendes Verhalten, physische Einschüchterung, Bedrohung mit einer Waffe und körperlicher Angriff (z. B. Schlagen, Kneifen, Stoßen, Spucken, Treten, Gebrauch einer Waffe).

Als theoretischer Rahmen wurde das ,General Aggression Model (GAM)` sowie das ,bedürfnisbedingte Verhaltensmodell (NDB-Modell)' verwendet, um die vielfältigen Faktoren bei der Aggressionsentstehung zu erklären. Um die Charakteristika involvierter Pflegender zu reflektieren, wurde das Modell des, interaktiven Verhaltens der Pflegenden' als weitere theoretische Fundierung integriert.

Mit dem Ziel, die verfügbaren wissenschaftlichen Erkenntnisse zu aggressivem Verhalten zusammenzufassen, fand eine Literaturrecherche statt. Relevante Forschungsarbeiten wurde analysiert mit Blick auf die Formen aggressiven Verhaltens und deren Häufigkeit, die Situationen, in denen Aggression auftritt sowie die Strategien, die Pflegende im Umgang mit Aggression anwenden. Die Ergebnisse dieser Literaturrecherche werden in Kapitel zwei vorgestellt und beziehen sich auf die erste Forschungsfrage dieser Arbeit. In einer umfangreichen Suche in den elektronischen Datenbanken Medline, CINAHL (Cumulative Index of Nursing and Allied Health Literature) und PsycINFO, ergänzt durch die Überprüfung der Referenzen und die Suche nach unveröffentlichten Manuskripten, wurden 72 Publikationen identifiziert.

Nach Anwendung der Ausschlusskriterien und einer unabhängigen kritischen Bewertung durch zwei Gutachterinnen (erste und zweite Autorin), verblieben 21 Publikationen zur weiteren Analyse. Dreizehn basieren auf einem quantitativen und acht auf einem qualitativen Forschungsdesign. Die am häufigsten verwendete quantitative Methode war das retrospektive Querschnittdesign. In zwei Studien wurde ein prospektiver Ansatz gewählt und eine Veröffentlichung basierte auf einer Beobachtungsstudie. Von den acht qualitativen Publikationen hatten zwei einen phänomenologisch-hermeneutischen Ansatz, eine wendete die Methode der ,Grounded Theory' an und eine weitere Studie fundierte auf einer ethnographischen Untersuchung. In vier von acht Publikationen waren nur wenige Informationen über die gewählte Methode enthalten.

Die Beschreibungen aggressiven Verhaltens und verwandter Begriffe lassen sich zwei Hauptkategorien zuordnen: verbale und physische Aggression. Die Prävalenz aggressiven Verhaltens wurde prospektiv oder retrospektiv mit verschiedenen Instrumenten in 13 quantitativen Publikationen erfasst. Die Ergebnisse zur Aggressionsprävalenz zeigten eine beträchtliche Varianz von 1,2 Vorfällen pro Tag bis zu ein bis vier Vorfällen pro Jahr. Trotz des schwierigen Vergleichs der Prävalenzraten aufgrund unterschiedlicher Messmethoden unterstreichen die Angaben die Bedeutung aggressiven Verhaltens für Pflegefachpersonen in Alters- und Pflegeheimen. 
Die eingeschlossenen Publikationen erfassten Situationen, in denen aggressives Verhalten auftrat, auf verschiedenen Ebenen: Einige Studien fokussierten auf die Interaktion zwischen Pflegenden und Bewohnenden während der Körperpflege sowie auf psychosoziale Belastungen der Bewohner(innen) als Aggressionsauslöser. Weitere Erklärungen zu möglichen Aggressionsursachen beziehen sich auf organisatorische Bedingungen, die sich auf die Haltung der Pflegenden und ihre Interaktion mit den Bewohnenden auswirken. Die anspruchsvollen Arbeitsbedingungen in Alters- und Pflegeheimen tragen zum Auftreten von Aggression bei. Bedürfnisse der Bewohnenden und ihrer Angehörigen sowie die Anforderungen von Seiten der Institution schaffen eine Atmosphäre, in der die Pflege und Betreuung oft unter großem Zeitdruck stattfindet.

Die Analyse der Ergebnisse hinsichtlich der pflegerischen Strategien und Maßnahmen im Umgang mit aggressivem Verhalten ergab fünf Kategorien: 1) Strategien mit dem Ziel, aggressives Verhalten zu verhindern oder in einem frühen Stadium zu erkennen, 2) beruhigende und deeskalierend wirkende Strategien bei Anzeichen aggressiven Verhaltens, 3) repressive, sanktionierende Interventionen, 4) medikamentöse Behandlung und 5) institutionsbezogene Maßnahmen.

Die Ergebnisse dieser Literaturübersicht zeigen die Schwierigkeit, genaue Prävalenzraten zu ermitteln. Sie weisen auf das komplexe Zusammenspiel zwischen mehreren Faktoren hin, die zu Aggression führen. Es scheint, dass aggressives Verhalten auf einem Zusammenwirken zwischen Bewohnerinnen bzw. Bewohnern und Umgebungsfaktoren sowie auf zwischenmenschlichen Interaktionen und organisatorische Bedingungen beruht. Neben der mangelnden Evidenz hinsichtlich der Wirksamkeit verschiedener Interventionen fehlen auch Daten über die bevorzugten Maßnahmen, die Pflegefachpersonen in der Praxis bei aggressivem Verhalten anwenden.

Aus diesem Grund wurde in einem nächsten Schritt eine qualitative Studie durchgeführt mit dem Ziel, die Perspektive der Pflegenden zu erforschen hinsichtlich der Bedingungen und Situationen, in denen aggressives Verhalten auftritt sowie hinsichtlich der Strategien, die sie bei Aggressionsereignissen anwenden. Die Studie bezieht sich auf die Forschungsfragen zwei, drei und vier. Die Ergebnisse dieser qualitativen Untersuchung werden in Kapitel drei vorgestellt. Es wurden fünf Fokusgruppeninterviews anhand eines semi-strukturierten Leitfadens mit insgesamt 30 Teilnehmenden durchgeführt. Die qualitative Inhaltsanalyse der Interviews führte zu drei Hauptkategorien mit zusätzlichen Unterkategorien. Eine Hauptkategorie bezieht sich auf Erklärungen der Teilnehmenden zu möglichen Ursachen aggressiven Verhaltens. Diese Kategorie ist in zwei Unterkategorien unterteilt: a) bewohnerbedingteFaktoren: Bewohnende realisieren den Verlust ihrer Fähigkeiten, verstehen die Situation nicht und sind überfordert; aggressives Verhalten stellt die letzte verbliebene Fähigkeit der Bewohnenden dar, sich auszudrücken und b) Faktoren von Seiten der Pflegenden: Arbeiten 
unter Zeitdruck, mangelnde Aufmerksamkeit und Angst vor dem aggressiven Verhalten der Bewohnenden.

Die Maßnahmen im Umgang mit aggressivem Verhalten der Bewohnenden sind in der zweiten Kategorie "Umgang mit den Bewohnenden" beschrieben: Gewohnheiten und Bedürfnisse kennen, die kontinuierliche Suche nach neuen Lösungen oder die Konfrontation der Bewohnenden mit ihrem Verhalten. Die dritte Kategorie beschreibt Strategien der Pflegenden in der Konfrontation mit aggressivem Verhalten: sich selbst schützen und die Situation bewältigen.

Mit dieser Studie erhielten wir einen Einblick in die Sichtweise der Pflegenden hinsichtlich aggressionsauslösender Faktoren und ihrer Strategien im Umgang mit Aggression. Die Ergebnisse zeigen, dass Pflegende ein breites Spektrum an Maßnahmen einsetzen, um aggressives Verhalten zu reduzieren. Einige davon werden auch in Leitlinien empfohlen. Der Zusammenhang zwischen aggressivem Verhalten und physiologischen Problemen, z. B. Schmerz oder Ausscheidungsprobleme, wird jedoch wenig beachtet. Die Teilnehmenden verknüpfen ihr praktisches Wissen kaum mit theoretischen Erkenntnissen. Hinzu kommt, dass sie nur in wenigen Fällen eine systematische Vorgehensweise im Umgang mit Aggression anwenden. Die Angst der Pflegenden vor aggressivem Verhalten und dessen Auswirkungen auf ihre Reaktionsweise ist ein noch wenig erforschter Bereich.

In Kapitel vier werden die Ergebnisse einer explorativen deskriptiven Querschnittsstudie in 21 Schweizer Pflegeheimen vorgestellt, an der 814 Pflegende teilgenommen haben. Diese Studie bezieht sich auf die Forschungsfragen drei, vier, fünf und sechs. Die Datenerhebung erfolgte mittels eines Fragebogens, der deutschen Version des, Survey of Violence Experienced by Staff' (SOVES-G).

Die Ergebnisse dieser erstmalig in Schweizer Pflegeheimen durchgeführten Studie zeigen, dass etwa 80\% der Teilnehmenden in den letzten 12 Monaten und 38,2\% im Zeitraum der letzten sieben Arbeitstage mit aggressivem Verhalten konfrontiert waren. Die Angaben über das eindrücklichste Aggressionsereignis während der letzten sieben Tage zeigten, dass die Teilnehmenden vor allem mit verbalen Beleidigungen und körperlichen Angriffen konfrontiert waren. Die meisten der beteiligten Bewohner(innen) hatten eine Einschränkung in ihren kognitiven Fähigkeiten, in der Mobilität und in der Kommunikation oder litten an einer Inkontinenz. In fast 60\% aller Fälle trat das aggressive Verhalten während einer Pflegeintervention mit Körperkontakt auf.

Als Auslöser für aggressives Verhalten identifizierten die Teilnehmenden bei den Bewohnenden vor allem das Nichtverstehen der Situation und Überforderung. Die Maßnahmen ,beruhigendes Gespräch“ und ,auf Distanz gehen“ wurden am häufigsten verwendet, um die Situation zu beruhigen. Fast die Hälfte der Teilnehmenden berichtete, dass sie keine langfristigen Maßnahmen im Umgang mit aggressivem Verhalten der Bewohnenden eingesetzt ha- 
ben. Zur Erkennung von Mustern bei den eindrücklichsten Aggressionsereignissen wurde eine Clusteranalyse durchgeführt, die drei klar voneinander getrennte Cluster ergeben hat. Das erste Cluster enthält eine Gruppe von Bewohnenden mit intakten kognitiven Fähigkeiten. Bei zwei weiteren Gruppen (Cluster zwei und drei) waren vorwiegend Bewohnende mit eingeschränkten kognitiven Fähigkeiten involviert. Bei der Gruppe in Cluster zwei bestand zusätzlich meistens eine Einschränkung der kommunikativen Fähigkeiten und zum Zeitpunkt des Aggressionsereignisses wurde eine pflegerische Intervention mit Körperkontakt durchgeführt. Bei den Bewohnenden in Cluster drei bestand auch eine Beeinträchtigung der kognitiven Fähigkeiten, ihre kommunikativen Fähigkeiten waren jedoch intakt.

Darüber hinaus zeigen die Ergebnisse dieser Studie, dass Aggressionsereignisse die Pflegenden unterschiedlich belasten, abhängig von der Art der Aggression, die sie erlebt haben. Etwa 40\% der Teilnehmenden erlebten körperlichen Angriffe als besonders belastend. Über 23\% hatten Angst, vor allem, wenn aggressives Verhalten ohne Vorwarnung aufgetreten ist. Fast $4 \%$ der Teilnehmenden vermieden nach einem Aggressionsvorfall den Kontakt zu den Bewohnerinnen und Bewohnern, rund $12 \%$ erlebten eine beeinträchtigte Beziehung zu ihnen.

Wie die Ergebnisse dieser Studie deutlich machen, sind Pflegende in Alters- und Pflegeheimen in hohem Ausmaß mit aggressivem Verhalten von Bewohnenden konfrontiert. Sie empfinden aggressives Verhalten als belastend, insbesondere körperliche Angriffe und sie haben Angst, wenn Aggression ohne Vorwarnung auftritt. Es stellt sich die Frage, ob die Pflegenden womöglich Frühwarnzeichen beginnender Aggression nicht erkennen und folglich nicht in der Lage sind, sich zu schützen oder Maßnahmen der Deeskalation zu ergreifen. Die Resultate zeigen auch, dass die Beziehung zu den Bewohnenden negativ beeinflusst werden kann. Dies birgt die Gefahr, dass Bedürfnisse, die möglicherweise zu aggressivem Verhalten geführt haben, nicht erkannt werden, weil die Pflegenden sich von den Bewohnerinnen bzw. Bewohnern distanzieren.

Die Studie in Kapitel fünf fokussiert auf die Anwendung von Maßnahmen, die in Richtlinien für den Umgang mit aggressivem Verhalten empfohlen werden und bezieht sich auf die siebte Fragestellung. Das Ziel dieser Untersuchung war, Merkmale von Pflegenden zu identifizieren hinsichtlich ihrer Anwendung von Maßnahmen im Umgang mit Aggression. Mögliche Unterschiede zwischen den Pflegenden aufgrund ihrer Charakteristika sollten ebenfalls aufgedeckt werden. Das dafür verwendete Instrument hat die Erstautorin entwickelt. Es basiert auf publizierten Empfehlungen zum Umgang mit aggressivem Verhalten sowie auf Expertenempfehlungen. Dieses Instrument war Teil des Fragebogens der in Kapitel vier erläuterten Querschnittsstudie.

Die Ergebnisse dieser Untersuchung zeigen, dass die Pflegenden unterschiedlichste Maßnahmen einsetzen, um eine Situation zu beruhigen und die Bedeutung aggressiven Ver- 
haltens zu verstehen. Dies führt uns zu der Annahme, dass Pflegende in Schweizer Altersund Pflegeheimen einen personenzentrierten Ansatz bei der Betreuung von Bewohnenden mit aggressivem Verhalten anstreben. Dennoch zeigen die Ergebnisse, dass die Anwendung bestimmter Maßnahmen gefördert werden sollte, z. B. der Einsatz interdisziplinärer Fallbesprechungen und die Anwendung von Instrumenten für eine standardisierte Beurteilung und Dokumentation aggressiven Verhaltens.

Darüber hinaus zeigen die Resultate einen signifikanten Unterschied zwischen den Pflegenden hinsichtlich der Häufigkeit in der Anwendung empfohlener Maßnahmen. Faktoren, welche die Anwendung fördern, sind die Unterstützung von den Vorgesetzten und die institutionalisierte Unterstützung von Pflegenden, die mit aggressivem Verhalten konfrontiert wurden. Zudem sind die Berufserfahrung und die Fähigkeit der Pflegenden, sich in die Situation der Bewohnenden einfühlen zu können, relevante Einflussfaktoren für den Einsatz empfohlener Maßnahmen.

Alters- und Pflegeheime sollten diese Faktoren bei der Entwicklung von Pflegekonzepten berücksichtigen. Trainingsprogramme für Aggressionsmanagement sollte kritisch überprüft werden im Hinblick auf ihre Inhalte und Zielsetzungen. Diese Notwendigkeit ergibt sich aus der Tatsache, dass Pflegende, die eine Weiterbildung in Aggressionsmanagement absolviert haben, die empfohlenen Maßnahmen signifikant weniger häufig anwenden. In weiteren Forschungen sollten die Ergebnisse dieser Studie durch Beobachtungen objektiviert werden.

Die Studie in Kapitel sechs untersucht das Risiko der Pflegenden, Aggression zu erleben und bezieht sich auf die achte Forschungsfrage. Daten für diese Untersuchung wurden ebenfalls im Rahmen der in Kapitel vier beschriebenen Querschnittsstudie erhoben. Basierend auf den Erfahrungen der Pflegenden mit Aggression während der letzten zwölf Monate ergab der Selektionsprozess der jeweiligen Variablen ein multiples Regressionsmodell für das Erleben körperlicher Angriffe und Bedrohungen.

Die Resultate der multiplen Regressionsanalyse zeigen, dass ausgebildete Pflegende häufiger körperliche Aggression erleben als Auszubildende. Zudem erleben weibliche Pflegende häufiger körperliche Aggressionen im Vergleich mit männlichen Pflegenden. Für Pflegende unter 30 Jahren ist das Risiko, Aggression zu erfahren, mehr als doppelt so hoch verglichen mit Pflegenden, die über 45 Jahre alt sind. Die Einschätzung der Pflegenden, mit Aggression umgehen zu können, erhöht das Risiko, mit physischer Aggression konfrontiert zu werden, um das eineinhalbfache.

Im Regressionsmodell für das Erleben von Bedrohungen stellen das Ausbildungsniveau und das Alter der Pflegenden die prädiktiven Variablen dar. Diplomierte Pflegende sind häufiger mit Bedrohung konfrontiert als Pflegende ohne Diplomabschluss oder Auszubildende. Die Ergebnisse in Bezug auf den Einflussfaktor ,Alter' sind ähnlich wie im Regressionsmodell für das Erleben physischer Aggression. 
Die in dieser Studie identifizierten Risikofaktoren stehen teilweise im Einklang mit ähnlichen Untersuchungen. Wir fanden jedoch auch widersprüchliche Ergebnisse wie das signifikant höhere Risiko für diplomierte Pflegende, mit Aggression konfrontiert zu werden. Dies sollte Gegenstand kritischer Reflexion sein mit Blick auf ihre beruflichen Kompetenzen und Rollen in den Teams. Basierend auf den Ergebnissen dieser Studie können wir davon ausgehen, dass die Zuteilung von Pflegeaktivitäten, vor allem der Körperpflege, das Risiko beeinflusst, mit Aggression konfrontiert zu werden. Es war in dieser Studie nicht möglich, weitere Risikofaktoren für das Erleben von Aggression, zum Beispiel Umgebungsfaktoren oder Merkmale von Bewohnenden zu identifizieren. Dies unterstreicht die Notwendigkeit weiterer Studien in diesem Bereich, um relevante Faktoren für die Entwicklung und Verbesserung der Arbeitsbedingungen für Pflegende in Alters- und Pflegeheimen zu erkennen.

In Kapitel sieben sind die wichtigsten Ergebnisse der Arbeit zusammengefasst und die methodischen Limitationen der Studien werden kritisch diskutiert. Die Resultate zeigen, dass Pflegende in Schweizer Alters- und Pflegeheimen aggressives Verhalten von Bewohnenden in hohem Ausmaß erfahren. Die Befragten empfinden dies als belastend und weisen auf den negativen Einfluss von Aggression auf die Beziehung zwischen Pflegenden und Pflegebedürftigen hin. Es besteht Handlungsbedarf in Bezug auf die Entwicklung beruflicher Kompetenzen der Pflegenden in den Bereichen Assessment und Erfassung aggressionsfördernder Umgebungsfaktoren und Bedingungen.

Darüber hinaus unterstreichen die Ergebnisse, dass Unterstützung durch Vorgesetzte wichtig ist. Ebenso notwendig ist ein institutionalisiertes Angebot für betroffene Pflegende im Hinblick auf den Einsatz von Maßnahmen, die in Leitlinien für den Umgang mit aggressivem Verhalten von Bewohnenden empfohlen werden.

Unter Berücksichtigung der Ergebnisse und Limitationen der Studien beziehen sich die Empfehlungen für die weitere Forschung auf die Untersuchung von Faktoren, die das Auftreten aggressiven Verhaltens fördern, auf die Inhalte von Schulungen in Aggressionsmanagement sowie auf die Wirksamkeit der Maßnahmen, welche in diesen Schulungen empfohlen werden. Zudem könnten durch Einbezug von Bewohnerinnen und Bewohnern in Untersuchungen wertvolle Erkenntnisse über mögliche Risikofaktoren und wirksame Maßnahmen zur Prävention aggressiven Verhaltens generiert werden. 


\section{Acknowledgements}

In the completion of this dissertation many people and institutions were involved, to whom I would like to say: Thank you very much indeed.

For the continued support and encouragement through all stages of my dissertation, I thank my supervisors Prof. Dr. Gerjo Kok, Maastricht University, Dr. Ruud JG Halfens, Maastricht University and Prof. Theo Dassen, Charité Berlin. I would like to thank Gerjo Kok for his encouraging feedback to all my questions, which took me further into my work on the dissertation. I would like to thank Theo Dassen for his very pertinent remarks, which were very valuable in the revision of the manuscripts. My special thanks to Ruud Halfens who was always available for all my questions. He supported me patiently with valuable feedback and suggestions and was an important source for critical reflection in the progress of my thesis.

For the support in all statistical questions I would like to thank Prof. Dr. Marianne Müller. She opened my view for the possibilities of data analysis and accompanied me patiently through all statistical issues. Prof. Dr. Ian Needham was the first who I discussed the idea of my dissertation with. His friendly advice and generous support helped me in the critical moments during my working process, particularly in dealing with feedback by reviewers of the manuscripts.

I would also like to thank all the nursing homes, which opened their doors to me and made it possible to conduct the study. Thank you, particularly the caregivers who participated in the interviews and the participants who completed the survey.

Many thanks go to Prof. Martina Merz-Staerkle. She allowed me time off to concentrate the work on my thesis. Her optimism was infectious and strengthened my back on this long journey. Furthermore, I would like to thank the University of Applied Sciences FHS St.Gallen, an in particular my colleagues, for their support and motivating discussions.

Mark Simpson, Dr. Diana Staudacher and Dr. Heather Murray were always ready to carry out the English corrections in a short time, thank you very much.

Diana Grywa, who unfortunately cannot be with us motivated me to investigate aggressive behaviour in nursing homes. We spent many hours together and discussed my issue from several perspectives. My heartfelt thanks for these precious moments. A big thank also to Prof. Dr. Sabine Hahn, my colleague since the beginning of this thesis. I shared with her my interest in the field of research in aggression. She supported me with good advice and I appreciated her optimism as well as her pragmatic attitude in difficult times.

Dear family members, dear friends, thank you for your patience over the last years, when you have to wait for me and my priorities where in the dissertation. Margrit, without your help, patience and always encouraging words this dissertation have never been finished. I am deeply grateful to you, you were always there for me. 


\section{Curriculum vitae}

Adelheid Zeller was born on the $4^{\text {th }}$ of October 1960 in Burgberg, Germany. In 1981 she completed her professional training in general nursing care at the nursing school in Augsburg, Germany. As a registered nurse, she worked in a surgical ward and an intensive care unit for seven years in Switzerland. In 1989 she became an assistant at the nursing school in St. Gallen. She achieved her diploma as a nurse tutor at the school for post-graduate education in Aarau in 1992 and held a teaching position at the nursing school in St. Gallen from 1992 to 1997 . She was in charge of the training programme for general nursing at the nursing school in St. Gallen until 2005.

She received her Master's Degree in Health Sciences (Nursing Science) from Maastricht University in 2003. From 2005 to 2006 she worked part time as a clinical nursing expert at the Psychiatric Clinik in Wil and concurrently, was appointed as a member in a project group who was delegated by the St. Gallen Cantonal Health Department to develop a Bachelor Programme in Nursing Science at the University of Applied Sciences, FHS St.Gallen. In 2006 she started her PhD-study in the PhD-Programme at Maastricht University, Charite Centre for the Humanities and Sciences, Berlin and Medical University of Graz.

Since 2006 she has been working as the head of the Bachelor Programme in Nursing at the University of Applied Sciences, FHS St.Gallen. 